\title{
American Cancer Society/American Society of Clinical Oncology Breast Cancer Survivorship Care Guideline
}

\author{
Authors: Carolyn D. Runowicz, Corinne R. Leach, Norah Lynn Henry, Karen Scanlon \\ Henry, Heather Mackey, Rebecca L. Cowens-Alvarado, Rachel Cannady, Mandi L. Pratt- \\ Chapman, Stephen B. Edge, Linda A. Jacobs, Arti Hurria, Lawrence B. Marks, Samuel J. \\ LaMonte, Ellen Warner, Gary H. Lyman, Patricia A. Ganz.
}

Keywords: breast cancer; survivorship; clinical care; follow-up; guideline; primary care; quality of life; survivorship care plan; long-term effects; late effects; care coordination

\section{Author Insitutions:}

Carolyn D. Runowicz, MD, Herbert Wertheim College of Medicine Florida International University, Miami FL

Corinne R. Leach, PhD, MS, MPH, American Cancer Society, Atlanta, GA

N. Lynn Henry, MD, PhD, University of Michigan, Ann Arbor, MI

Karen Scanlon Henry, MSN, ARNP, FNP-BC, AOCNP, University of Miami, Miami FL

Heather Mackey, RN, MSN, ANP, AOCN, Oncology Nursing Society, Pittsburgh, PA

Rebecca L. Cowens-Alvarado, MPH, American Cancer Society, Atlanta, GA

Rachel Cannady, BS, American Cancer Society, Atlanta, GA

Mandi L. Pratt-Chapman, MA, The George Washington University Cancer Institute, Washington, DC

Stephen B. Edge, MD, FACS, Baptist Cancer Center, Memphis, TN

Linda A. Jacobs, PhD, RN, University of Pennsylvania, Philadelphia PA

Arti Hurria, MD, City of Hope, Duarte, CA

Lawrence B. Marks, MD, University of North Carolina, Chapel Hill, NC

Samuel J. LaMonte, MD, American Cancer Society, Atlanta, GA

Ellen Warner, MD, FRCPC, FACP, M.Sc., Sunnybrook Health Sciences Centre, Toronto, ON

Gary H. Lyman, MD, MPH, FASCO, FACP, Fred Hutchinson Cancer Research Center, Seattle, WA

Patricia A. Ganz, MD, University of California, Los Angeles, CA

Running head: ACS/ASCO BrCa Survivorship Guideline

Authors' disclosures of potential conflicts of interest and author contributions are found at the end of this article.

Complete mailing address, telephone, fax, and e-mail for correspondence and reprints:

Corinne R. Leach, MS PhD MPH

Director, Cancer and Aging Research

American Cancer Society

250 Williams Street, NW, Suite 600

Atlanta, Georgia, 30303

Ph. 404.329.4453

Fx. 404.929.6832

Em. corinne.leach@cancer.org

Total number of each: Text pages- 49 ; Tables - 6 ; Appendix -4

This is the author manuscript accepted for publication and has undergone full peer review but has not been through the copyediting, typesetting, pagination and proofreading process, which may lead to differences between this version and the Version record. Please cite this article as doi:10.3322/ caac.21319. 


\begin{abstract}
Purpose: The purpose of the ACS/ASCO Breast Cancer Survivorship Care Guideline is to provide recommendations to assist primary care and other clinicians in the care of female adult survivors of breast cancer.

Methods: A systematic review of the literature was conducted using PubMed through April 2015. A multidisciplinary expert workgroup, with expertise in primary care, gynecology, surgical oncology, medical oncology, radiation oncology, and nursing was formed and tasked with drafting the Breast Cancer Survivorship Care Guideline.

Results: A total of 1073 articles met inclusion criteria and after full text review, 237 were included as the evidence base. Patients should undergo regular surveillance for breast cancer recurrence, including evaluation with a cancer-related history and physical exam, and should be screened for new primary breast cancer. Data do not support performing routine laboratory tests or imaging tests in asymptomatic patients to evaluate for breast cancer recurrence. Primary care clinicians should counsel patients about the importance of maintaining a healthy lifestyle, monitor for post-treatment symptoms that can adversely affect quality of life, and monitor for adherence to endocrine therapy. Recommendations provided in this guideline are based on current evidence in the literature and expert consensus opinion. Most of the evidence is not sufficient to warrant a strong evidence-based recommendation.

Recommendations: Recommendations on surveillance for breast cancer recurrence, screening for second primary cancers, assessment and management of physical and psychosocial long-term and late effects of breast cancer and treatment, health promotion and care co-ordination/practice implications are made.
\end{abstract}




\section{INTRODUCTION}

Breast cancer is the most common non-cutaneous malignancy for women, representing 4 in 10 female cancer survivors in the U.S. ${ }^{1}$ Long-term survival is common after breast cancer treatment, with a 5 -year survival rate of almost $90 \%^{2}$; thus addressing survivors' unique posttreatment needs is critical to providing quality health care ${ }^{3}$.

Nearly a decade ago, two landmark publications from the Institute of Medicine (IOM) highlighted the importance of surveillance, health promotion, and assessing and managing the myriad of physical, psychological, spiritual, social and practical long-term and late effects faced by many cancer survivors after completing active treatment ${ }^{4,5}$. Recent publications affirm the importance of addressing health, wellness and quality of life concerns of post-treatment cancer survivors ${ }^{3,6,7}$. In recognition of the increasing need for information to support primary care clinicians who care for breast cancer survivors, this guideline was developed to provide recommendations to enhance the quality of clinical follow-up care for those who have completed initial treatment for female breast cancer (e.g., surgery, radiation, targeted therapy, and/or chemotherapy $)^{8}$.

While many evidence-based clinical guidelines exist for diagnosis and treatment, there are few evidence-based clinical care guidelines addressing life-long follow-up care for survivors by cancer type. The National Comprehensive Cancer Network (NCCN) developed consensusbased guidelines for the treatment of patients with breast cancer ${ }^{9}$ which include information on recommended surveillance for cancer recurrence or new cancers. The NCCN also has symptom-specific survivorship care guidelines addressing anthracycline-induced cardiac toxicity, anxiety and depression, cognitive function, fatigue, pain, sexual function, sleep disorders, and healthy lifestyles ${ }^{10}$. In addition, the American Society of Clinical Oncology (ASCO) has guidelines for the follow-up and management of patients with breast cancer ${ }^{11,12}$ as well as symptom-based guidelines specific to fatigue ${ }^{13}$, chemotherapy-induced peripheral neuropathy ${ }^{14}$, and anxiety and depressive symptoms ${ }^{15} ; \mathrm{ASCO}$ is also developing guidelines on 
the prevention and monitoring of cardiac dysfunction in survivors of adult cancers and on the management of chronic pain. In addition, ASCO has recently endorsed the ACS guideline on prostate cancer survivorship ${ }^{16}$. The ACS/ASCO Breast Cancer Survivorship Care Guideline builds upon prior guidelines by providing comprehensive, holistic recommendations specific to post-treatment breast cancer clinical care to help primary care clinicians better manage potential long-term and late-effects, and to provide timely and appropriate screening and surveillance to improve overall health and quality of life of breast cancer survivors.

This year approximately 231,840 women will be newly diagnosed with breast cancer and an estimated 3.1 million breast cancer survivors are alive in the $U . S^{17}$. The median age at diagnosis is 61 years with $43 \%$ over the age of 65 , thus cancer survivorship must be managed in coordination with comorbidities associated with aging ${ }^{1}$. Approximately $61 \%$ will have localized disease where survival outcomes are highest (99\% 5-year relative survival rates for localized stage breast cancer versus $25 \%$ 5-year relative survival rate for distant stage breast cancer) ${ }^{2}$. Breast cancer treatment depends on the stage at diagnosis, size and location of the tumor, and tumor characteristics. Those who are Stage II or III at diagnosis may have more involved cancer treatment, which can result in greater likelihood and severity of the impact of treatment. Treatment generally includes two key components - treatment of the breast and local lymph nodes with surgery either with or without radiation therapy ("local therapy") and drug treatments for cancer cells that may have spread ("adjuvant systemic therapy") outside the breast. Surgical treatment for breast cancer includes breast conserving surgery with radiation or mastectomy with or without radiation and with or without immediate/delayed reconstruction. In women with a very high risk of contralateral cancer from inherited susceptibility (e.g., patients with mutations in BRCA1/2), contralateral prophylactic mastectomy may be performed ${ }^{18,19}$. Systemic therapy may precede (“neoadjuvant”) or follow (“adjuvant”) local therapy, and consists of combinations of hormonal therapy, chemotherapy and biological agents. 
There is no standardized follow-up model for early stage breast cancer patients who have completed surgery, chemotherapy and radiation. Most of these women will have endocrine responsive tumors and will require endocrine therapy for a total of 5 to 10 years. Randomized trials have shown equivalent outcomes with follow-up by either the oncologist or a primary care physician ${ }^{20}$. Shared follow-up care between one or more oncologists and the primary physician is an additional possibility. However, the great majority of these patients will eventually be discharged back to their primary clinician for ongoing follow-up. It should be noted that these patients remain at risk indefinitely for complications of their previous cancer treatment. Most also remain at risk indefinitely for local and/or systemic recurrence of their breast cancer.

Gaps in post-treatment cancer survivorship resources and clinical follow-up care were identified through the work of the National Cancer Survivorship Resource Center (The Survivorship Center; http://www.cancer.org/survivorshipcenter), a collaboration between the American Cancer Society (ACS), The George Washington University (GW) Cancer Institute, and the Centers for Disease Control and Prevention (CDC), and funded by a five-year cooperative agreement from the CDC. The overarching goals of The Survivorship Center are to improve individual-, system-, and policy-level post-treatment survivorship clinical care, to develop resources to help survivors achieve optimal health and quality of life (QoL), as well as to highlight the importance of post-treatment survivorship as a public health issue ${ }^{8}$. A strategic partnership with the American Society of Clinical Oncology (ASCO) was formed to optimize consistent, evidence-based recommendations for survivorship care in patients with breast cancer. 


\section{GUIDELINE QUESTIONS:}

This clinical practice guideline addresses five key areas of breast cancer survivorship to provide recommendations on best practice in the management of adult women after breast cancer treatment, focusing on the role of primary care clinicians and other clinicians who care for post-treatment breast cancer survivors. The five areas covered include (1) surveillance for breast cancer recurrence, (2) screening for second primary cancers, (3) assessment and management of physical and psychosocial long-term and late effects of breast cancer and treatment, (4) health promotion, and (5) care coordination and practice implications.

The Bottom Line

\section{Recommendations for the ACS/ASCO Breast Cancer Survivorship Care Guideline}

\section{Target Population}

Female adult breast cancer survivors

Target Audience

Primary care providers, medical oncologists, radiation oncologists, and other clinicians caring for breast cancer survivors

Methods: An Expert Panel was convened to develop clinical practice guideline recommendations based on a systematic review of the medical literature.

ACSIASCO Key Recommendations for Breast Cancer Survivorship Care:

SURVEILLANCE FOR BREAST CANCER RECURRENCE

History and Physical

Recommendation 1.1: It is recommended that primary care clinicians (a) Should individualize clinical follow-up care provided to breast cancer survivors based on age, specific diagnosis and treatment protocol and as recommended by the treating oncology team ( $L O E=2 A)$; (b) Should make sure the patient receives a detailed cancer-related history and physical examination every 3 to 6 months for the first 3 years after primary therapy, every 6 to 12 months for the next 2 years, and annually thereafter $(\mathrm{LOE}=2 \mathrm{~A})$.

Screening the breast for local recurrence or a new primary breast cancer

Recommendation 1.2: It is recommended that primary care clinicians (a) Should refer women who have received a unilateral mastectomy for annual mammography on the intact breast and for those with lumpectomies an annual mammography of both breasts (LOE=2A); (b) Should not refer for routine screening with MRI of the breast unless the patient meets high risk criteria for increased breast cancer surveillance as per ACS Guidelines ${ }^{21}$ (LOE=2A). 


\section{Laboratory Tests and Imaging}

Recommendation 1.3: It is recommended that primary care clinicians should not offer routine laboratory tests or imaging, except mammography if indicated, for the detection of disease recurrence in the absence of symptoms ( $\mathrm{LOE}=2 \mathrm{~A})$.

Signs of Recurrence

Recommendation 1.4: It is recommended that primary care clinicians should educate and counsel all women about the signs and symptoms of local or regional recurrence (LOE=2A).

\section{Risk Evaluation and Genetic Counseling}

Recommendation 1.5: It is recommended that primary care clinicians (a) Should assess your patient's cancer family history; (b) Should offer genetic counseling if potential hereditary risk factors are suspected (e.g., women with a strong family history of cancer [breast, colon, endometrial], or age 60 or younger with triple negative breast cancer $)^{22}$ (LOE=2A).

\section{Endocrine Treatment Impacts, Symptom Management}

Recommendation 1.6: It is recommended that primary care clinicians should counsel patients to adhere to adjuvant endocrine (anti-estrogen) therapy ( $L O E=2 A)$.

\section{SCREENING FOR SECOND PRIMARY CANCERS}

Cancer Screenings in the Average Risk Patient

Recommendation 2.1: It is recommended that primary care clinicians (a) Should screen for other cancers as they would for patients in the general population. (b) Should provide an annual gynecological assessment for post-menopausal women on selective estrogen receptor modulator therapies (SERMs).

ASSESSMENT AND MANAGEMENT OF PHYSICAL AND PSYCHOSOCIAL LONG-TERM AND LATE EFFECTS OF BREAST CANCER AND TREATMENT

Body Image Concerns

Recommendation 4.1: It is recommended that primary care clinicians (a) Should assess for patient body image/appearance concerns ( $\mathrm{LOE}=0$ ); (b) Should offer the option of adaptive devices (e.g. breast prostheses, wigs) and/or surgery when appropriate (LOE: 0); (c) Should refer for psychosocial care as indicated $(\mathrm{LOE}=\mathrm{IA})$.

\section{Lymphedema}

Recommendation 4.2: It is recommended that primary care clinicians (a) Should counsel survivors on how to prevent / reduce risk of lymphedema, including weight loss for those who are overweight or obese (LOE=0); (b) Should refer patients with clinical symptoms or swelling suggestive of lymphedema to a therapist knowledgeable about the diagnosis and treatment of lymphedema, such as a physical therapist, occupational therapist, or lymphedema specialist $(\mathrm{LOE}=0)$.

\section{Cardiotoxicity}

Recommendation 4.3: It is recommended that primary care clinicians (a) Should monitor lipid levels and provide cardiovascular monitoring, as indicated (LOE=0); (b) Should educate breast cancer survivors on healthy lifestyle modifications, potential cardiac risk factors, and when to report relevant symptoms (shortness of breath or fatigue) to their health care provider ( $L O E=I$ ).

\section{Cognitive Impairment}

Recommendation 4.4: It is recommended that primary care clinicians (a) Should ask patients if they are experiencing cognitive difficulties (LOE=0); (b) Should assess for reversible contributing factors of cognitive impairment and optimally treat when possible (LOE=IA); (c) Should refer patients with signs 
of cognitive impairment for neurocognitive assessment and rehabilitation, including group cognitive training if available (LOE=IA).

Distress, Depression, Anxiety

Recommendation 4.5: It is recommended that primary care clinicians (a) Should assess patients for distress, depression, and/or anxiety $(\mathrm{LOE}=\mathrm{I})$; (b) Should conduct a more probing assessment for patients at a higher risk of depression (e.g., young patients, those with a history of prior psychiatric disease, and patients with low socioeconomic status) (LOE=III); (c) Should offer in-office counseling and/or pharmacotherapy and/or refer to appropriate psycho-oncology and mental health resources as clinically indicated if signs of distress, depression, or anxiety are present ( $L O E=I)$.

\section{Fatigue}

Recommendation 4.6: It is recommended that primary care clinicians (a) Should assess for fatigue and treat any causative factors for fatigue, including anemia, thyroid dysfunction, and cardiac dysfunction $(\mathrm{LOE}=0)$; (b) Should offer treatment or referral for factors that may impact fatigue (e.g. mood disorders, sleep disturbance, pain, etc.) for those who do not have an otherwise identifiable cause of fatigue (LOE= I); (c) Should counsel patients to engage in regular physical activity and refer for cognitive behavioral therapy as appropriate (LOE=I).

\section{Bone Health}

Recommendation 4.7: It is recommended that primary care clinicians (a) Should refer post-menopausal breast cancer survivors for a baseline DEXA scan (LOE=0); (b) Should refer for repeat DEXA scans every 2 years for women taking an aromatase inhibitor, premenopausal women taking tamoxifen and/or a $\mathrm{GnRH}$ agonist, and women who have chemo-induced premature menopause (LOE=0).

Musculoskeletal Health

Recommendation 4.8: It is recommended that primary care clinicians (a) Should assess for musculoskeletal symptoms, including pain, by asking patients about their symptoms at each clinical encounter (LOE=0); (b) Should offer one or more of the following interventions based on clinical indication: acupuncture, physical activity, referral for physical therapy or rehabilitation (LOE=III).

\section{Pain and Neuropathy}

Recommendation 4.9: It is recommended that primary care clinicians (a) Should assess for pain and contributing factors for pain with the use of a simple pain scale and comprehensive history of the patient's complaint (LOE=0); (b) Should offer interventions, such as acetaminophen, nonsteroidal antiinflammatory drugs, physical activity and/or acupuncture, for pain (LOE=I); (c) Should refer to an appropriate specialist depending on the etiology of the pain once the underlying etiology has been determined (e.g., lymphedema specialist, occupational therapist, etc.) (LOE=0); (d) Should assess for peripheral neuropathy and contributing factors for peripheral neuropathy by asking the patient about their symptoms, specifically numbness and tingling in their hands and/or feet, and the characteristics of that symptom (LOE=0); (e) Should offer physical activity for neuropathy; (f) Should offer duloxetine for patients with neuropathic pain, numbness and tingling (LOE=IB).

\section{Infertility}

Recommendation 4.10: It is recommended that primary care clinicians should refer survivors of childbearing age who experience infertility to a specialist in reproductive endocrinology and infertility as soon as possible ( $\mathrm{LOE}=0)$.

\section{Sexual Health}

Recommendation 4.11: It is recommended that primary care clinicians (a) Should assess for signs and symptoms of sexual dysfunction or problems with sexual intimacy (LOE=0); (b) Should assess for 
reversible contributing factors to sexual dysfunction and treat, when appropriate (LOE=0); (c) Should offer nonhormonal, water-based lubricants and moisturizers for vaginal dryness (LOE=IA); (d) Should refer for psychoeducational support, group therapy, sexual counseling, marital counseling or intensive psychotherapy, when appropriate (LOE=IA).

\section{Premature Menopause/Hot Flashes}

Recommendation 4.12: It is recommended that primary care clinicians should offer selective serotoninnorepinephrine reuptake inhibitors (SNRIs), selective serotonin reuptake inhibitors (SSRIs), gabapentin, lifestyle modifications and/or environmental modifications to help mitigate vasomotor symptoms of premature menopausal symptoms (LOE=IA).

\section{HEALTH PROMOTION}

\section{Information}

Recommendation 5.1: It is recommended that primary care clinicians (a) Should assess the information needs of the patient related to breast cancer and its treatment, side effects, other health concerns, and available support services ( $\mathrm{LOE}=0$ ); (b) Should provide or refer survivors to appropriate resources to meet these needs (LOE $=0$ ).

\section{Obesity}

Recommendation 5.2: It is recommended that primary care clinicians (a) Should counsel survivors to achieve and maintain a healthy weight (LOE=III); (b) Should counsel survivors if overweight or obese to limit consumption of high-calorie foods and beverages and increase physical activity to promote and maintain weight loss (LOE=IA, III).

\section{Physical Activity}

Recommendation 5.3: It is recommended that primary care clinicians should counsel survivors to engage in regular physical activity consistent with the ACS guideline ${ }^{23}$ and specifically: (a) Should avoid inactivity and return to normal daily activities as soon as possible following diagnosis (LOE=III); (b) Should aim for at least 150 minutes of moderate or 75 minutes of vigorous aerobic exercise per week (LOE=I, IA); (c) Should include strength training exercises at least 2 days per week. Emphasize strength training for women treated with adjuvant chemotherapy or hormone therapy (LOE= IA).

\section{Nutrition}

Recommendation 5.4: It is recommended that primary care clinicians should counsel survivors to achieve a dietary pattern that is high in vegetables, fruits, whole grains, and legumes, low in saturated fats, and limited in alcohol consumption (LOE= IA, III).

\section{Smoking Cessation}

Recommendation 5.5: It is recommended that primary care clinicians should counsel survivors to avoid smoking and refer survivors who smoke to cessation counseling and resources (LOE= I).

\section{CARE COORDINATION / PRACTICE IMPLICATIONS}

\section{Survivorship Care Plan}

Recommendation 6.1: It is recommended that primary care clinicians should consult with the cancer treatment team and obtain a treatment summary and Survivorship Care Plan (LOE=0, III).

\section{Communication with Oncology Team}

Recommendation 6.2: It is recommended that primary care clinicians should maintain communication with the oncology team throughout your patient's diagnosis, treatment and post-treatment care to ensure care is evidence-based and well-coordinated $(L O E=0)$. 
Inclusion of Family

Recommendation 6.3 It is recommended that primary care clinicians should encourage the inclusion of caregivers, spouses, or partners in usual breast cancer survivorship care and support (LOE=0).

Additional Resources: More information, including a Data Supplement with additional evidence tables, is available at www.asco.org/guidelines/xxx and www.asco.org/guidelineswiki. Patient information is available at www.cancer.net.

\section{METHODS}

Methods used to develop this guideline reflect an evolving process that was influenced by ACS screening ${ }^{24}$ and survivorship ${ }^{16}$ guidelines. Where appropriate, this guideline builds upon the recently published ASCO symptom-based guidelines for adult cancer survivors ${ }^{14,15,25}$.

\section{Panel Formation}

A multidisciplinary expert workgroup was formed and tasked with drafting the Breast Cancer Survivorship Care Guideline. Workgroup members had expertise in primary care, gynecology, surgical oncology, medical oncology, radiation oncology, and nursing. In addition a cancer survivor was included to provide a patient perspective.

\section{Literature Review}

The literature review began with an environmental scan of existing guidelines and guidance developed by other organizations [e.g., $\operatorname{NCCN}^{9,26,27}$; ASCO 11, 14, 15, 25, 28; Long-term Follow-up Guidelines for Survivors of Childhood, Adolescent, and Young Adult Cancers of the Children's Oncology Group (http://survivorshipguidelines.org)], specific medical centers (e.g., The University of Texas MD Anderson Clinical Tools and Resources Breast Cancer Survivorship algorithm ${ }^{29}$, US Preventive Services Task Force ${ }^{22,30,31}$, the American Association of Clinical Endocrinologists ${ }^{32}$, individual publications ${ }^{33-36}$, available from other countries (e.g., Australian Cancer Survivorship Centre), and from other expert panels (e.g., Breast Health Global Initiative guidelines ${ }^{37}$ ). 


\section{Literature Search Strategy}

A systematic review of the literature was conducted using PubMed through April 2015. Studies on childhood cancers, qualitative studies, and non-English publications were excluded. Search terms included: cancer survivor AND review OR meta-analysis OR systematic review OR guidelines; guidance AND breast cancer OR breast cancer survivor; breast cancer patient post-treatment AND symptom management OR late effects OR long-term effects OR psychosocial care OR palliative care OR health promotion OR surveillance OR screening for new cancers OR self-management OR guidelines OR guidance OR follow up OR follow-up OR side effects OR (chemotherapy AND side effects) OR (radiation AND side effects), OR surgery OR treatment complications OR genetic counseling and testing OR survivor or patient interventions OR provider interventions OR provider education OR barriers. Additional search attempts included breast cancer OR breast cancer survivor OR breast cancer patient posttreatment AND (symptom-specific terms, such as lymphedema, body image, early menopause, etc).

The highest priority was given to articles that met the following criteria: peer reviewed publication in English since 2004, unless a seminal article published before that date still carried the most weight, including randomized controlled trials (RCTs), prospective cohort studies, and well-conducted, population-based, case-control studies; large studies of more than 100 cancer cases analyzed and with high-quality assessment of covariates, and analytic methods; and analyses controlled for important confounders (e.g., pre-existing comorbid conditions).

\begin{tabular}{|l|l|}
\hline $\begin{array}{l}\text { Level of Evidence } \\
\text { (LOE) }\end{array}$ & \\
\hline I & Meta analyses of RCTs \\
\hline IA & RCT of breast cancer survivors \\
\hline IB & RCT based on cancer survivors across multiple cancer sites \\
\hline IC & $\begin{array}{l}\text { RCT not based on cancer survivors, but on general population } \\
\text { experiencing a specific long-term or late effect (e.g., managing } \\
\text { menopausal symptoms, sexual dysfunction, etc.) }\end{array}$ \\
\hline IIA & Non-randomized clinical trials based on breast cancer survivors \\
\hline IIB & Non-randomized clinical trials based on cancer survivors across multiple \\
\hline
\end{tabular}




\begin{tabular}{|l|l|}
\hline & sites \\
\hline IIC & $\begin{array}{l}\text { Non-randomized clinical trials not based on cancer survivors, but on } \\
\text { general population experiencing a specific long-term or late effect }\end{array}$ \\
\hline III & Case-control study or prospective cohort study \\
\hline 0 & $\begin{array}{l}\text { Expert opinion, observational study (excluding case-control and } \\
\text { prospective cohort studies), clinical practice, literature review, or pilot } \\
\text { study }\end{array}$ \\
\hline $2 \mathrm{~A}$ & NCCN guideline \\
\hline
\end{tabular}

Workgroup members were also asked to consider the specific level of evidence criteria along with consistency across studies and study designs; dose-response when presenting treatment impacts; race / ethnicity differences; and second primary cancers for which survivors are at high risk due to treatment and genetic considerations. After finalization by the workgroup, the guideline manuscript was sent to additional internal and external experts for review and comment prior to submission for publication. The manuscript summarizes literature with the highest level of evidence (i.e., RCTs). A comprehensive list of evidence is available in the Appendix.

This is the most recent information as of the publication date. For updates, the most recent information, and to submit new evidence, please visit www.asco.org/guidelines/xxx and the ASCO Guidelines Wiki (www.asco.org/guidelineswiki). Based on formal review of the emerging literature, ACS/ASCO will determine the need to update on a regular basis. At minimum, it will be updated every 5 years.

\section{Guideline Disclaimer}

The Clinical Practice Guidelines and other guidance published herein are provided by ACS and ASCO to assist providers in clinical decision making. The information herein should not be relied upon as being complete or accurate, nor should it be considered as inclusive of all proper treatments or methods of care or as a statement of the standard of care. With the rapid development of scientific knowledge, new evidence may emerge between the time information 
is developed and when it is published or read. The information is not continually updated and may not reflect the most recent evidence. The information addresses only the topics specifically identified therein and is not applicable to other interventions, diseases, or stages of diseases. This information does not mandate any particular course of medical care. Further, the information is not intended to substitute for the independent professional judgment of the treating provider, as the information does not account for individual variation among patients. Recommendations reflect high, moderate, or low confidence that the recommendation reflects the net effect of a given course of action. The use of words like "must," "must not," "should," and "should not" indicates that a course of action is recommended or not recommended for either most or many patients, but there is latitude for the treating physician to select other courses of action in individual cases. In all cases, the selected course of action should be considered by the treating provider in the context of treating the individual patient. Use of the information is voluntary. ACS and ASCO provide this information on an "as is" basis and make no warranty, express or implied, regarding the information. ACS and ASCO specifically disclaim any warranties of merchantability or fitness for a particular use or purpose. ACS and ASCO assume no responsibility for any injury or damage to persons or property arising out of or related to any use of this information, or for any errors or omissions.

\section{Guideline and Conflicts of Interest}

The Expert Panel was assembled in accordance with ACS's Conflict of Interest Procedures and ASCO's Conflict of Interest Management Procedures for Clinical Practice Guidelines ("Procedures," summarized at http://www.asco.org/rwc). Members of the Panel completed ACS's Guidelines Development Participant Disclosure Form, ASCO's disclosure form, and the International Committee of Medical Journal Editors (ICMJE) Form for Disclosure of Potential Conflicts of Interest, which requires disclosure of financial and other interests that are relevant to the subject matter of the guideline, including relationships with commercial entities that are 
reasonably likely to experience direct regulatory or commercial impact as a result of promulgation of the guideline. Categories for disclosure include employment; leadership; stock or other ownership; honoraria, consulting or advisory role; speaker's bureau; research funding; patents, royalties, other intellectual property; expert testimony; travel, accommodations, expenses; and other relationships. In accordance with the Procedures, the majority of the members of the Panel did not disclose any such relationships.

\section{RESULTS}

A total of 1073 articles (list is available as a supplement to this manuscript) met inclusion criteria and after full text review, 237 were included as the evidence base. Only $2 \%$ of eligible articles were rated as Level I evidence, $7 \%$ were Level IA, and $2 \%$ were Level IIA. The majority of evidence was rated as Level III (26\%) and Level 0 (64\%). Recommendations provided in this guideline are based on current evidence in the literature and expert consensus opinion. Most of the evidence is not sufficient to warrant a strong evidence-based recommendation. Rather, recommendations should be largely viewed as possible management strategies given the current limited evidence base and the logistical challenges of comprehensively adhering to these recommendations.

\section{RECOMMENDATIONS}

\section{SURVEILLANCE FOR BREAST CANCER RECURRENCE}

(Table 1: Guideline for Surveillance for Breast Cancer Recurrence and Genetic Counseling) Genetic Testing / Counseling

The guiding principle of surveillance is that it should consider a patient's risk of recurrence, in the context of functional status and patient preferences. In asymptomatic patients, routine screening tests to detect recurrence are not recommended. However, a careful 
history is often needed to assure that patients are indeed asymptomatic. Patients at a higher risk for local recurrence should have appropriate screening.

\section{History and Physical}

\section{Recommendation 1.1: It is recommended that primary care clinicians (a) Should} individualize clinical follow-up care provided to breast cancer survivors based on age, specific diagnosis and treatment protocol as recommended by the treating oncology team ( $L O E=2 A)$; (b) Should make sure the patient receives a detailed cancer-related history and physical examination every 3 to 6 months for the first 3 years after primary therapy, every 6 to 12 months for the next 2 years, and annually thereafter by the treating oncology team (LOE=2A).

Clinical interpretation: Perform periodic history and physical examination on all breast cancer survivors. In a previous ASCO guideline, ASCO recommended that all female breast cancer survivors have a detailed history and physical examination every 3 to 6 months for the first 3 years after primary therapy, every 6 to 12 months for the next 2 years, and annually thereafter in order to detect cancer recurrence at an early stage ${ }^{11,12}$. Frequency should be determined by the treating oncologist and be based on the individual risk profile and perspective of the patient. This can be done in collaboration with the primary care clinician. Patients should be made aware of the signs and symptoms of disease recurrence and be instructed to seek medical attention if any of the signs or symptoms occur between scheduled follow-up visits. If one or more additional oncology health care providers are following the patient, the frequency of the primary physician's visits should be adjusted accordingly. Clinicians can recommend vaccinations to their patients with a breast cancer history as appropriate based on guidelines; they can receive flu (shot, not nasal) or pneumonia vaccine at any time, including during chemotherapy, and zoster vaccine when not receiving chemotherapy ${ }^{38}$.

\section{Screening the Breast for Local Recurrence or a New Primary Breast Cancer}


Recommendation 1.2: It is recommended that primary care clinicians (a) Should refer women who have received a unilateral mastectomy for annual mammography on the intact breast and for those with lumpectomies an annual mammography of both breasts (LOE=2A); (b) Should not refer for routine screening with MRI of the breast unless the patient meets high risk criteria for increased breast cancer surveillance as per ACS Guidelines $^{21}$ (LOE=2A).

Clinical interpretation: Mammography should be performed yearly on the breast treated by breast conserving surgery and on the intact contralateral breast. More frequent mammography is only warranted for evaluation or follow-up of a suspicious finding ${ }^{11}$. Following mastectomy, the site of the reconstructed breast does not require imaging. While MRI of the breast is more sensitive than mammography, there is an increased risk of false positive findings that may lead to unnecessary additional imaging and often unnecessary biopsies. Use of MRI can only be justified if the probability of missing a cancer with mammography alone is sufficiently high. In women who have not undergone bilateral mastectomy, the use of MRI of the breasts in screening for local recurrence or a new primary cancer should be restricted to women who meet the high risk criteria by the ACS or ASCO ${ }^{11,21,39}$. High risk is defined as a woman with a lifetime risk of a second primary breast cancer $>20 \%$, such as a woman with a BRCA $1 / 2$ mutation or a very strong family history of breast cancer ${ }^{21}$.

\section{Laboratory Tests and Imaging}

Recommendation 1.3: It is recommended that primary care clinicians should not offer routine laboratory tests or imaging, except mammography if indicated, for the detection of disease recurrence in the absence of symptoms (LOE=2A).

Clinical interpretation: Consistent with ASCO and NCCN guidelines, routine testing with breast cancer tumor markers or imaging studies (e.g., bone scan, chest x-ray, PET-CT scans, MRI scans, biomarkers) should not be performed for screening purposes because they have not 
been shown to improve survival outcomes or quality of life in asymptomatic patients ${ }^{9,11}$. Chest x-rays and advanced body imaging (i.e., CT, MRI, PET-CT, bone scan) should be ordered only if disease recurrence is suspected ${ }^{40}$. Randomized trials in the 1980 s comparing clinical followup to periodic advanced imaging did not demonstrate a survival advantage with advanced imaging, and did show a significant rate of false-positive findings with additional testing ${ }^{41-43}$.

\section{Signs of Recurrence}

Recommendation 1.4: It is recommended that primary care clinicians should educate and counsel all women about the signs and symptoms of local or regional recurrence (LOE=2A).

Clinical interpretation: Physicians should educate and counsel patients about the signs and symptoms of local or regional recurrence including new lumps (e.g., in underarm or neck), rash or skin changes on the breast or chest wall, chest pain, changes in the contour/shape/size of the breast, and swelling of the breast or arm ${ }^{11}$. Evaluation of patient-reported symptoms is essential in detecting a recurrence as early as possible which may impact survival.

\section{Risk Evaluation and Genetic Counseling}

Recommendation 1.5: It is recommended that primary care clinicians (a) Should assess your patient's cancer family history; (b) Should offer genetic counseling if potential hereditary risk factors are suspected (e.g., women with a strong family history of cancer [breast, colon, endometrial], or age 60 or younger with triple negative breast cancer) ${ }^{22}$ $(\mathrm{LOE}=2 \mathrm{~A})$.

Clinical interpretation: To identify those women with breast cancer who have a high risk of a second primary breast cancer and / or may have a genetic susceptibility to cancer that may affect other family members, a detailed history including key risk factors and paternal and maternal family history should be obtained for all patients. Those with a family history of breast 
or ovarian cancer or with cancer in a certain age group and / or cancer type should be referred for genetic counseling for consideration of testing for hereditary predisposition to genetic mutations. Specifically, genetic counseling for consideration of testing for hereditary predisposition to gene mutations should be recommended for breast cancer survivors: with at least one grandparent of Ashkenazi Jewish heritage; younger than 50 years of age at diagnosis; with a history of ovarian cancer at any age or in any first- or second-degree relative; with a firstdegree relative with breast cancer diagnosed before the age of 50; with two or more first- or second-degree relatives diagnosed with breast cancer at any age; with a diagnosis of bilateral breast cancer; with a history of breast cancer in a male relative; or any survivor diagnosed at age 60 or younger with triple negative breast cancer ${ }^{22}$. It is important to periodically review these issues with the patient as some survivors may not have been offered genetic counseling or testing at the time of diagnosis and/or new cancer events may have occurred in the family after the initial diagnosis and treatment. Because new primary cancers may be associated with some hereditary syndromes, identifying the risk of genetic mutations in the survivor may help to formulate a prevention strategy to reduce the risk of a new cancer. In addition, this information could be helpful to family members as well.

Genetic testing should be preceded by consultation with a genetics counselor or other trained professional to assure full discussion of the risks and benefits, and to assure that other genetic syndromes beyond BRCA1 and BRCA2 breast / ovarian syndromes are considered. Depending on the hereditary gene that is identified, different screening and prevention strategies may be offered. Recommendations for alternate screening and prevention strategies depend on the specific genetic syndrome, and should be left to a trained professional in coordination with the oncology team and primary care clinician.

\section{Endocrine Treatment Impacts, Symptom Management}


Recommendation 1.6: It is recommended that primary care clinicians should counsel patients to adhere to adjuvant endocrine (anti-estrogen) therapy (LOE=2A).

Clinical interpretation: Endocrine therapy (tamoxifen, aromatase inhibitors, or ovarian suppression therapy) used as adjuvant systemic therapy for 5-10 years reduces the risk of recurrence and of subsequent second primary breast cancers and improves overall survival. Adherence to endocrine therapy is necessary to achieve its survival benefits. Unfortunately some women discontinue endocrine therapy because of cost, side effects and other reasons. Reported adherence for a 5 year course of therapy ranges from 50 to $92 \%$ of breast cancer patients ${ }^{44}$. Primary care clinicians should assess and encourage adherence to adjuvant endocrine therapy at each visit ${ }^{9}$.

\section{SCREENING FOR SECOND PRIMARY CANCERS}

Table 2: ACS Guidelines for the Early Detection of Cancer in Average Risk, Asymptomatic Individuals

\section{Cancer Screenings in the Average Risk Patient}

Recommendation 2.1: It is recommended that primary care clinicians (a) Should screen for other cancers as they would for patients in the general population; (b) Should provide an annual gynecological assessment for post-menopausal women on selective estrogen receptor modulator therapies (SERMs). ${ }^{45}$

Clinical interpretation: Women should be advised to follow the ACS screening and early detection guidelines for cervical, colorectal, endometrial, and lung cancers detailed in Table $2^{45}$. Post-menopausal women taking SERMs, such as tamoxifen or raloxifene, should be advised to report any vaginal spotting or bleeding as these drugs slightly increase the risk of endometrial cancer in post-menopausal women. In the absence of abnormal vaginal spotting or bleeding, periodic imaging is not of value and may lead to unwarranted biopsies ${ }^{46}$. Discuss the risks, benefits, and limitations of screening modalities with your patients. 


\section{ASSESSMENT AND MANAGEMENT OF PHYSICAL AND PSYCHOSOCIAL LONG-TERM}

\section{AND LATE EFFECTS OF BREAST CANCER AND TREATMENT}

The risk of physical long-term and late effects following therapy for breast cancer is associated with several factors, including: a) type of treatment, b) duration and dose of treatment(s) (increasing cumulative dose and duration of therapy increases the potential risk), c) specific type of chemotherapy, d) receipt of and type of hormone treatment, and e) age of patient during treatment. Modalities of treatment include surgery, radiation therapy, chemotherapy, targeted therapy, and/or endocrine therapy. Primary care clinicians should refer to the patient's cancer treatment summary, if available, for specific drugs and doses (see Recommendation 6.1). Table 3 lists potential physical and psychosocial long-term and late effects associated with surgery, radiation, chemotherapy, hormone therapy and targeted treatment. Long-term effects are medical problems that develop during active treatment and persist after the completion of treatment; whereas, late effects are medical problems that develop or become apparent months or years after treatment is completed. Recommendations for the assessment and management of specific physical and psychosocial long-term and late effects most commonly experienced by breast cancer survivors are detailed in Table 4.

Table 4: Guidelines for Assessment and Management of Physical and Psychosocial Long-term / Late Effects

\section{Body Image Concerns}

Recommendation 4.1: It is recommended that primary care clinicians (a) Should assess for patient body image/appearance concerns (LOE=0); (b) Should offer the option of adaptive devices (e.g., breast prostheses, wigs) and/or surgery when appropriate (LOE: 0); (c) Should refer for psychosocial care as indicated (LOE=IA). 
Clinical interpretation: Body image / appearance changes can be a major area of concern affecting $31-67 \%$ of breast cancer survivors ${ }^{47}$. Factors such as the loss of a breast, scarring and / or lymphedema following surgery, hair loss or sexual dysfunction /chemotherapy-related early menopause, skin changes from radiation, and weight gain can all lead to changes in body image with negative implications on short and long term QoL ${ }^{48}$. These body image implications are especially relevant for young breast cancer survivors ${ }^{49-51}$. Among female breast cancer survivors who are sexually active, greater body image problems have been found to be associated with mastectomy with or without reconstruction, hair loss from chemotherapy, concern with weight change, decreased self-esteem prior to the time of cancer diagnosis, poorer mental health, and a partner's difficulty understanding one's feelings ${ }^{50}$.

Patients with radiation-associated breast/soft-tissue fibrosis should be considered for therapy with oral pentoxifylline (trental) and vitamin $E^{52-55}$. A radiation oncologist should evaluate such patients to assure that the clinical findings are consistent with the radiation treatment delivered. Recurrent cancer or infection can sometimes be mistaken for radiation-associated fibrosis. Primary care clinicians should refer back to the oncologist (medical, surgical, or radiation) if they ever are uncertain about potential recurrence.

Breast reconstructive surgery should be considered in women who do not feel comfortable with the results of their initial breast surgery, whether lumpectomy or mastectomy, as there may be ways to improve symmetry or appearance. Breast forms/prostheses or bras are options that are available to survivors who have undergone mastectomy or non-breast conserving therapies, and generally require a prescription from a physician. Special lingerie, attachable nipples, and other resources can help the survivor regain self-esteem. Most insurance plans cover mastectomy prostheses and specialty bras. In addition, wigs, hats, scarves and other accessories are available for survivors who experience permanent hair loss (alopecia is a rare complication of chemotherapy), color or texture change. Women should check with their insurance company and obtain a prescription from their physicians. Breast 
cancer care centers or specialists often maintain directories of resources in their community where patients can find these products.

Primary care clinicians should refer patients having body image concerns that are not corrected by above options for psychosocial care. For example, for women who experience early menopause or for those with sexual concerns, support groups, psychotherapy, cognitive behavioral therapy, couple-based interventions or sex therapy may be helpful. Couple-based interventions can promote coping skills and provide specific techniques to address body image issues $^{56}$

\section{Lymphedema}

Recommendation 4.2: It is recommended that primary care clinicians (a) Should counsel survivors on how to prevent / reduce risk of lymphedema, including weight loss for those who are overweight or obese $(\mathrm{LOE}=0)$; (b) Should refer patients with clinical symptoms or swelling suggestive of lymphedema to a therapist knowledgeable about the diagnosis and treatment of lymphedema, such as a physical therapist, occupational therapist, or lymphedema specialist (LOE=0).

Clinical interpretation: All breast cancer survivors who undergo breast surgery and / or radiation are at risk for lymphedema. This is arm, breast, or chest wall swelling as a result of a blockage of the lymphatic fluid from the arm and / or breast leading to retention of fluid and swelling. The incidence of lymphedema among breast cancer survivors varies widely ${ }^{57}$ though it is estimated that over $40 \%$ of survivors will experience lymphedema to some degree ${ }^{58,59}$. The risk of lymphedema is much lower with sentinel lymph node dissections than with the full axillary lymph node dissection previously performed in all cases ${ }^{60}$. Lymphedema may occur immediately after treatment or develop after many years. Radiation treatment may cause or exacerbate lymphedema, especially radiation to the supraclavicular nodes or axilla ${ }^{61}$. 
The degree of swelling associated with lymphedema varies widely even for those receiving similar surgery and /or radiation. In most cases, it is generally limited in extent and is not disabling. In some cases the swelling is extensive and leads to significant disability such as limitation of the ability to perform fine motor functions with the hand as well as limited range of motion of other affected joints ${ }^{62}$. In addition, the swelling may cause symptoms ranging from mild discomfort to overt pain. The swelling may be of a noticeable degree and make clothes difficult to fit, and cause pain from the added weight of the arm. The International Society of Lymphedema provides a staging system to categorize the extent of lymphedema ${ }^{63}$. Patients with lymphedema are also at greater risk for the development of cellulitis of the breast, arm or chest which, especially if not promptly treated with antibiotics, may exacerbate lymphedema.

More studies are needed in the area of lymphedema prevention above and beyond biopsy types and surgical strategies (sentinel lymph node dissections and axillary reverse mapping ${ }^{64}$. Obesity is also a risk factor for lymphedema ${ }^{65,66}$ so physicians should recommend weight loss for those who are overweight or obese and the importance of maintaining a normal weight (see also Recommendation 5.2). Historically patients with axillary lymphadenectomies/radiation have been advised to avoid physical activity and heavy lifting with the arm on the affected side. However, one study has shown that supervised slowly progressive resistance training is safe and effective for breast cancer survivors with regards to lymphedema development. Further, this type of physical activity may reduce the likelihood of arm swelling among breast cancer survivors at high risk for lymphedema due to having 5 or more nodes removed and in improving the symptoms and severity for those in whom the condition was already present ${ }^{67}$. While the results of this study suggest a promising intervention for lymphedema, additional research is warranted.

Therefore, primary care clinicians should focus on the early identification and management of lymphedema among their patients with breast cancer ${ }^{68}$. 
Patients who develop clinical symptoms or swelling suggestive of lymphedema should be referred to a therapist knowledgeable about the diagnosis and treatment of lymphedema. Depending on available resources in a community, this may be a physical ${ }^{69}$ or occupational $^{70}$ therapist or a specialist therapist trained in lymphedema management.

\section{Cardiotoxicity}

Recommendation 4.3: It is recommended that primary care clinicians (a) Should monitor lipid levels and provide cardiovascular monitoring, as indicated (LOE=0); (b) Should educate breast cancer survivors on healthy lifestyle modifications, potential cardiac risk factors, and when to report relevant symptoms (shortness of breath or fatigue) to their health care provider $(L O E=I)$.

Clinical interpretation: Radiation, chemotherapy and hormonal/endocrine therapy with aromatase inhibitors have been associated with an increased risk of cardiovascular disease in patients with breast cancer ${ }^{71,72}$. The risk of heart disease increases in post-menopausal women, as endogenous estrogens in younger women contribute to the low prevalence of cardiovascular disease in that population. Breast cancer patients who experience treatment-related early menopause may therefore be at higher risk for heart disease than age-matched women in the general population. The chemotherapeutic agents epirubicin and doxorubicin are associated with a low but real risk of cardiomyopathy ${ }^{73}$; similarly, trastuzumab is associated with an increased risk of cardiac dysfunction, most notably when given concomitantly or after an anthracycline, as has been detailed by the European Society for Medical Oncology ${ }^{74}$. Aromatase inhibitors can raise cholesterol levels ${ }^{75,76}$ and the risk of diabetes. Significant weight gain may lead to hypertension and insulin resistance which further elevate risk of cardiovascular disease. Primary care clinicians should monitor lipid levels and engage in cardiovascular monitoring consistent with clinical standards for other high risk populations (e.g., US Preventive Services Task Force recommendations ${ }^{30}$ ). 
It is important to educate breast cancer survivors about lifestyle modifications, including smoking cessation, diet and exercise (see Recommendations 5.3-5.5) that may reduce risk or severity of cardiotoxicity or cardiovascular diseases generally. Patients should be advised to be aware of the potential risk for cardiotoxicities and report symptoms such as shortness of breath or fatigue (without an otherwise identifiable cause) to their health care provider. However routine screening or testing for cardiovascular disease in asymptomatic patients beyond careful history and physical examination are not warranted.

ASCO is currently developing a guideline on the prevention and monitoring of cardiac dysfunction in survivors of adult cancers.

\section{Cognitive Impairment}

\section{Recommendation 4.4: It is recommended that primary care clinicians (a) Should ask} patients if they are experiencing cognitive difficulties (LOE=0); (b) Should assess for reversible contributing factors of cognitive impairment and optimally treat when possible (LOE=IA); (c) Should refer patients with signs of cognitive impairment for neurocognitive assessment and rehabilitation, including group cognitive training if available (LOE=IA). Clinical interpretation: Impairment in cognitive function as a result of cancer and its treatment can lead to distress and impaired quality of life in breast cancer survivors. Up to $75 \%$ of breast cancer patients in treatment and $35 \%$ following treatment report cognitive impairment, including problems with concentration, executive function, and memory ${ }^{77-79}$. Cognitive impairment can also have detrimental effects on the survivor's role within the family, workplace, and in society ${ }^{80,}$ 81. Clinicians should ask patients if they are having cognitive difficulties and listen to family members' reporting of patient cognitive symptoms. If this is an issue, consultation with a neuropsychologist for assessment and referral for cognitive rehabilitation strategies should be offered as one would do with the general population. 
The causes of cognitive impairment are thought to be multifactorial and may include treatable conditions, such as fatigue, insomnia, and depression. Links have been suggested between cognitive impairment and adjuvant chemotherapy ${ }^{82-84}$; surgery / anesthesia ${ }^{85}$; endocrine therapy ${ }^{77,86}$; as well as cancer itself ${ }^{77}$. Research suggests that older adults and / or those with lower cognitive reserves may be more susceptible to cognitive impairment from treatment ${ }^{87}$ and that there may also be genetic factors associated with certain estrogen metabolism genes ${ }^{88,89}$.

The treatment of cognitive impairment in the breast cancer survivor is not well established. A few studies have shown some success with pharmaceuticals, such as modafinil ${ }^{90}$, that have helped improve cognitive impairment, but the data are not consistent ${ }^{91}$. Cognitive rehabilitation strategies including the practice of group cognitive training (i.e., interventions geared towards improving, restoring or maintaining mental function through structured, repetitive practice of tasks posing a mental challenge or requiring the person to problem solve) has been found to be helpful at reducing cognitive impairment in breast cancer survivors ${ }^{92},{ }^{93}$. Primary care clinicians should provide referral for neurocognitive assessment and rehabilitation as clinically indicated.

\section{Distress, Depression, and Anxiety}

Recommendation 4.5: It is recommended that primary care clinicians (a) Should assess patients for distress, depression, and/or anxiety (LOE=I); (b) Should conduct a more probing assessment for patients at a higher risk of depression (e.g., young patients, those with a history of prior psychiatric disease, and patients with low socioeconomic status) (LOE=III); (c) Should offer in-office counseling and/or pharmacotherapy and/or refer to appropriate psycho-oncology and mental health resources as clinically indicated if signs of distress, depression, or anxiety are present (LOE=I). 
Clinical interpretation: Many cancer survivors report ongoing difficulties in recovery and returning to 'normal' following treatment ${ }^{1,2,17,94}$. Some survivors of cancer experience fear of recurrence $(F O R)^{95}$, contributing to significant mental health problems for which they may already have an increased risk, including distress, depression, and anxiety ${ }^{96,97}$. Older age and African American breast cancer survivors have been found to have less FOR. Shorter interval of time since diagnosis, having received chemotherapy, and having more symptoms, especially pain, were found to be related to higher levels of FOR ${ }^{98}$. Prevalence estimates for anxiety, depression, and distress in cancer survivors vary widely as a result of inconsistency in the use of measurement tools and differences in methodological approaches, such as the choice of comparators from the general population. The estimated prevalence of anxiety and depression is $17.9 \%$ and $11.6 \%$, respectively, among the general cancer survivor population ${ }^{99}$. In a systematic review of observational studies, the prevalence of depression and anxiety among breast cancer survivors, specifically, was $22 \%$ (range=13-56\%) using the Center for Epidemiological Studies for Depression (CES-D), 22\% (range=17-48\%) using the Beck Depression Inventory, and 10\% (range=1-22\%) using the Hospital Anxiety and Depression Scale ${ }^{100}$.

In order to provide timely and appropriate support for their patients with a history of breast cancer, primary care clinicians should be familiar with the mental health concerns they may experience, the tools to screen for and assess these problems, and the resources to care for their patients. A tool for initial screening is the distress thermometer (http://www.nccn.org/patients/resources/life_with_cancer/pdf/nccn_distress_thermometer.pdf): 0 (no distress) to 10 (extreme distress). A score of four or higher ${ }^{101}$ suggests a level of distress that has clinical significance. The PHQ- $9^{102}$ and the GAD- $7^{103}$ are validated methods for screening for depression and anxiety, respectively, and are available free online at http://www.phqscreeners.com/. For patients elevated on these screeners, further discussion and assessment of the issues is needed, as in the general population. For more information on 
screening and assessing adults with cancer for psychosocial distress, see the depression and anxiety algorithms in the online Appendix which is reproduced from the ASCO guidelines ${ }^{15}$.

The risk of having major depression after a diagnosis of breast cancer was higher among younger patients, patients with a history of prior psychiatric disease, patients with low socioeconomic status, and those who were unemployed ${ }^{104}$. Among patients with breast cancer, decreased libido, poor self-image, and relationship issues were common among those who were depressed $^{105-107}$.

Treatment for depression and anxiety in cancer patients and survivors with medication and psychotherapy is comprehensively described in the recent ASCO anxiety and depression guideline adaptation (http://www.instituteforquality.org/screening-assessment-and-care-anxietyand-depressive-symptoms-adults-cancer-american-society) ${ }^{15}$. In addition, or instead of pharmacotherapy, mindfulness-based approaches, expression of positive emotions, spiritual interventions, hope therapy, and meaning-making interventions have shown promise in addressing psychosocial needs of breast cancer survivors ${ }^{108}$. While the methodology studying the effectiveness of these interventions varied, survivors experienced positive changes, such as enhanced quality of life and well-being ${ }^{108}$. If a patient has a clinically significant score on any of the previously discussed instruments, it is recommended that primary care clinicians refer patients to the appropriate psychosocial oncology specialists, mental health professionals and/or resources in the community ${ }^{27}$. After referring to the appropriate resource(s), primary care clinicians should follow-up with patients to check their adherence to recommended therapies and/or assess the need for additional referrals. If a patient has difficulties with adherence to recommendations, primary care clinicians should identify the challenges with adherence and help the patient overcome these obstacles before discussing alternative interventions ${ }^{15}$. The American Psychosocial Oncology Society website (http://www.apos-society.org/) can help primary care clinicians identify resources for their patients. 


\section{Fatigue}

Where appropriate, these recommendations build upon the recently published ASCO screening, assessment and treatment of cancer-related fatigue guidelines among adult cancer survivors $^{25}$.

Recommendation 4.6: It is recommended that primary care clinicians (a) Should assess for fatigue and treat any causative factors for fatigue, including anemia, thyroid dysfunction, and cardiac dysfunction (LOE= 0); (b) Should offer treatment or referral for factors that may impact fatigue (e.g. mood disorders, sleep disturbance, pain, etc.) for those who do not have an otherwise identifiable cause of fatigue (LOE= I); (c) Should counsel patients to engage in regular physical activity and refer for cognitive behavioral therapy as appropriate (LOE=I).

Clinical interpretation: Cancer-related fatigue is very common among those treated for cancer, especially those who undergo treatment with radiation therapy and chemotherapy ${ }^{13,25,109}$, with an estimated prevalence of $28 \%-91 \%{ }^{110,111}$. Recommendations for how to screen and assess for fatigue can be found in the online Appendix and come from ASCO's guideline ${ }^{25}$. For some, fatigue lasts long after treatment and can significantly interfere with QoL. Treatable causes of fatigue include anemia, thyroid dysfunction, and cardiac dysfunction ${ }^{25}$. For those who do not have an identifiable physical cause of fatigue (i.e., anemia), contributing factors, such as mood disorders, sleep disturbance, and pain, should be addressed ${ }^{25}$. Additional information related to distress/depression and pain can be found under Recommendation 4.5.

A regular exercise regimen can reduce fatigue, help survivors feel better physically and emotionally and help them cope as has been demonstrated by several RCTs in breast cancer survivors $^{23,25,112}$ (see also Recommendation 5.3). Cognitive behavioral therapy may also lessen fatigue ${ }^{113,114}$. There are minimal data to support use of pharmacologic agents for management of fatigue in this population ${ }^{25}$. Interventions should be tailored to the needs and abilities of the individual breast cancer survivor. ASCO has more detailed information on the 
management of fatigue for cancer survivors (http://www.instituteforquality.org/screening$\underline{\text { assessment-and-management-fatigue-adult-survivors-cancer-american-society-clinical) }}{ }^{25}$.

\section{Bone Health}

Recommendation 4.7: It is recommended that primary care clinicians (a) Should refer post-menopausal breast cancer survivors for a baseline DEXA scan (LOE=0); (b) Should refer for repeat DEXA scans every 2 years for women taking an aromatase inhibitor, premenopausal women taking tamoxifen and/or a GnRH agonist, and women who have chemo-induced premature menopause $(\mathrm{LOE}=0)$.

Clinical interpretation: The rate and magnitude of bone loss caused by cancer therapy is significantly higher than normal age-related bone loss ${ }^{115,116}$. Up to $80 \%$ of breast cancer patients experience bone loss ${ }^{117,118}$. Osteoporosis risk factors unique to patients following cancer therapy include chemotherapy-induced premature menopause, gonadotropin-releasing hormone $(\mathrm{GnRH})$ suppression of gonadal function, antiestrogen therapies and glucocorticoids $^{119}$. These risk factors are cumulative with other known risk factors, including age, prior fracture history and family history of fracture ${ }^{120,121}$. Lifestyle-related factors, including smoking, excess alcohol, inadequate exercise, low calcium and vitamin D deficiency are common in this population and increase the risk of osteoporosis ${ }^{119}$. The primary care clinician should manage symptoms as he or she would in the general population.

Post-menopausal women treated with aromatase inhibitors are at increased risk of osteoporosis and should have initial and periodic (every 2 years) DEXA scan screening. If major risk factors change, a repeat DEXA scan at one year is reasonable to consider ${ }^{119}$. All postmenopausal women or premenopausal women receiving ovarian suppression therapy with $\mathrm{GnRH}$ agonists are at risk for developing osteoporosis and should be screened according to the US Preventive Services Task Force ${ }^{31}$ and the American Association of Clinical Endocrinologists guide for postmenopausal osteoporosis diagnosis and treatment ${ }^{32}$. 
Initial strategies to reduce the morbidity associated with bone loss include education about risk factors and a healthy lifestyle. These should include physical activity and regular weight-bearing exercise, avoiding tobacco use, limiting alcohol intake, and consider supplementation with calcium (to achieve a total intake of $1200 \mathrm{mg} / \mathrm{d}$ ) and Vitamin $D_{3}(800-1000$ IU/day) for all adults > age 50 years ${ }^{119,122-127}$. In addition to lifestyle and nutritional interventions, pharmacologic options should be considered in patients at high risk for bone loss and/or fracture ${ }^{119}$. Bisphosphonates or denosumab can prevent bone loss and/or treat established osteoporosis $^{119,128-130}$. However, these drugs do have side effects and risks so that the risk vs. benefit of antiresorptive therapy must be carefully considered before starting therapy. Estrogen receptor modulators (raloxifene and tamoxifen) also have antiresorptive properties. However, in one large trial, combining a SERM and aromatase inhibitor blunted the reduction in breast cancer recurrence compared to Al alone. Therefore, SERM's should not be used for the prevention of osteoporosis in women taking an aromatase inhibitor ${ }^{131}$.

\section{Musculoskeletal Health}

Recommendation 4.8: It is recommended that primary care clinicians (a) Should assess for musculoskeletal symptoms, including pain, by asking patients about their symptoms at each clinical encounter (LOE=0); (b) Should offer one or more of the following interventions based on clinical indication: acupuncture, physical activity, referral for physical therapy or rehabilitation (LOE=III).

Clinical interpretation: Breast cancer survivors may report difficulties with the ipsilateral upper extremity following surgery, including decreased range of motion, rotator cuff injury, adhesive capsulitis ("frozen shoulder" with stiffness and pain in the shoulder joint), and axillary web syndrome ("cording" in the skin of the inner arm with sensations of pain and tightness that appear as a web or corded rope $)^{132,133}$. These abnormalities can lead to a decreased ability to perform activities of daily living and can impact employment. Systemic therapies for breast 
cancer have also been associated with the development of musculoskeletal symptoms ${ }^{134}$. The prevalence of musculoskeletal symptoms among breast cancer patients varies greatly: shoulder range of motion (1.5-50\%), musculoskeletal pain (12-51\%), upper limb weakness (18-23\%), and numbness $(29-81 \%)^{132,135-137}$. In particular, up to $50 \%$ of postmenopausal women receiving treatment with aromatase inhibitor medications report arthralgias (joint pain) and myalgias (muscle pain) which are severe enough in $20 \%$ of women to lead to treatment discontinuation ${ }^{138,}$ 139. These aromatase inhibitor associated musculoskeletal symptoms are often not responsive to nonsteroidal anti-inflammatory drugs and acetaminophen. Another option for treatment is to change from one anti-estrogen therapy to another. About $40 \%$ who discontinue the drug may tolerate a different $\mathrm{Al}$ or different formulation of the $\mathrm{Al}$. The rest generally tolerate tamoxifen ${ }^{140}$. Poor compliance adherence to therapy has been shown to result in an increased risk of breast cancer recurrence, so helping patients manage their symptoms and encouraging drug compliance is important ${ }^{141}$.

Physical therapy, including stretching and other exercises, has been shown to be effective for managing post-surgical musculoskeletal symptoms ${ }^{142,143}$. Recent data from the Hormones and Physical Exercise trial, a prospective cohort study, demonstrated that participation in an intensive exercise regimen resulted in a $20 \%$ decrease in aromatase inhibitorassociated pain ${ }^{144}$. To date, only acupuncture ${ }^{107}$ and exercise ${ }^{145}$ have been demonstrated to result in a statistically significant improvement in aromatase inhibitor-associated symptoms ${ }^{145,}$ 146 .

\section{Pain and Neuropathy}

Recommendation 4.9: It is recommended that primary care clinicians (a) Should assess for pain and contributing factors for pain with the use of a simple pain scale and comprehensive history of the patient's complaint (LOE=0). (b) Should offer interventions, such as acetaminophen, nonsteroidal anti-inflammatory drugs, physical activity and/or 
acupuncture, for pain (LOE=I); (c) Should refer to an appropriate specialist depending on the etiology of the pain once the underlying etiology has been determined (e.g., lymphedema specialist, occupational therapist, etc.) (LOE=0); (d) Should assess for peripheral neuropathy and contributing factors for peripheral neuropathy by asking the patient about their symptoms, specifically numbness and tingling in their hands and/or feet, and the characteristics of that symptom (LOE=0); (e) Should offer physical activity for neuropathy (LOE=IA); (f) Should offer duloxetine for patients with neuropathic pain, numbness and tingling (LOE=IB).

Clinical interpretation: A substantial percentage of breast cancer survivors experience long-term treatment-related chronic pain that can negatively impact QoL. Published reports demonstrate that $25-60 \%$ of breast cancer survivors experience chronic pain as a result of the treatments administered, including surgery, radiation therapy, chemotherapy, and endocrine therapy ${ }^{139,147-}$ 150 .

Patients should also be evaluated for secondary causes of pain, such as lymphedema or tightness of the chest wall or axilla, and referred to lymphedema specialists or occupational therapists as indicated. Once the work-up and assessment are complete and underlying causes identified or ruled out, chronic pain following breast cancer surgery is typically treated with standard analgesics, including acetaminophen and nonsteroidal anti-inflammatory drugs.

Acupuncture and physical activity have been shown in meta-analyses of RCTs to improve pain among breast cancer survivors and are typically used to complement traditional cancer care. Treatment-related joint pain among breast cancer survivors is quite commonly treated with acupuncture, with many trials and systematic reviews demonstrating its efficacy in decreasing pain intensity ${ }^{146,151}$. However, evidence is lacking to show that acupuncture directly benefits breast cancer survivors who are experiencing cancer-induced peripheral neuropathy (CIPN). Physical activity has been shown in multiple RCTs to improve pain ${ }^{152}$. 
Neuropathy, including numbness, tingling, and burning pain, is also common following a diagnosis of breast cancer and subsequent treatment. It is particularly common following surgery and after treatment with taxane- or platinum-based chemotherapy regimens, reported in $30-40 \%$ of patients ${ }^{149}$. ASCO recently published a Clinical Practice Guideline about the prevention and management of chemotherapy-induced peripheral neuropathy (CIPN; http://www.instituteforquality.org/prevention-and-management-chemotherapy-inducedperipheral-neuropathy-survivors-adult-cancers) ${ }^{14}$ and we endorse this guideline.

Prevention and treatment approaches for the management of CIPN in adult cancer survivors, reproduced from the ASCO guideline, are available in the online Appendix. In a few small RCTs with breast cancer survivors, physical activity has been shown to improve arthralgias, neuropathy, and neuropathy symptoms ${ }^{145,153}$. A number of pharmaceutical agents have been tested for management of CIPN. The serotonin-norepinephrine reuptake inhibitor (SNRI), duloxetine, was shown in a randomized placebo-controlled trial to decrease neuropathic pain significantly more than placebo, and may also improve numbness and tingling. The trial used an initial dose of $30 \mathrm{mg}$ daily for the first week to reduce the likelihood of nausea, which was then increased to $60 \mathrm{mg}$ daily. Associated relative risk benefit was $30-50 \%$ in pain reduction ${ }^{154}$. Studies of tricyclic antidepressants and anticonvulsants have not demonstrated consistent significant improvements in symptoms. Additional recommendations for the prevention and management of chemotherapy-induced peripheral neuropathy can be found in the recently published ASCO guidelines ${ }^{14}$.

Infertility

Recommendation 4.10: It is recommended that primary care clinicians should refer survivors of childbearing age who experience infertility to a specialist in reproductive endocrinology and infertility as soon as possible (LOE=0). 
Clinical interpretation: Infertility, as a result of cancer treatment, is a potential long-term side effect faced by younger breast cancer survivors (younger than age 45). When it occurs, it can have profound impact on a survivor's physical, psychosocial, and QoL ${ }^{48}$. Breast cancer cases among patients between the ages of 20 and 45 represent $10.9 \%$ of all new breast cancer cases in the United States ${ }^{2}$ making infertility an issue for many younger survivors ${ }^{155}$.

Chemotherapy can be gonadotoxic leading to reduced fertility or early menopause secondary to premature ovarian failure ${ }^{77,155}$. Many of the most frequently used chemotherapy agents in the treatment of breast cancer (e.g., alkylating agents, platinum agents, and taxanes) are also those that most often lead to premature ovarian failure ${ }^{156}$. The incidence of chemotherapy-related amenorrhea increases with age, as the female ovarian reserve is nonrenewable and diminishes steadily with age. However, there is considerable variation in ovarian reserve in women of similar age $\mathrm{e}^{157}$. There is limited literature related to the gonadotoxicity of biologics and targeted therapies and more studies are needed. Primary care clinicians should involve the treating medical oncologist in any potential discussion related to the optimal time for pregnancy after the completion of breast cancer treatment. Pre-menopausal women who desire pregnancy and are having difficulty conceiving for 6 months or more (or have had more than one miscarriage) should be referred to a fertility specialist. Timely referral is crucial due to the rapid loss of ovarian reserve in these women.

\section{Sexual Health}

Recommendation 4.11: It is recommended that primary care clinicians (a) Should assess for signs and symptoms of sexual dysfunction or problems with sexual intimacy (LOE=0); (b) Should assess for reversible contributing factors to sexual dysfunction and treat, when appropriate (LOE=0); (c) Should offer nonhormonal, water-based lubricants and moisturizers for vaginal dryness (LOE=IA); (d) Should refer for psychoeducational 
support, group therapy, sexual counseling, marital counseling or intensive psychotherapy, when appropriate (LOE=IA).

Clinical interpretation: Sexual complaints are a common problem among breast cancer survivors that should be assessed. They can include sexual desire disorder / decreased libido (23-64\%), arousal or lubrication concerns (20-48\%), orgasmic concerns (16-36\%), and dyspareunia (35$38 \%)^{77}$. Patients who were treated with chemotherapy tend to have more of these sexual concerns than those treated only with surgery and/or radiation ${ }^{50}$. Treatment with aromatase inhibitors may cause vaginal dryness, dyspareunia (which can be severe), menopausal symptoms, and loss of sexual desire ${ }^{158}$. Radiation therapy can often cause skin fibrosis, loss of sexual sensitivity of the skin, and uncommonly cardiac and respiratory damage, all of which negatively impact sexual desire and response ${ }^{159}$.

It is important to counsel patients concerning possible sexual dysfunction remedies including treatments for vaginal dryness. Nonhormonal, water-based lubricants and moisturizers remain the primary treatment ${ }^{160}$. Silicone-based products may last longer than water or glycerin-based products. A combination of therapies may provide additional short-term comfort. Hormonal therapies, such as a low dose estrogen vaginal tablet or estradiol vaginal ring, may be recommended for vaginal dryness due to urogenital atrophy, although results commonly take approximately 6-12 weeks ${ }^{160,161}$. The safety of these therapies in women with a history of breast cancer is not well established at this time. The level of estrogen absorption is variable, which raises concerns in patients with a history of breast cancer. Use of hormonal therapies for women on aromatase inhibitors is not recommended ${ }^{162}$. Treating dyspareunia secondary to vaginal atrophy and stenosis with vaginal dilators or pelvic floor relaxation techniques may be helpful ${ }^{77}$.

Referral for interventions, such as brief psychoeducational support, group therapy, sexual counseling, marital counseling or intensive psychotherapy should be offered to all breast cancer survivors with sexual complaints specifically addressing possible anxiety, stress, 
unpleasant symptoms including hot flashes, sexual comfort in lovemaking, and mood changes ${ }^{50}$, 158, 163. Taken together, the trio of counseling, over-the-counter treatments, and pharmacologic treatments can do much to ameliorate the sexual issues caused by breast cancer and its management ${ }^{158}$. See Recommendation 4.1 to address body image concerns.

\section{Premature Menopause/Hot Flashes}

Recommendation 4.12: It is recommended that primary care clinicians should offer selective serotonin-norepinephrine reuptake inhibitors (SNRIs), selective serotonin reuptake inhibitors (SSRIs), gabapentin, lifestyle modifications and/or environmental modifications to help mitigate vasomotor symptoms of premature menopausal symptoms (LOE=IA).

Clinical interpretation: Women can experience menopausal symptoms if chemotherapy results in premature cessation of ovarian function or as a side effect of endocrine therapies. Vasomotor symptoms are typically more severe in younger survivors due to the abrupt change in hormones ${ }^{164}$ and when present, can have significant impact on QoL. For younger women on endocrine therapies, $50-70 \%$ will likely experience hot flashes while on tamoxifen ${ }^{77}$.

Systemic hormone therapy is rarely, if ever, given to patients with breast cancer to control menopausal symptoms. Non-hormonal medications such as serotonin-norepinephrine reuptake inhibitors (SNRIs) and selective serotonin reuptake inhibitors (SSRIs) can decrease the intensity and severity of vasomotor symptoms, although are not FDA approved for this indication. The SNRI, venlafaxine, has been found to be safe and effective at reducing hot flashes $^{165}$. There is concern that SSRIs that inhibit the CYP2D6 enzyme pathway, such as paroxetine, may reduce the conversion of tamoxifen to active metabolites, although a negative impact on breast cancer outcomes has not been conclusively demonstrated ${ }^{166}$. Consistent with recommendations by ASCO and NCCN, patients should not be screened for CYP2D6 ${ }^{\text {9, } 167}$. The anticonvulsant gabapentin has also been shown to be effective in reducing hot flashes ${ }^{168-170}$. 
Similarly, the antihypertensive, clonidine, has been used in clinical practice ${ }^{171}$. Antihypertensive medications, lifestyle and environmental modifications may also help decrease the intensity and severity of menopausal symptoms. Acupuncture has been shown, in a meta-analysis of RCTs with breast cancer survivors, to reduce menopausal symptoms and hot flashes ${ }^{172}$. Lifestyle interventions, including rhythmic breathing, vitamins, exercise, and avoiding spicy foods caffeine, and alcohol, have had variable results. Environmental modifications such as cool rooms and dressing in layers can also be helpful. Complementary therapies have been studied and some have been found to be minimally effective ${ }^{173}$.

\section{HEALTH PROMOTION}

Women with breast cancer are likely to have long-term survival ${ }^{1}$. Thus enhancing length and quality of life is an important goal in the care of patients with breast cancer and in creating a survivorship care plan (see Recommendations 5.1 and 6.1 for more information on Survivorship Care Plans). Healthy behaviors are paramount to reducing the risk of second cancers, comorbidities, obesity, and possibly recurrence; improving prognosis; ameliorating cancerrelated symptoms ${ }^{174-179}$; and decreasing risk of mortality ${ }^{176-186}$.

Table 5 outlines this information, including physical activity, nutrition, and smoking cessation recommendations for breast cancer survivorship, incorporating existing ACS Nutrition and Physical Activity recommendations ${ }^{23}$.

(Table 5: Health Promotion Guidelines)

\section{Information}

Recommendation 5.1: It is recommended that primary care clinicians (a) Should assess the information needs of the patient related to breast cancer and its treatment, side effects, other health concerns, and available support services (LOE=0); (b) Should provide or refer survivors to appropriate resources to meet these needs (LOE=0). 
Clinical interpretation: Breast cancer survivors often express unmet needs for information after treatment, including information on the effects of cancer treatment, emotional distress, and lifestyle changes ${ }^{187,188}$. Younger breast cancer patients can be particularly vulnerable to the physical, emotional, and psychosocial late effects of treatment due to the aggressiveness of their disease, intensity of treatment plan $^{48,189}$, and based on younger age when a cancer diagnosis is not as common or expected ${ }^{190,191}$. Treatment summaries and individualized survivorship care plans provide survivors with individualized information on their cancer care. However, to date, there exists inconsistency in their implementation, comprehensiveness, and perceived helpfulness for both patients and primary care clinicians ${ }^{63,192-194}$.

Results from randomized trials of survivorship care plans are mixed ${ }^{195-198}$ making the direct benefits of survivorship care plans less clear. However, failure of specialists to provide treatment summaries and survivorship care plans to primary care clinicians is an obstacle to primary care clinicians providing relevant information and care to their patients with a history of breast cancer.

The informational needs of breast cancer survivors and caregivers should be routinely assessed and information about the long-term and late effects of breast cancer treatment, as well as information on risk reduction and health promotion, should be provided. Resources that may be beneficial to share with patients include the ACS Survivorship Center website (www.cancer.org/survivorshipcenter ${ }^{62}$, the ACS website ${ }^{199}$, Journey Forward (www.journeyforward.org), the American Society of Clinical Oncology's (ASCO) survivor and caregiver site (www.cancer.net), and the National Comprehensive Cancer Network (NCCN) patient and caregiver resources (http://www.nccn.org/patients/default.aspx).

\section{Obesity}

Recommendation 5.2: It is recommended that primary care clinicians (a) Should counsel survivors to achieve and maintain a healthy weight (LOE=III); (b) Should counsel 
survivors if overweight or obese to limit consumption of high-calorie foods and beverages and increase physical activity to promote and maintain weight loss (LOE=IA, III).

Clinical interpretation: Approximately $62 \%$ of breast cancer survivors are overweight/obese (have a BMI of least $25 \mathrm{~kg} / \mathrm{m}^{2}$ ), of which $30 \%$ are classified as obese $\left(\mathrm{BMI} 30 \mathrm{~kg} / \mathrm{m}^{2}\right.$ or higher) ${ }^{200}$. Sufficient evidence documents obesity as a risk factor for post-operative complications, second cancers, risk of recurrence, development of diabetes, and other issues. Conversely, weight loss mitigates symptoms and improves quality of life ${ }^{201}$. ASCO issued a position statement underscoring the need for oncology providers to counsel their patients about achieving a healthy weight ${ }^{202}$. Primary care clinicians should also counsel cancer survivors to achieve or maintain a healthy weight ${ }^{201}$ and refer to multi-component obesity treatment programs where appropriate 203 $i$

\section{Physical Activity}

Recommendation 5.3: It is recommended that primary care clinicians should counsel survivors to engage in regular physical activity consistent with the ACS guideline ${ }^{23}$ and specifically: (a) Should avoid inactivity and return to normal daily activities as soon as possible following diagnosis (LOE=III); (b) Should aim for at least 150 minutes of moderate or 75 minutes of vigorous aerobic exercise per week (LOE=I, IA); (c) Should include strength training exercises at least 2 days per week. Emphasize strength training for women treated with adjuvant chemotherapy or hormone therapy (LOE= IA).

Clinical interpretation: Approximately $32 \%$ of cancer survivors meet the recommendations for physical activity ${ }^{204}$. Numerous systematic reviews and meta-analyses document the many health benefits from physical activity in breast cancer survivors, including mitigating treatment side-effects (i.e., fatigue) and improving quality of life and physical functioning. The data suggesting a potential survival benefit of physical activity come from observational data with the 
most recent review of this literature citing 16 studies reporting an average relative risk of 0.72 for breast cancer deaths in physically active breast cancer survivors (95\% Cl: .60-.85) and 0.52 for all-cause mortality (95\% Cl: .42-.64) ${ }^{205}$. Breast cancer survivors should be advised to return to normal daily activities as soon as possible following diagnosis and continue to engage in regular physical activity. Breast cancer survivors should strive to exercise at least 150 minutes moderately or 75 minutes vigorously per week and include strength training exercises at least 2 days per week ${ }^{23}$. Additional details regarding the amount of time needed for each strength training session is less clear. However, studies indicate that $37-53 \%$ of breast cancer survivors meet the aerobic guideline $e^{206,207}$ and $23 \%$ meet the strength training guideline ${ }^{208}$. Observational evidence suggests greater amounts of activity may be needed although the evidence is insufficient to make this a recommendation at this time; aerobic exercise of 3 hours or more per week may be needed to improve breast cancer survival ${ }^{186,209}$.

\section{Nutrition}

Recommendation 5.4: It is recommended that primary care clinicians should counsel survivors to achieve a dietary pattern that is high in vegetables, fruits, whole grains, and legumes, low in saturated fats (LOE= IA, III), and limited in alcohol consumption (LOE=0). Clinical interpretation: Only $18-34 \%$ of breast cancer survivors report eating 5 or more fruit and vegetables a day ${ }^{207}$. Eating a diet characterized by high amounts of vegetables, fruits, whole grains, and legumes (vs. a typical Western diet) has been associated with reduced risk (15$43 \%$ ) for all-cause mortality ${ }^{210-212}$. Data from the two large RCTs of diet interventions in breast cancer survivors suggest that dietary change sufficient to result in weight loss may be needed to favorably impact breast cancer recurrence and prognosis ${ }^{213,214}$. Per ACS Nutrition and Physical Activity Guidelines, alcohol consumption should be limited to no more than one drink per day for women, as in the general population ${ }^{215,216}$. Data are inconsistent but suggest that 
breast cancer survivors who consume more than 3 to 4 drinks per week are at increased risk for breast cancer recurrence ${ }^{217}$.

Studies have shown that the carcinogenic ingredients of alcohol increase the risk of developing many types of cancers ${ }^{218-220}$ when alcohol, regardless of the type of (i.e., wine, beer, etc), is consumed in excess of daily recommended limits ${ }^{221}$. Approximately $7 \%$ of breast cancer survivors report excessive drinking ${ }^{206}$. Based on these data, survivors should be counseled to: achieve a dietary pattern that is high in vegetables, fruits, whole grains, and legumes; limit alcohol intake to no more than one drink per day; and follow the ACS Guidelines on Nutrition and Physical Activity for Cancer Survivors ${ }^{23}$ with a focus on successful weight management.

\section{Smoking Cessation}

Recommendation 5.5: It is recommended that primary care clinicians should counsel survivors to avoid smoking and refer survivors who smoke to cessation counseling and resources $($ LOE= I).

Clinical interpretation: Approximately $10-12 \%$ of breast cancer survivors smoke ${ }^{206,207 .}$ Numerous observational studies show that women who smoke at the time of diagnosis have substantially worse breast cancer-specific and overall survival than former and never smokers $^{222}$. A recent meta-analysis of this observational work documents a $33 \%$ increased risk of mortality from breast cancer in women who are smokers at diagnosis compared to former smokers ${ }^{222}$. Survivors should discontinue smoking and avoid subsequent tobacco product use. Clinicians should identify smokers and motivate and encourage patients to quit through cessation programs, brochures and pamphlets, counseling, pharmacotherapy and regular follow-up ${ }^{223}$. These programs should be initiated at the time of initial diagnosis if possible.

\section{CARE COORDINATION / PRACTICE IMPLICATIONS}

(Table 6: Care Coordination Guideline) 
There are no clear guidelines for the shared care and co-management of patients with breast cancer after the completion of active treatment. The time to transition is variable and dependent on medical, geographic, and resource restraints. Some patients return to their primary care clinician immediately after treatment is completed ${ }^{224-226}$. Others may choose to transition to their follow-up care only after they are considered at little or low risk for disease recurrence or late effects of cancer treatment ${ }^{227,228}$. Several RCTs show that care led by primary care clinicians is as effective as hospital- or specialist-led care, including similar rates of recurrence-related serious clinical events, levels of health-related QoL ${ }^{229}$, and patient satisfaction with care ${ }^{230}$.

Breast cancer survivors may continue to see their oncology team for follow-up disease surveillance; however, they should also be seen by their primary care clinician for health maintenance and management of co-morbidities that may or may not be related to their cancer diagnosis and treatment ${ }^{225,231 .}$.

\section{Survivorship Care Plan}

Recommendation 6.1: It is recommended that primary care clinicians should consult with the cancer treatment team and obtain a treatment summary and Survivorship Care Plan (LOE=0, III).

Clinical interpretation: Survivorship care plans are recommended as an important tool to facilitate communication and allocation of responsibility during the transition from active treatment to survivorship care ${ }^{4,232}$. A summary of a patient's diagnosis and treatment received should be provided by the oncology care team when a patient with breast cancer transitions care to other providers; a treatment summary should describe the type and stage/side of the cancer, type of surgery, the name of the chemotherapy/hormones/biologics and cumulative doses of chemotherapy and the types and cumulative doses of radiation therapy, including the 
fields and extent of the radiation ${ }^{4,192}$. Patients can initiate the building of a survivorship care plan process on ASCO's website: http://www.cancer.net/survivorship/follow-care-after-cancertreatment/asco-cancer-treatment-and-survivorship-care-plans, at http://www.journeyforward.org/ or at http://www.livestrongcareplan.org/.

Ideally, the oncology team should also work with the patient to develop an individualized cancer survivorship care plan for breast cancer survivors. This care plan guides

recommendations for the type and timing of follow up imaging, laboratory tests, and office visits. The care plan should include information on the risk for late effects of treatment and what to watch for specifically based on the type of cancer and treatment received. Survivors should be assessed for the presence of these physical (e.g., cardiovascular issues, musculoskeletal issues), as well as psychosocial effects (e.g., cognitive dysfunction, depression, fear of recurrence, body image and sexual dysfunction) and be referred to the appropriate providers and services.

The field of oncology is, however, broadly struggling with how to best meet this recommendation, and in identifying the specific benefits of such care plans. Various tools and strategies to facilitate the creation and distribution of these care plans are being actively considered, for all tumor sites, including breast cancer. Challenges in workflow and tools make this difficult currently but the field is working toward a sustainable solution.

\section{Communication with Oncology Team}

Recommendation 6.2: It is recommended that primary care clinicians should maintain communication with the oncology team throughout your patient's diagnosis, treatment and post-treatment care to ensure care is evidence-based and well-coordinated (LOE=0). Clinical interpretation: Communication and cooperation among providers and survivors is critical, with the oncology team providing concrete recommendations for care when needed or 
requested by other providers ${ }^{232}$. Clear communication regarding the respective roles of different members of the health-care team is critical to a successful transition to survivorship care.

The primary care clinician should serve as a general medical care coordinator throughout the spectrum of breast cancer detection and aftercare, focusing on evidence-based preventive care and the management of preexisting comorbid conditions, regularly addressing the patient's overall physical and psychosocial status, making appropriate referrals for psychosocial, rehabilitative, or other specialist care as needed, and coordinating those components of survivorship care that are agreed upon with the treating clinicians. Treatment of breast cancer is complex and rapidly changing; therefore, decisions about and coordination of cancer treatment should be left to the oncology team.

\section{Inclusion of Family}

Recommendation 6.3: It is recommended that primary care clinicians should encourage the inclusion of caregivers, spouses, or partners in usual breast cancer survivorship care and support (LOE=0).

Clinical interpretation: Caregivers have to cope with the physical aftermath of the survivors' treatment and manage their long-term and late effects, in addition to their own psychosocial and physical unmet needs ${ }^{233}$. Research has shown that for 14-24 months after a survivor's cancer diagnosis, caregivers provide consistent, continuing care involvement ${ }^{234}$ for patients following breast cancer treatment. Successful coordination of care involves not only a comprehensive care team, including primary care clinicians, but also the informal caregivers (usually the spouse/partner/family member) who provide ongoing care to cancer survivors in the home ${ }^{235}$. Furthermore most caregivers are older adults who are also managing their own health problems. When possible, primary care clinicians should include caregivers of breast cancer survivors in all follow-up care appointments to optimize survivor wellness. 


\section{DISCUSSION}

A significant limitation of this guideline is the limited evidence-base to provide clear and specific recommendations for the prevention and management of long-term and late effects of cancer survivors. There are few prospective, randomized controlled trials testing interventions among breast cancer survivors even though studies in breast cancer survivors dominate the survivorship literature. The majority of the citations characterizing the risk and magnitude of risk of late effects and management recommendations rely predominantly on case-control studies with fewer than 500 participants and reviews that combine studies with varying outcome measures. There were several cohort studies that used population-based data to estimate the risk of late effects.

Another limitation is the reliance on previous guidelines for surveillance and symptom management. Additionally, the literature review was not managed by a clinical epidemiologist due to limited resources; and instead was conducted by project staff and an ACS librarian. Furthermore, the guidelines did not result directly from the development of specific clinical questions asked prior to the literature review; and guidelines included in the literature review were not evaluated through an instrument such as the Rigor of Development subscale of the Appraisal for Guidelines for Research and Evaluation (AGREE II). Recommendations are based on current evidence in the literature, but most evidence is not sufficient to warrant a strong recommendation. Rather, recommendations should be largely seen as possible management strategies given the current limited evidence base.

\section{HEALTH DISPARITIES}

Although the ACS/ASCO clinical practice guidelines represent expert recommendations on the best practices in disease management to provide the highest level of cancer care, it is important to note that many patients have limited access to medical care. Racial and ethnic disparities in health care contribute significantly to this problem in the United States. Patients with cancer who are members of racial/ethnic minorities suffer disproportionately from 
comorbidities, experience more substantial obstacles to receiving care, are more likely to be uninsured, and are at greater risk of receiving care of poor quality than other Americans ${ }^{236-239}$. Many other patients lack access to care because of their geographic location and distance from appropriate treatment facilities. Awareness of these disparities in access to care should be considered in the context of this clinical practice guideline, and health care providers should strive to deliver the highest level of cancer care to these vulnerable populations.

\section{ACS and ASCO believe that cancer clinical trials are vital to inform medical decisions and improve cancer care, and that all patients should have the opportunity to participate.}

\section{MULTIPLE CHRONIC CONDITIONS}

Creating evidence-based recommendations to inform treatment of patients with additional chronic conditions, a situation in which the patient may have two or more such conditions - referred to as multiple chronic conditions (MCC)—is challenging ${ }^{240}$. Patients with MCC are a complex and heterogeneous population, making it difficult to account for all of the possible permutations to develop specific recommendations for care. In addition, the best available evidence for treating index conditions, such as cancer, is often from clinical trials whose study selection criteria may exclude these patients in order to avoid potential interaction effects or confounding of results associated with MCC. As a result, the reliability of outcome data from these studies may be limited, thereby creating constraints for expert groups to make recommendations for care in this heterogeneous patient population.

As many patients for whom guideline recommendations apply present with MCC, any treatment plan needs to take into account the complexity and uncertainty created by the presence of MCC and highlights the importance of shared decision making regarding guideline use and implementation. Therefore, in consideration of recommended care for the target index 
condition, clinicians should review all other chronic conditions present in the patient and take those conditions into account when formulating the treatment and follow-up plan.

In light of the above considerations, practice guidelines should provide information on how to apply the recommendations for patients with MCC, perhaps as a qualifying statement for recommended care. This may mean that some or all of the recommended care options are modified or not applied, as determined by best practice in consideration of any MCC.

\section{EXTERNAL REVIEW}

After finalization by the workgroup, the guideline manuscript was sent to additional internal (ACS and ASCO) and external experts for review and comment prior to submission for publication. Review comments were reviewed by the Expert Panel and integrated into the final manuscript before approval by the CPGC.

\section{GUIDELINE IMPLEMENTATION}

ACS/ASCO guidelines are developed for implementation across health settings. Barriers to implementation include the need to increase awareness of the guideline recommendations among front-line practitioners and survivors of cancer and caregivers, and also to provide adequate services in the face of limited resources. The guideline Bottom Line Box was designed to facilitate implementation of recommendations. This guideline will be distributed widely through the ASCO Practice Guideline Implementation Network. ACS/ASCO guidelines are posted on the ACS Website and ASCO Website. This joint ACS-ASCO guideline is also published in the Journal of Clinical Oncology.

\section{SUMMARY}

Breast cancer survivors face potentially significant impacts of cancer and its treatment and deserve high-quality, comprehensive, coordinated clinical follow-up care. Primary care 
clinicians must consider each patient's individual risk profile and preferences of care to address physical and psychosocial impacts. Survivors should be provided support to address fear of recurrence, depression, anxiety, cognitive impairment, body image issues, sexual concerns, functional changes and physical impairments, relationship changes, other social role difficulties, employment concerns, and financial challenges, among others. Breast cancer survivors also need to be counseled on health promotion strategies to minimize and mitigate long-term and late effects, ameliorate comorbid health conditions and to potentially increase survival.

To clarify the roles of all clinicians working with cancer survivors, we concur with the IOM that survivors and primary care clinicians receive a survivorship care plan, which includes a concise summary of treatment as well as a clinical follow-up care plan. Ideally, this plan would be constructed in partnership with the survivor to identify and prioritize goals for survivorship care and would be communicated to the patient to ensure understanding of individual risks; recommended tests, procedures and supportive care strategies; and how to optimize wellness. Survivorship care should be coordinated with treating cancer specialists.

\section{ADDITIONAL RESOURCES}

In addition to this guideline, tools and resources are available to assist primary care clinicians in implementing these recommendations. The CA Journal offers the CA Patient Page (publisher insert URL) to help patients understand how to use this guideline to talk to their doctor about surveillance and screening, symptom management, healthy behaviors and care coordination. The Survivorship Center also offers The GW Cancer Institute's Cancer Survivorship E-Learning Series for Primary Care Providers (The E-Learning Series), a free, innovative online continuing education program to educate primary care clinicians about how to better understand and care for survivors in the primary care setting. Continuing education credits are available at no cost to physicians, nurse practitioners, nurses and physician assistants for each 1-hour module. Learn more about The E-learning Series at 
www.cancersurvivorshipcentereducation.org. Visit www.asco.org/guidelineswiki to provide comments on the guideline or to submit new evidence.

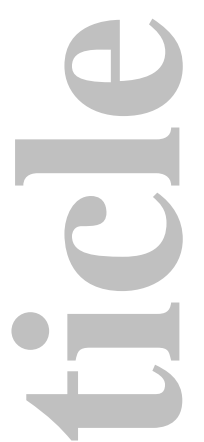

1. DeSantis CE, Lin CC, Mariotto AB, et al. Cancer treatment and survivorship statistics, 2014. CA Cancer J Clin. 2014;64: 252-271.

2. Howlader N NA, Krapcho M, et al. . SEER Cancer Statistics Review, 1975-2012.

3. Ganz PA. Survivorship: adult cancer survivors. Prim Care. 2009;36: 721-741.

4. IOM. From cancer patient to cancer survivor: lost in transition. Washington DC: The National Academies Press, 2005.

5. IOM. Cancer Care for the Whole Patient: Meeting Psychosocial Health Needs. Washington (DC): National Academies Press (US), 2008.

6. Earle CC, Ganz PA. Cancer survivorship care: don't let the perfect be the enemy of the good. J Clin Oncol. 2012;30: 3764-3768.

7. Ganz PA, Earle CC, Goodwin PJ. Journal of Clinical Oncology update on progress in cancer survivorship care and research. J Clin Oncol. 2012;30: 3655-3656.

8. Cowens-Alvarado R, Sharpe K, Pratt-Chapman M, et al. Advancing survivorship care through the National Cancer Survivorship Resource Center: developing American Cancer Society guidelines for primary care providers. CA Cancer J Clin. 2013;63: 147150.

9. NCCN. NCCN Clinical Practice Guidelines in Oncology, Breast Cancer, Version 2.2015: National Comprehensive Cancer Network, 2015.

10. NCCN. NCCN Clinical Practice Guidelines in Oncology: Survivorship Version 1.2015. Available from URL:

http://www.nccn.org/professionals/physician gls/pdf/survivorship.pdf [accessed May 15, 2015.

11. Khatcheressian JL, Hurley P, Bantug E, et al. Breast cancer follow-up and management after primary treatment: American Society of Clinical Oncology clinical practice guideline update. J Clin Oncol. 2013;31: 961-965.

12. ASCO. American Society of Clinical Oncology: Cancer Survivorship. Available from URL: http://www.asco.org/practice-research/cancer-survivorship [accessed May 15, 2015.

13. Bower JE. Cancer-related fatigue--mechanisms, risk factors, and treatments. Nat Rev Clin Oncol. 2014;11: 597-609.

14. Hershman DL, Lacchetti C, Dworkin RH, et al. Prevention and management of chemotherapy-induced peripheral neuropathy in survivors of adult cancers: American Society of Clinical Oncology clinical practice guideline. J Clin Oncol. 2014;32: 19411967. 
15. Andersen BL, DeRubeis RJ, Berman BS, et al. Screening, assessment, and care of anxiety and depressive symptoms in adults with cancer: an American Society of Clinical Oncology guideline adaptation. J Clin Oncol. 2014;32: 1605-1619.

16. Skolarus TA, Wolf AM, Erb NL, et al. American Cancer Society prostate cancer survivorship care guidelines. CA Cancer J Clin. 2014;64: 225-249.

17. Siegel RL, Miller KD, Jemal A. Cancer statistics, 2015. CA Cancer J Clin. 2015;65: 5-29.

18. Jatoi I. Options in breast cancer local therapy: who gets what? World J Surg. 2012;36: 1498-1502.

19. Jatoi I, Proschan MA. Randomized trials of breast-conserving therapy versus mastectomy for primary breast cancer: a pooled analysis of updated results. Am J Clin Oncol. 2005;28: 289-294.

20. Kerrigan $D$, Waters $P$, Ryan $M$, et al. Follow-up arrangements for breast cancer patients; is it appropriate to transfer surveillance to general practitioners? Ir Med J. 2014; 107: 273-275.

21. Saslow D, Boetes C, Burke W, et al. American Cancer Society guidelines for breast screening with MRI as an adjunct to mammography. CA Cancer J Clin. 2007;57: 75-89. 22. Moyer VA. Risk Assessment, Genetic Counseling, and Genetic Testing for BRCARelated Cancer in Women: U.S. Preventive Services Task Force Recommendation Statement. Ann Intern Med. 2014;160: 271-281.

23. Rock CL, Doyle C, Demark-Wahnefried W, et al. Nutrition and physical activity guidelines for cancer survivors. CA Cancer J Clin. 2012;62: 242-274.

24. Brawley O, Byers T, Chen A, et al. New American Cancer Society process for creating trustworthy cancer screening guidelines. Jama. 2011;306: 2495-2499.

25. Bower JE, Bak K, Berger A, et al. Screening, assessment, and management of fatigue in adult survivors of cancer: an American Society of Clinical oncology clinical practice guideline adaptation. J Clin Oncol. 2014;32: 1840-1850.

26. NCCN. NCCN Clinical Practice Guidelines in Oncology, Survivorship Version 1.2014: National Comprehensive Cancer Network, 2014.

27. NCCN. NCCN Clinical Practice Guidelines in Oncology: Distress Management Version 1.2015: National Comprehensive Cancer Network, 2015.

28. Loren AW, Mangu PB, Beck LN, et al. Fertility preservation for patients with cancer: American Society of Clinical Oncology clinical practice guideline update. J Clin Oncol. 2013;31: 2500-2510.

29. Survivorship- Invasive Breast Cancer. Available from URL:

http://www.mdanderson.org/education-and-research/resources-forprofessionals/clinical-tools-and-resources/practice-algorithms/survivorship-breastinvasive-web-algorithm.pdf [accessed 04/07/2014.

30. Helfand M, Carson S. U.S. Preventive Services Task Force Evidence Syntheses, formerly Systematic Evidence Reviews. Screening for Lipid Disorders in Adults:

Selective Update of 2001 US Preventive Services Task Force Review. Rockville (MD): Agency for Healthcare Research and Quality (US), 2008.

31. Screening for osteoporosis: U.S. preventive services task force recommendation statement. Ann Intern Med. 2011;154: 356-364. 
32. Watts NB, Bilezikian JP, Camacho PM, et al. American Association of Clinical Endocrinologists Medical Guidelines for Clinical Practice for the diagnosis and treatment of postmenopausal osteoporosis. Endocr Pract. 2010;16 Suppl 3: 1-37.

33. Chalasani P, Downey L, Stopeck AT. Caring for the breast cancer survivor: a guide for primary care physicians. Am J Med. 2010;123: 489-495.

34. Harris SR, Schmitz KH, Campbell KL, McNeely ML. Clinical practice guidelines for breast cancer rehabilitation: syntheses of guideline recommendations and qualitative appraisals. Cancer. 2012;118: 2312-2324.

35. Stout NL, Binkley JM, Schmitz KH, et al. A prospective surveillance model for rehabilitation for women with breast cancer. Cancer. 2012;118: 2191-2200.

36. van Londen G, Beckjord E, Dew M, Cuijpers P, Tadic S, Brufsky A. Breast cancer survivorship symptom management: current perspective and future development. Breast Cancer Manag. 2013;2: 71-81.

37. Ganz PA, Yip CH, Gralow JR, et al. Supportive care after curative treatment for breast cancer (survivorship care): resource allocations in low- and middle-income countries. A Breast Health Global Initiative 2013 consensus statement. Breast. 2013;22: 606-615.

38. CDC. Vaccines: VPD-VAC/Who Should NOT Get Vaccinated? Available from URL: http://www.cdc.gov/vaccines/vpd-vac/should-not-vacc.htm [accessed 8/17/2015.

39. Rojas MP, Telaro E, Russo A, et al. Follow-up strategies for women treated for early breast cancer. Cochrane Database Syst Rev. 2005: Cd001768.

40. Salani R, Andersen BL. Gynecologic care for breast cancer survivors: assisting in the transition to wellness. American journal of obstetrics and gynecology. 2012;206: 390-397.

41. Del Turco M, Palli D, Cariddi A, Ciatto S, Pacini P, Distante V. Intensive diagnostic follow-up after treatment of primary breast cancer: A randomized trial. JAMA. 1994;271: 1593-1597.

42. Impact of follow-up testing on survival and health-related quality of life in breast cancer patients. A multicenter randomized controlled trial. The GIVIO Investigators. JAMA. 1994;271: 1587-1592.

43. Henry LN, Hayes DF, Ramsey SD, Hortobagyi GN, Barlow WE, Gralow JR. Promoting Quality and Evidence-Based Care in Early-Stage Breast Cancer Follow-up. J Natl Cancer Inst. 2014.

44. Ruddy K, Mayer E, Partridge A. Patient adherence and persistence with oral anticancer treatment. CA Cancer J Clin. 2009;59: 56-66.

45. Smith RA, Manassaram-Baptiste D, Brooks D, et al. Cancer screening in the United States, 2015: a review of current American cancer society guidelines and current issues in cancer screening. CA Cancer J Clin. 2015;65: 30-54.

46. Runowicz CD. Gynecologic surveillance of women on tamoxifen: first do no harm. J Clin Oncol. 2000;18: 3457-3458.

47. Falk Dahl CA, Reinertsen KV, Nesvold IL, Fossa SD, Dahl AA. A study of body image in long-term breast cancer survivors. Cancer. 2010;116: 3549-3557.

48. Partridge $\mathrm{AH}$. Cancer survivorship and the young breast cancer patient: addressing the important issues. Oncologist. 2013;18: e19-20.

49. Avis NE, Crawford S, Manuel J. Quality of life among younger women with breast cancer. J Clin Oncol. 2005;23: 3322-3330. 
50. Fobair P, Spiegel D. Concerns about sexuality after breast cancer. Cancer J. 2009;15: 19-26.

51. Rosenberg SM, Tamimi RM, Gelber S, et al. Body image in recently diagnosed young women with early breast cancer. Psychooncology. 2013;22: 1849-1855.

52. Delanian S, Porcher R, Balla-Mekias S, Lefaix JL. Randomized, placebo-controlled trial of combined pentoxifylline and tocopherol for regression of superficial radiationinduced fibrosis. J Clin Oncol. 2003;21: 2545-2550.

53. Haddad P, Kalaghchi B, Amouzegar-Hashemi F. Pentoxifylline and vitamin E combination for superficial radiation-induced fibrosis: a phase II clinical trial. Radiother Oncol. 2005;77: 324-326.

54. Magnusson $M$, Hoglund $P$, Johansson $K$, et al. Pentoxifylline and vitamin $E$ treatment for prevention of radiation-induced side-effects in women with breast cancer: a phase two, double-blind, placebo-controlled randomised clinical trial (Ptx-5). Eur J Cancer. 2009;45: 2488-2495.

55. Okunieff $P$, Augustine E, Hicks JE, et al. Pentoxifylline in the treatment of radiationinduced fibrosis. J Clin Oncol. 2004;22: 2207-2213.

56. Scott JL, Kayser K. A review of couple-based interventions for enhancing women's sexual adjustment and body image after cancer. Cancer J. 2009;15: 48-56.

57. Armer JM. The problem of post-breast cancer lymphedema: impact and measurement issues. Cancer Invest. 2005;23: 76-83.

58. Armer JM, Stewart BR. Post-breast cancer lymphedema: incidence increases from 12 to 30 to 60 months. Lymphology. 2010;43: 118-127.

59. Radina ME, Armer JM, Stewart BR. Making self-care a priority for women at risk of breast cancer-related lymphedema. J Fam Nurs. 2014;20: 226-249.

60 . Krag DN, Anderson SJ, Julian TB, et al. Sentinel-lymph-node resection compared with conventional axillary-lymph-node dissection in clinically node-negative patients with breast cancer: overall survival findings from the NSABP B-32 randomised phase 3 trial. Lancet Oncol. 2010;11: 927-933.

61. Warren LEG, Miller CL, Horick N, et al. The Impact of Radiation Therapy on the Risk of Lymphedema After Treatment for Breast Cancer: A Prospective Cohort Study. International Journal of Radiation Oncology*Biology*Physics. 2014;88: 565-571. 62. Fu MR, Rosedale M. Breast cancer survivors' experiences of lymphedema-related symptoms. J Pain Symptom Manage. 2009;38: 849-859.

63. Forsythe LP, Parry C, Alfano CM, et al. Use of survivorship care plans in the United States: associations with survivorship care. J Natl Cancer Inst. 2013;105: 1579-1587. 64. Shaitelman SF, Cromwell KD, Rasmussen JC, et al. Recent progress in the treatment and prevention of cancer-related lymphedema. CA Cancer J Clin. 2015;65: $55-81$.

65. Ostby PL, Armer JM, Dale PS, Van Loo MJ, Wilbanks CL, Stewart BR. Surveillance recommendations in reducing risk of and optimally managing breast cancer-related lymphedema. J Pers Med. 2014;4: 424-447.

66. Coriddi M, Khansa I, Stephens J, Miller M, Boehmler J, Tiwari P. Analysis of factors contributing to severity of breast cancer-related lymphedema. Ann Plast Surg. 2015;74: 22-25.

67. Schmitz KH, Ahmed RL, Troxel AB, et al. Weight lifting for women at risk for breast cancer-related lymphedema: a randomized trial. JAMA. 2010;304: 2699-2705. 
68. Cemal Y, Pusic A, Mehrara BJ. Preventative measures for lymphedema: separating fact from fiction. J Am Coll Surg. 2011;213: 543-551.

69. Ahmed RL, Thomas W, Yee D, Schmitz KH. Randomized controlled trial of weight training and lymphedema in breast cancer survivors. J Clin Oncol. 2006;24: 2765-2772. 70. Dominick SA, Natarajan L, Pierce JP, Madanat H, Madlensky L. Patient compliance with a health care provider referral for an occupational therapy lymphedema consult. Support Care Cancer. 2014;22: 1781-1787.

71. Darby SC, Ewertz M, McGale $P$, et al. Risk of ischemic heart disease in women after radiotherapy for breast cancer. N Engl J Med. 2013;368: 987-998.

72. Barton M. Cholesterol and atherosclerosis: modulation by oestrogen. Curr Opin Lipidol. 2013;24: 214-220.

73. Chalasani P, Livingston R. Differential Chemotherapeutic Sensitivity for Breast Tumors With "BRCAness": A Review. The Oncologist. 2013;18: 909-916.

74. Curigliano G, Cardinale D, Suter $T$, et al. Cardiovascular toxicity induced by chemotherapy, targeted agents and radiotherapy: ESMO Clinical Practice Guidelines. Annals of Oncology. 2012;23: vii155-vii166.

75. Bell LN, Nguyen AT, Li L, et al. Comparison of changes in the lipid profile of postmenopausal women with early stage breast cancer treated with exemestane or letrozole. J Clin Pharmacol. 2012;52: 1852-1860.

76. Mouridsen H, Giobbie-Hurder A, Goldhirsch A, et al. Letrozole therapy alone or in sequence with tamoxifen in women with breast cancer. N Engl J Med. 2009;361: 766776.

77. Stan D, Loprinzi CL, Ruddy KJ. Breast cancer survivorship issues. Hematol Oncol Clin North Am. 2013;27: 805-827, ix.

78. Von Ah D, Habermann B, Carpenter JS, Schneider BL. Impact of perceived cognitive impairment in breast cancer survivors. Eur J Oncol Nurs. 2013;17: 236-241.

79. Janelsins MC, Kohli S, Mohile SG, Usuki K, Ahles TA, Morrow GR. AN UPDATE ON CANCER-AND CHEMOTHERAPY-RELATED COGNITIVE DYSFUNCTION: CURRENT STATUS. Seminars in oncology. 2011;38: 431-438.

80. Reid-Arndt SA, Yee A, Perry MC, Hsieh C. Cognitive and psychological factors associated with early posttreatment functional outcomes in breast cancer survivors. $J$ Psychosoc Oncol. 2009;27: 415-434.

81. Reuter-Lorenz P, Cimprich B. Cognitive function and breast cancer: promise and potential insights from functional brain imaging. Breast Cancer Research and Treatment. 2013;137: 33-43.

82. Bruno J, Hosseini SM, Kesler S. Altered resting state functional brain network topology in chemotherapy-treated breast cancer survivors. Neurobiol Dis. 2012;48: 329338.

83. Dumas JA, Makarewicz J, Schaubhut GJ, et al. Chemotherapy altered brain functional connectivity in women with breast cancer: a pilot study. Brain Imaging Behav. 2013;7: 524-532.

84. Falleti MG, Sanfilippo A, Maruff P, Weih L, Phillips KA. The nature and severity of cognitive impairment associated with adjuvant chemotherapy in women with breast cancer: a meta-analysis of the current literature. Brain Cogn. 2005;59: 60-70. 
85. Hurria A, Lachs $M$. Is cognitive dysfunction a complication of adjuvant chemotherapy in the older patient with breast cancer? Breast Cancer Research and Treatment. 2007;103: 259-268.

86. Ganz PA, Petersen L, Castellon SA, et al. Cognitive function after the initiation of adjuvant endocrine therapy in early-stage breast cancer: an observational cohort study. J Clin Oncol. 2014;32: 3559-3567.

87. Ahles TA, Saykin AJ, McDonald BC, et al. Longitudinal Assessment of Cognitive Changes Associated With Adjuvant Treatment for Breast Cancer: Impact of Age and Cognitive Reserve. Journal of Clinical Oncology. 2010;28: 4434-4440.

88. Ahles TA, Saykin AJ. Breast cancer chemotherapy-related cognitive dysfunction. Clin Breast Cancer. 2002;3 Suppl 3: S84-90.

89. Small BJ, Rawson KS, Walsh E, et al. Catechol-O-methyltransferase genotype modulates cancer treatment-related cognitive deficits in breast cancer survivors. Cancer. 2011;117: 1369-1376.

90. Kohli S, Fisher SG, Tra Y, et al. The effect of modafinil on cognitive function in breast cancer survivors. Cancer. 2009;115: 2605-2616.

91. Von Ah D, Jansen C, Allen DH, Schiavone RM, Wulff J. Putting evidence into practice: evidence-based interventions for cancer and cancer treatment-related cognitive impairment. Clin J Oncol Nurs. 2011;15: 607-615.

92. Von Ah D, Carpenter JS, Saykin A, et al. Advanced cognitive training for breast cancer survivors: a randomized controlled trial. Breast Cancer Res Treat. 2012;135: 799-809.

93. Ercoli LM, Petersen L, Hunter AM, et al. Cognitive rehabilitation group intervention for breast cancer survivors: results of a randomized clinical trial. Psychooncology. 2015. 94. Siegel R, Desantis C, Jemal A. Colorectal cancer statistics, 2014. CA Cancer J Clin. 2014;64: 104-117.

95. Simard S, Thewes B, Humphris G, et al. Fear of cancer recurrence in adult cancer survivors: a systematic review of quantitative studies. J Cancer Surviv. 2013;7: 300-322. 96. Boyes AW, Girgis A, Zucca AC, Lecathelinais C. Anxiety and depression among long-term survivors of cancer in Australia: results of a population-based survey.

Comment. Med J Aust. 2009;191: 295.

97. Hoffman KE, McCarthy EP, Recklitis CJ, Ng AK. Psychological distress in long-term survivors of adult-onset cancer: results from a national survey. Arch Intern Med. 2009;169: 1274-1281.

98. McGinty HL, Goldenberg JL, Jacobsen PB. Relationship of threat appraisal with coping appraisal to fear of cancer recurrence in breast cancer survivors.

Psychooncology. 2012;21: 203-210.

99. Mitchell AJ, Ferguson DW, Gill J, Paul J, Symonds P. Depression and anxiety in long-term cancer survivors compared with spouses and healthy controls: a systematic review and meta-analysis. Lancet Oncol. 2013;14: 721-732.

100. Zainal NZ, Nik-Jaafar NR, Baharudin A, Sabki ZA, Ng CG. Prevalence of depression in breast cancer survivors: a systematic review of observational studies. Asian Pac J Cancer Prev. 2013;14: 2649-2656.

101. Patel D, Sharpe L, Thewes B, Bell ML, Clarke S. Using the Distress Thermometer and Hospital Anxiety and Depression Scale to screen for psychosocial morbidity in patients diagnosed with colorectal cancer. J Affect Disord. 2011;131: 412-416. 
102. Kroenke K, Spitzer RL, Williams JB. The PHQ-9: validity of a brief depression severity measure. J Gen Intern Med. 2001;16: 606-613.

103. Spitzer RL, Kroenke K, Williams JB, Lowe B. A brief measure for assessing generalized anxiety disorder: the GAD-7. Arch Intern Med. 2006;166: 1092-1097. 104. Ewertz M, Jensen AB. Late effects of breast cancer treatment and potentials for rehabilitation. Acta Oncol. 2011;50: 187-193.

105. Ha EH, Cho YK. The Mediating Effects of Self-Esteem and Optimism on the Relationship between Quality of Life and Depressive Symptoms of Breast Cancer Patients. Psychiatry Investigation. 2014;11: 437-445.

106. Rosen RC, Lane RM, Menza M. Effects of SSRIs on sexual function: a critical review. J Clin Psychopharmacol. 1999;19: 67-85.

107. Speer JJ, Hillenberg B, Sugrue DP, et al. Study of sexual functioning determinants in breast cancer survivors. Breast J. 2005;11: 440-447.

108. Casellas-Grau A, Font A, Vives J. Positive psychology interventions in breast cancer. A systematic review. Psychooncology. 2014;23: 9-19.

109. Bower JE. Behavioral symptoms in patients with breast cancer and survivors. J Clin Oncol. 2008;26: 768-777.

110. Jacobsen PB, Hann DM, Azzarello LM, Horton J, Balducci L, Lyman GH. Fatigue in women receiving adjuvant chemotherapy for breast cancer: characteristics, course, and correlates. J Pain Symptom Manage. 1999;18: 233-242.

111. Gaston-Johansson F, Fall-Dickson JM, Bakos AB, Kennedy MJ. Fatigue, pain, and depression in pre-autotransplant breast cancer patients. Cancer Pract. 1999;7: 240-247. 112. Meneses-Echavez JF, Gonzalez-Jimenez E, Ramirez-Velez R. Effects of supervised exercise on cancer-related fatigue in breast cancer survivors: a systematic review and meta-analysis. BMC Cancer. 2015;15: 77.

113. Gielissen MF, Verhagen CA, Bleijenberg G. Cognitive behaviour therapy for fatigued cancer survivors: long-term follow-up. Br J Cancer. 2007;97: 612-618.

114. Duijts SF, Faber MM, Oldenburg HS, van Beurden M, Aaronson NK. Effectiveness of behavioral techniques and physical exercise on psychosocial functioning and healthrelated quality of life in breast cancer patients and survivors--a meta-analysis.

Psychooncology. 2011;20: 115-126.

115. Kanis JA, McCloskey EV, Powles T, Paterson AH, Ashley S, Spector T. A high incidence of vertebral fracture in women with breast cancer. Br J Cancer. 1999;79: 1179-1181.

116. Chen Z, Maricic M, Bassford TL, et al. Fracture risk among breast cancer survivors: results from the Women's Health Initiative Observational Study. Arch Intern Med. 2005;165: 552-558.

117. Chen Z, Maricic M, Pettinger $M$, et al. Osteoporosis and rate of bone loss among postmenopausal survivors of breast cancer. Cancer. 2005;104: 1520-1530.

118. Lindsey AM, Gross G, Twiss J, Waltman N, Ott C, Moore TE. Postmenopausal survivors of breast cancer at risk for osteoporosis: nutritional intake and body size. Cancer Nurs. 2002;25: 50-56.

119. Gralow JR, Biermann JS, Farooki A, et al. NCCN Task Force Report: Bone Health In Cancer Care. J Natl Compr Canc Netw. 2013;11 Suppl 3: S1-50; quiz S51. 120. Johnell O, Kanis JA, Oden A, et al. Predictive value of BMD for hip and other fractures. J Bone Miner Res. 2005;20: 1185-1194. 
121. Kanis JA, Borgstrom F, De Laet C, et al. Assessment of fracture risk. Osteoporos Int. 2005;16: 581-589.

122. Feskanich D, Willett W, Colditz G. Walking and leisure-time activity and risk of hip fracture in postmenopausal women. JAMA. 2002;288: 2300-2306.

123. Moyer VA. Prevention of falls in community-dwelling older adults: U.S. Preventive Services Task Force recommendation statement. Ann Intern Med. 2012;157: 197-204. 124. Cosman F, Beur SJd, LeBoff MS, et al. Clinican's guide to prevention and treatment of osteoporosis. Osteoporos Int. 2014;25: 2359-2381.

125. Chapuy MC, Arlot ME, Duboeuf F, et al. Vitamin D3 and calcium to prevent hip fractures in the elderly women. N Engl J Med. 1992;327: 1637-1642.

126. Dawson-Hughes B, Harris SS, Krall EA, Dallal GE. Effect of calcium and vitamin D supplementation on bone density in men and women 65 years of age or older. $\mathrm{N}$ Engl $\mathrm{J}$ Med. 1997;337: 670-676.

127. Murad MH, Elamin KB, Abu Elnour NO, et al. Clinical review: The effect of vitamin D on falls: a systematic review and meta-analysis. J Clin Endocrinol Metab. 2011;96: 2997-3006.

128. Greenspan SL, Nelson JB, Trump DL, Resnick NM. Effect of once-weekly oral alendronate on bone loss in men receiving androgen deprivation therapy for prostate cancer: a randomized trial. Ann Intern Med. 2007;146: 416-424.

129. Van Poznak C. Managing bone mineral density with oral bisphosphonate therapy in women with breast cancer receiving adjuvant aromatase inhibition. Breast Cancer Res. 2010;12: 110.

130. Van Poznak C, Hannon RA, Mackey JR, et al. Prevention of aromatase inhibitorinduced bone loss using risedronate: the SABRE trial. J Clin Oncol. 2010;28: 967-975. 131. Baum M, Budzar AU, Cuzick J, et al. Anastrozole alone or in combination with tamoxifen versus tamoxifen alone for adjuvant treatment of postmenopausal women with early breast cancer: first results of the ATAC randomised trial. Lancet. 2002;359: 2131-2139.

132. Stubblefield MD, Keole N. Upper body pain and functional disorders in patients with breast cancer. PM R. 2014;6: 170-183.

133. Harrington S, Padua D, Battaglini C, et al. Comparison of shoulder flexibility, strength, and function between breast cancer survivors and healthy participants. J Cancer Surviv. 2011;5: 167-174.

134. Fenlon D, Addington-Hall JM, O'Callaghan AC, Clough J, Nicholls P, Simmonds P. A survey of joint and muscle aches, pain, and stiffness comparing women with and without breast cancer. J Pain Symptom Manage. 2013;46: 523-535.

135. Karki A, Simonen R, Malkia E, Selfe J. Impairments, activity limitations and participation restrictions 6 and 12 months after breast cancer operation. J Rehabil Med. 2005;37: 180-188.

136. Kakuda JT, Stuntz M, Trivedi V, Klein SR, Vargas HI. Objective assessment of axillary morbidity in breast cancer treatment. Am Surg. 1999;65: 995-998.

137. Kuehn T, Klauss W, Darsow M, et al. Long-term morbidity following axillary dissection in breast cancer patients--clinical assessment, significance for life quality and the impact of demographic, oncologic and therapeutic factors. Breast Cancer Res Treat. 2000;64: 275-286. 
138. Crew KD, Greenlee H, Capodice J, et al. Prevalence of joint symptoms in postmenopausal women taking aromatase inhibitors for early-stage breast cancer. J Clin Oncol. 2007;25: 3877-3883.

139. Henry NL, Azzouz F, Desta Z, et al. Predictors of aromatase inhibitor discontinuation as a result of treatment-emergent symptoms in early-stage breast cancer. J Clin Oncol. 2012;30: 936-942.

140. Hershman DL, Kushi LH, Shao T, et al. Early discontinuation and nonadherence to adjuvant hormonal therapy in a cohort of 8,769 early-stage breast cancer patients. J Clin Oncol. 2010;28: 4120-4128.

141. Barron TI, Cahir C, Sharp L, Bennett K. A nested case-control study of adjuvant hormonal therapy persistence and compliance, and early breast cancer recurrence in women with stage I-III breast cancer. Br J Cancer. 2013;109: 1513-1521.

142. De Groef A, Van Kampen M, Dieltjens E, et al. Effectiveness of Postoperative Physical Therapy for Upper-Limb Impairments After Breast Cancer Treatment: A Systematic Review. Arch Phys Med Rehabil. 2015.

143. Loh SY, Musa AN. Methods to improve rehabilitation of patients following breast cancer surgery: a review of systematic reviews. Breast Cancer (Dove Med Press). 2015;7:81-98.

144. George SM, McTiernan A, Villasenor A, et al. Disentangling the body weight-bone mineral density association among breast cancer survivors: an examination of the independent roles of lean mass and fat mass. BMC Cancer. 2013;13: 497.

145. Irwin ML, Cartmel B, Gross CP, et al. Randomized exercise trial of aromatase inhibitor-induced arthralgia in breast cancer survivors. J Clin Oncol. 2015;33: 11041111.

146. Crew KD, Capodice JL, Greenlee H, et al. Randomized, blinded, sham-controlled trial of acupuncture for the management of aromatase inhibitor-associated joint symptoms in women with early-stage breast cancer. J Clin Oncol. 2010;28: 1154-1160. 147. Andersen KG, Kehlet H. Persistent pain after breast cancer treatment: a critical review of risk factors and strategies for prevention. J Pain. 2011;12: 725-746.

148. Gartner R, Jensen MB, Nielsen J, Ewertz M, Kroman N, Kehlet H. Prevalence of and factors associated with persistent pain following breast cancer surgery. JAMA. 2009;302: 1985-1992.

149. Pachman DR, Barton DL, Watson JC, Loprinzi CL. Chemotherapy-induced peripheral neuropathy: prevention and treatment. Clin Pharmacol Ther. 2011;90: 377387.

150. Steegers MA, Snik DM, Verhagen AF, van der Drift MA, Wilder-Smith OH. Only half of the chronic pain after thoracic surgery shows a neuropathic component. J Pain. 2008;9: 955-961.

151. Garcia MK, McQuade J, Haddad R, et al. Systematic review of acupuncture in cancer care: a synthesis of the evidence. J Clin Oncol. 2013;31: 952-960.

152. Mishra SI, Scherer RW, Geigle PM, et al. Exercise interventions on health-related quality of life for cancer survivors. Cochrane Database Syst Rev. 2012;8: CD007566. 153. Courneya KS, McKenzie DC, Mackey JR, et al. Subgroup effects in a randomised trial of different types and doses of exercise during breast cancer chemotherapy. $\mathrm{Br} \mathrm{J}$ Cancer. 2014;111: 1718-1725. 
154. Smith E, Pang H, Cirrincione $\mathrm{C}$, et al. Effect of duloxetine on pain, function, and quality of life among patients with chemotherapy-induced painful peripheral neuropathy: A randomized clinical trial. JAMA. 2013;309: 1359-1367.

155. Kort JD, Eisenberg ML, Millheiser LS, Westphal LM. Fertility issues in cancer survivorship. CA Cancer J Clin. 2014;64: 118-134.

156. Ganz PA, Land SR, Geyer CE, Jr., et al. Menstrual history and quality-of-life outcomes in women with node-positive breast cancer treated with adjuvant therapy on the NSABP B-30 trial. J Clin Oncol. 2011;29: 1110-1116.

157. Rosen MP, Sternfeld B, Schuh-Huerta SM, Reijo Pera RA, McCulloch CE, Cedars MI. Antral follicle count: absence of significant midlife decline. Fertil Steril. 2010;94: 2182-2185.

158. Sadovsky R, Basson R, Krychman M, et al. Cancer and sexual problems. J Sex Med. 2010;7: 349-373.

159. Berkey FJ. Managing the adverse effects of radiation therapy. Am Fam Physician. 2010;82: 381-388, 394.

160. Mazzarello S, Hutton B, Ibrahim MF, et al. Management of urogenital atrophy in breast cancer patients: a systematic review of available evidence from randomized trials. Breast Cancer Res Treat. 2015.

161. Pruthi S, Simon JA, Early AP. Current overview of the management of urogenital atrophy in women with breast cancer. Breast J. 2011;17: 403-408.

162. Kendall A, Dowsett M, Folkerd E, Smith I. Caution: Vaginal estradiol appears to be contraindicated in postmenopausal women on adjuvant aromatase inhibitors. Ann Oncol. 2006; 17: 584-587.

163. Rowland JH, Meyerowitz BE, Crespi CM, et al. Addressing intimacy and partner communication after breast cancer: a randomized controlled group intervention. Breast Cancer Res Treat. 2009;118: 99-111.

164. Murthy V, Chamberlain RS. Menopausal symptoms in young survivors of breast cancer: a growing problem without an ideal solution. Cancer Control. 2012;19: 317-329. 165. Kaplan M, Mahon S, Cope D, Keating E, Hill S, Jacobson M. Putting evidence into practice: evidence-based interventions for hot flashes resulting from cancer therapies. Clin J Oncol Nurs. 2011;15: 149-157.

166. Jin Y, Desta Z, Stearns V, et al. CYP2D6 genotype, antidepressant use, and tamoxifen metabolism during adjuvant breast cancer treatment. J Natl Cancer Inst. 2005;97: 30-39.

167. Burstein HJ, Prestrud AA, Seidenfeld J, et al. American Society of Clinical Oncology clinical practice guideline: update on adjuvant endocrine therapy for women with hormone receptor-positive breast cancer. J Clin Oncol. 2010;28: 3784-3796. 168. Loprinzi CL, Sloan J, Stearns V, et al. Newer antidepressants and gabapentin for hot flashes: an individual patient pooled analysis. J Clin Oncol. 2009;27: 2831-2837. 169. Bordeleau L, Pritchard KI, Loprinzi CL, et al. Multicenter, randomized, cross-over clinical trial of venlafaxine versus gabapentin for the management of hot flashes in breast cancer survivors. J Clin Oncol. 2010;28: 5147-5152.

170. Pandya KJ, Morrow GR, Roscoe JA, et al. Gabapentin for hot flashes in 420 women with breast cancer: a randomised double-blind placebo-controlled trial. Lancet. 2005;366: 818-824. 
171. Clayden JR, Bell JW, Pollard P. Menopausal flushing: double-blind trial of a nonhormonal medication. Br Med J. 1974;1: 409-412.

172. Chiu HY, Shyu YK, Chang PC, Tsai PS. Effects of Acupuncture on MenopauseRelated Symptoms in Breast Cancer Survivors: A Meta-analysis of Randomized Controlled Trials. Cancer Nurs. 2015.

173. Bordeleau L, Pritchard K, Goodwin P, Loprinzi C. Therapeutic options for the management of hot flashes in breast cancer survivors: An evidence-based review. Clinical Therapeutics. 2007;29: 230-241.

174. Chan DS, Vieira AR, Aune D, et al. Body mass index and survival in women with breast cancer-systematic literature review and meta-analysis of 82 follow-up studies. Ann Oncol, 2014;25: 1901-1914.

175. Protani M, Coory M, Martin JH. Effect of obesity on survival of women with breast cancer: systematic review and meta-analysis. Breast Cancer Res Treat. 2010;123: 627635.

176. McTiernan A, Irwin M, Vongruenigen V. Weight, physical activity, diet, and prognosis in breast and gynecologic cancers. J Clin Oncol. 2010;28: 4074-4080. 177. Wei EK, Wolin KY, Colditz GA. Time course of risk factors in cancer etiology and progression. J Clin Oncol. 2010;28: 4052-4057.

178. Patterson RE, Cadmus LA, Emond JA, Pierce JP. Physical activity, diet, adiposity and female breast cancer prognosis: a review of the epidemiologic literature. Maturitas. 2010;66: 5-15.

179. Kellen E, Vansant G, Christiaens MR, Neven P, Van Limbergen E. Lifestyle changes and breast cancer prognosis: a review. Breast Cancer Res Treat. 2009;114: 13-22.

180. Friedenreich CM. Physical activity and breast cancer: review of the epidemiologic evidence and biologic mechanisms. Recent Results Cancer Res. 2011;188: 125-139. 181. Barbaric M, Brooks E, Moore L, Cheifetz O. Effects of physical activity on cancer survival: a systematic review. Physiother Can. 2010;62: 25-34.

182. Carmichael AR, Daley AJ, Rea DW, Bowden SJ. Physical activity and breast cancer outcome: a brief review of evidence, current practice and future direction. Eur $\mathrm{J}$ Surg Oncol. 2010;36: 1139-1148.

183. Speed-Andrews AE, Courneya KS. Effects of exercise on quality of life and prognosis in cancer survivors. Curr Sports Med Rep. 2009;8: 176-181.

184. Irwin ML, Mayne ST. Impact of nutrition and exercise on cancer survival. Cancer J. 2008;14: 435-441.

185. Lahart IM, Metsios GS, Nevill AM, Carmichael AR. Physical activity, risk of death and recurrence in breast cancer survivors: A systematic review and meta-analysis of epidemiological studies. Acta Oncol. 2015;54: 635-654.

186. Ballard-Barbash R, Friedenreich CM, Courneya KS, Siddiqi SM, McTiernan A, Alfano CM. Physical activity, biomarkers, and disease outcomes in cancer survivors: a systematic review. J Natl Cancer Inst. 2012;104: 815-840.

187. Binkley JM, Harris SR, Levangie PK, et al. Patient perspectives on breast cancer treatment side effects and the prospective surveillance model for physical rehabilitation for women with breast cancer. Cancer. 2012;118: 2207-2216. 
188. Cappiello M, Cunningham RS, Knobf MT, Erdos D. Breast cancer survivors: information and support after treatment. Clin Nurs Res. 2007;16: 278-293; discussion 294-301.

189. Bloom JR, Stewart SL, Chang S, Banks PJ. Then and now: quality of life of young breast cancer survivors. Psychooncology. 2004;13: 147-160.

190. Blank TO, Bellizzi KM. A gerontologic perspective on cancer and aging. Cancer. 2008;112: 2569-2576.

191. Howard-Anderson J, Ganz PA, Bower JE, Stanton AL. Quality of life, fertility concerns, and behavioral health outcomes in younger breast cancer survivors: a systematic review. J Natl Cancer Inst. 2012;104: 386-405.

192. Stricker CT, Jacobs LA, Risendal B, et al. Survivorship care planning after the institute of medicine recommendations: how are we faring? J Cancer Surviv. 2011;5: 358-370.

193. Brennan ME, Gormally JF, Butow P, Boyle FM, Spillane AJ. Survivorship care plans in cancer: a systematic review of care plan outcomes. Br J Cancer. 2014;111: 1899-1908.

194. Mayer DK, Birken SA, Check DK, Chen RC. Summing it up: an integrative review of studies of cancer survivorship care plans (2006-2013). Cancer. 2015;121: 978-996. 195. Grunfeld E, Julian JA, Pond G, et al. Evaluating survivorship care plans: results of a randomized, clinical trial of patients with breast cancer. J Clin Oncol. 2011;29: 47554762.

196. Brothers BM, Easley A, Salani R, Andersen BL. Do survivorship care plans impact patients' evaluations of care? A randomized evaluation with gynecologic oncology patients. Gynecol Oncol. 2013;129: 554-558.

197. Hershman DL, Greenlee H, Awad D, et al. Randomized controlled trial of a clinicbased survivorship intervention following adjuvant therapy in breast cancer survivors. Breast Cancer Res Treat. 2013;138: 795-806.

198. Ezendam NP, Nicolaije KA, Kruitwagen RF, et al. Survivorship Care Plans to inform the primary care physician: results from the ROGY care pragmatic cluster randomized controlled trial. J Cancer Surviv. 2014;8: 595-602.

199. ACS. The American Cancer Society Webpage. Available from URL: cancer.org [accessed May 15, 2015.

200. Irwin ML, McTiernan A, Bernstein L, et al. Physical activity levels among breast cancer survivors. Med Sci Sports Exerc. 2004;36: 1484-1491.

201. Demark-Wahnefried W, Rogers LQ, Alfano CM, et al. Practical clinical interventions for diet, physical activity, and weight control in cancer survivors. CA Cancer J Clin. 2015;65: 167-189.

202. Ligibel JA, Alfano CM, Courneya KS, et al. American Society of Clinical Oncology position statement on obesity and cancer. J Clin Oncol. 2014;32: 3568-3574.

203. USPSTF. Obesity in Adults: Screening and Managment, June 2012. Available from URL:

http://www.uspreventiveservicestaskforce.org/Page/Document/RecommendationStatem entFinal/obesity-in-adults-screening-and-management\#references [accessed $08 / 17 / 2015$.

204. Underwood JM, Townsend JS, Stewart SL, et al. Surveillance of demographic characteristics and health behaviors among adult cancer survivors--Behavioral Risk 
Factor Surveillance System, United States, 2009. MMWR Surveill Summ. 2012;61: 123.

205. Schmid D, Leitzmann MF. Association between physical activity and mortality among breast cancer and colorectal cancer survivors: a systematic review and metaanalysis. Ann Oncol. 2014;25: 1293-1311.

206. Zhao G, Li C, Okoro CA, et al. Trends in modifiable lifestyle-related risk factors following diagnosis in breast cancer survivors. J Cancer Surviv. 2013;7: 563-569. 207. Blanchard CM, Courneya KS, Stein K. Cancer survivors' adherence to lifestyle behavior recommendations and associations with health-related quality of life: results from the American Cancer Society's SCS-II. J Clin Oncol. 2008;26: 2198-2204.

208. Forbes CC, Blanchard CM, Mummery WK, Courneya K. Prevalence and correlates of strength exercise among breast, prostate, and colorectal cancer survivors. Oncol Nurs Forum. 2015;42: 118-127.

209. Irwin ML, McTiernan A, Manson JE, et al. Physical activity and survival in postmenopausal women with breast cancer: results from the women's health initiative. Cancer Prev Res (Phila). 2011;4: 522-529.

210. Kroenke CH, Fung TT, Hu FB, Holmes MD. Dietary patterns and survival after breast cancer diagnosis. J Clin Oncol. 2005;23: 9295-9303.

211. Kwan ML, Weltzien E, Kushi LH, Castillo A, Slattery ML, Caan BJ. Dietary patterns and breast cancer recurrence and survival among women with early-stage breast cancer. J Clin Oncol. 2009;27: 919-926.

212. Vrieling A, Buck K, Seibold $P$, et al. Dietary patterns and survival in German postmenopausal breast cancer survivors. Br J Cancer. 2013;108: 188-192.

213. Chlebowski RT, Blackburn GL, Thomson CA, et al. Dietary fat reduction and breast cancer outcome: interim efficacy results from the Women's Intervention Nutrition Study. J Natl Cancer Inst. 2006;98: 1767-1776.

214. Pierce JP, Natarajan L, Caan BJ, et al. Influence of a diet very high in vegetables, fruit, and fiber and low in fat on prognosis following treatment for breast cancer: the Women's Healthy Eating and Living (WHEL) randomized trial. JAMA. 2007;298: 289298.

215. ACS. Alcohol Use and Cancer. Available from URL:

http://www.cancer.org/cancer/cancercauses/dietandphysicalactivity/alcohol-use-andcancer [accessed 01/06/2015.

216. McGuire S. U.S. Department of Agriculture and U.S. Department of Health and Human Services, Dietary Guidelines for Americans, 2010. 7th Edition, Washington, DC: U.S. Government Printing Office, January 2011. Advances in Nutrition. 2011;2: 293294.

217. Kwan ML, Kushi LH, Weltzien E, et al. Alcohol consumption and breast cancer recurrence and survival among women with early-stage breast cancer: the life after cancer epidemiology study. J Clin Oncol. 2010;28: 4410-4416.

218. Baan R, Straif K, Grosse Y, et al. Carcinogenicity of alcoholic beverages. Lancet Oncol. 2007;8: 292-293.

219. Nelson DE, Jarman DW, Rehm J, et al. Alcohol-attributable cancer deaths and years of potential life lost in the United States. Am J Public Health. 2013;103: 641-648. 
220. Scoccianti C, Lauby-Secretan B, Bello PY, Chajes V, Romieu I. Female breast cancer and alcohol consumption: a review of the literature. Am J Prev Med. 2014;46: S16-25.

221. Terry MB, Zhang FF, Kabat G, et al. Lifetime alcohol intake and breast cancer risk. Ann Epidemiol. 2006;16: 230-240.

222. Berube S, Lemieux J, Moore L, Maunsell E, Brisson J. Smoking at time of diagnosis and breast cancer-specific survival: new findings and systematic review with meta-analysis. Breast Cancer Res. 2014;16: R42.

223. Nayan S, Gupta MK, Strychowsky JE, Sommer DD. Smoking cessation interventions and cessation rates in the oncology population: an updated systematic review and meta-analysis. Otolaryngol Head Neck Surg. 2013;149: 200-211.

224. Boekhout AH, Maunsell E, Pond GR, et al. A survivorship care plan for breast cancer survivors: extended results of a randomized clinical trial. J Cancer Surviv. 2015. 225. Mao JJ, Bowman MA, Stricker CT, et al. Delivery of survivorship care by primary care physicians: the perspective of breast cancer patients. J Clin Oncol. 2009;27: 933938.

226. Shulman LN, Jacobs LA, Greenfield S, et al. Cancer care and cancer survivorship care in the United States: will we be able to care for these patients in the future? J Oncol Pract. 2009;5: 119-123.

227. Travis LB, Yahalom J. Cancer Survivorship. Preface. Hematol Oncol Clin North Am. 2008;22: xi-xii.

228. COG. Long-term follow-up guidelines for survivors of childhood, adolescent, and young adult cancers. Available from URL: http://www.survivorshipguidelines.org/ [accessed May 15, 2015.

229. Grunfeld E, Levine MN, Julian JA, et al. Randomized trial of long-term follow-up for early-stage breast cancer: a comparison of family physician versus specialist care. J Clin Oncol. 2006;24: 848-855.

230. Grunfeld E, Fitzpatrick R, Mant D, et al. Comparison of breast cancer patient satisfaction with follow-up in primary care versus specialist care: results from a randomized controlled trial. Br J Gen Pract. 1999;49: 705-710.

231. Dawes AJ, Hemmelgarn M, Nguyen DK, et al. Are primary care providers prepared to care for survivors of breast cancer in the safety net? Cancer. 2015;121: 1249-1256. 232. Palmer SC, Stricker CT, Panzer SL, et al. Outcomes and satisfaction after delivery of a breast cancer survivorship care plan: results of a multicenter trial. J Oncol Pract. 2015;11: e222-229.

233. Kim Y, Kashy DA, Spillers RL, Evans TV. Needs assessment of family caregivers of cancer survivors: three cohorts comparison. Psychooncology. 2010;19: 573-582. 234. Kim Y, Spillers RL, Hall DL. Quality of life of family caregivers 5 years after a relative's cancer diagnosis: follow-up of the national quality of life survey for caregivers. Psychooncology. 2012;21: 273-281.

235. Given BA, Given CW, Sherwood PR. Family and caregiver needs over the course of the cancer trajectory. J Support Oncol. 2012;10: 57-64.

236. United States Cancer Statistics: 1999-2011 Incidence and Mortality Web-based Report. Available from URL: http://nccd.cdc.gov/uscs/.

237. ACS. Cancer Facts \& Figures for African Americans 2013-2014. Atlanta, GA: American Cancer Society, 2013. 
238. SEER Cancer Statistics Review, 1975-2011. Available from URL:

http://seer.cancer.gov/archive/csr/1975 2011/.

239. Mead H, Cartwright-Smith L, Jones K, Ramos C, Woods K, Siegel B. Racial and Ethnic Disparities in U.S. Health Care: A Chartbook2008.

240. Patient-centered care for older adults with multiple chronic conditions: a stepwise approach from the American Geriatrics Society: American Geriatrics Society Expert Panel on the Care of Older Adults with Multimorbidity. J Am Geriatr Soc. 2012;60: 19571968.
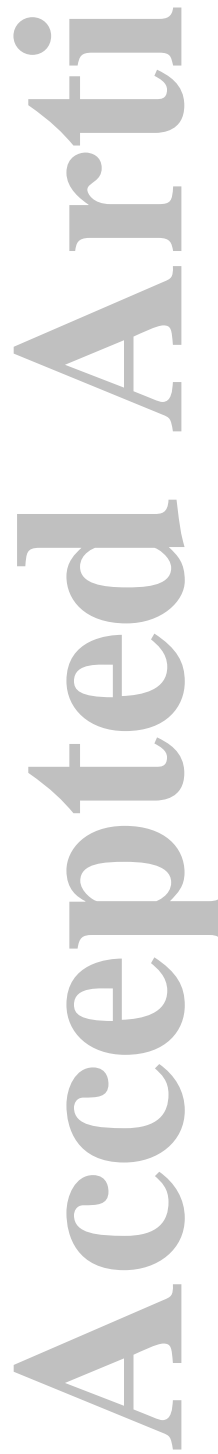


\section{Table 1: Guideline for Surveillance for Breast Cancer Recurrence and Genetic Counseling}

\begin{tabular}{|c|c|}
\hline It is recommended that primary care clinicians: & Level of Evidence $^{\text {a }}$ \\
\hline $\begin{array}{l}\text { 1.1 History and Physical } \\
\text { (a) Should individualize clinical follow-up care provided to breast } \\
\text { cancer survivors based on age, specific diagnosis and treatment } \\
\text { protocol as recommended by the treating oncology team. } \\
\text { (b) Should make sure the patient receives a detailed cancer-related } \\
\text { history and physical examination every } 3 \text { to } 6 \text { months for the first } 3 \\
\text { years after primary therapy, every } 6 \text { to } 12 \text { months for the next } 2 \text { years, } \\
\text { and annually thereafter by the treating oncology team. }\end{array}$ & $2 \mathrm{~A}^{\mathrm{b}}$, \\
\hline $\begin{array}{l}\text { 1.2 Screening the Breast for Local Recurrence or a New Primary Breast } \\
\text { Cancer } \\
\text { (a) Should refer women who have received a unilateral mastectomy } \\
\text { for annual mammography on the intact breast and for those yith } \\
\text { lumpectomies an annual mammography of both breasts } \\
\text { (b) Should not refer for routine screening with MRI of the breast } \\
\text { unless the patient meets high risk criteria for increased breast cancer } \\
\text { surveillance as per ACS Guidelines. }\end{array}$ & \\
\hline $\begin{array}{l}\text { 1.3 Laboratory Tests and Imaging } \\
\text { Should not offer routine laboratory tests } \\
\text { mammography if indicated, for the detect } \\
\text { absence of symptoms. }\end{array}$ & $2 \mathrm{~A}^{\mathrm{b}}$, \\
\hline $\begin{array}{l}\text { 1.4 Signs of Recurrence } \\
\text { Should educate and counsel all } \\
\text { local or regional recurrence. }\end{array}$ & $2 \mathrm{~A}^{\mathrm{b}}$ \\
\hline $\begin{array}{l}1.5 \text { Risk Evaluation and Genetic Counseling } \\
\text { (a) Should assess your patient's cancen family history. } \\
\text { (b) Should offer genetic counseling if potential hereditary risk factors } \\
\text { are suspected (e.g., women with a strong family history of cancer } \\
\text { [breast, colon, endometrial], or age } 60 \text { or younger with triple negative } \\
\text { breast cancer). }\end{array}$ & $2 \mathrm{~A}^{\mathrm{b}}$ \\
\hline $\begin{array}{l}\text { 1.6 Endocrine Treatment Impacts, Symptom Management } \\
\text { Should counsel patients to adhere to adjuvant endocrine (anti-estrogen) } \\
\text { therapy. }\end{array}$ & $2 \mathrm{~A}^{\mathrm{b}}$, \\
\hline
\end{tabular}

${ }^{\mathrm{a}}$ Levelof evidence: I, meta-analyses of randomized controlled trials (RCTs); IA, RCT of breast cancer survivors; $\mathbb{B}, \mathrm{RCT}$ based on cancer survivors across multiple sites; IC, RCT not based on cancer survivors but on general population experiencing a specific long-term or late effect (eg, managing fatigue, lymphedema, etc); IIA, non-RCT based on breast cancer survivors; IIB, nonRCT based on cancer survivors across multiple sites; IIC, non-RCT not based on cancer survivors but on general population experiencing a specific long-term or late effect (eg, managing urinary incontinence, erectile dysfunction, etc); III, case-control or prospective cohort study; 0, expert opinion, observation, clinical practice, literature review, or pilot study.; ${ }^{b}$ National Comprehensive Cancer Network rating 2A indicates that "based upon lower-level evidence, there is uniform consensus that the intervention is appropriate"; ${ }^{\mathrm{c}} \mathrm{ASCO}$ 
Table 2: ACS Guidelines for the Early Detection of Cancer in Average Risk, Asymptomatic Individuals

Recommendation 2.1: Among average risk patients, it is recommended that primary care clinicians:

(a) Should screen for other cancers as they would for patients in the general population.

(b) Should provide an annual gynecological assessment for post-menopausal women on selective estrogen receptor modulator therapies (SERMs).

\begin{tabular}{|c|c|c|c|}
\hline $\begin{array}{l}\text { CANCER } \\
\text { SITE }\end{array}$ & POPULATION & $\begin{array}{l}\text { TEST OR } \\
\text { PROCEDURE }\end{array}$ & FREQUENCY \\
\hline Cervix & $\begin{array}{l}\text { Women, aged } \\
21-65 y\end{array}$ & $\begin{array}{l}\text { Pap test and } \\
\text { HPV DNA test }\end{array}$ & $\begin{array}{l}\text { Cervical cancer screening should begin at } \\
\text { age } 21 \text { y. For womenaged } 21-29 y \text {, } \\
\text { screening should be done every } 3 \text { y with } \\
\text { conventional or liquid-based Pap tests. } \\
\text { For women aged } 30-65 \text { y, screening } \\
\text { should be done every } 5 \text { y with both the } \\
\text { HPV test and the Pap test (preferred), or } \\
\text { ereryy } 3 \text { y with the Pap test alone } \\
\text { (acceptable). Women aged }>65 \text { y who } \\
\text { have had } \geq 3 \text { consecutive negative Pap } \\
\text { tests or } \geq 2 \text { consecutive negative HPV and } \\
\text { Pap tests within the last } 10 \text { y, with the } \\
\text { mostrecent test occurring within the last } 5 \\
\text { y, and women who have had a total } \\
\text { hysterectomy should stop cervical cancer } \\
\text { screening if they no longer have a cervix } \\
\text { and are without a history of CIN } 2 \text { or a } \\
\text { more severe diagnosis in the past } 20 \text { y or } \\
\text { cervical cancer ever. Women at any age } \\
\text { should not be screened annually by any } \\
\text { screening method. }\end{array}$ \\
\hline & & $\begin{array}{l}\text { FOBT with at } \\
\text { least } 50 \% \text { test } \\
\text { sensitivity for } \\
\text { cancer, or FIT } \\
\text { with at least } \\
50 \% \text { test } \\
\text { sensitivity for } \\
\text { cancer, or }\end{array}$ & $\begin{array}{l}\text { Annual, starting at age } 50 \text { y. Testing at } \\
\text { home with adherence to manufacturer's } \\
\text { recommendation for collection techniques } \\
\text { and number of samples is recommended. } \\
\text { FOBT with the single stool sample } \\
\text { collected on the clinician's fingertip } \\
\text { during a DRE in the health care setting is } \\
\text { not recommended. Guaiac-based toilet } \\
\text { bowl FOBT tests also are not } \\
\text { recommended. In comparison with } \\
\text { guaiac-based tests for the detection of } \\
\text { occult blood, immunochemical tests are } \\
\text { more patient-friendly, and are likely to be } \\
\text { equal or better in sensitivity and }\end{array}$ \\
\hline
\end{tabular}




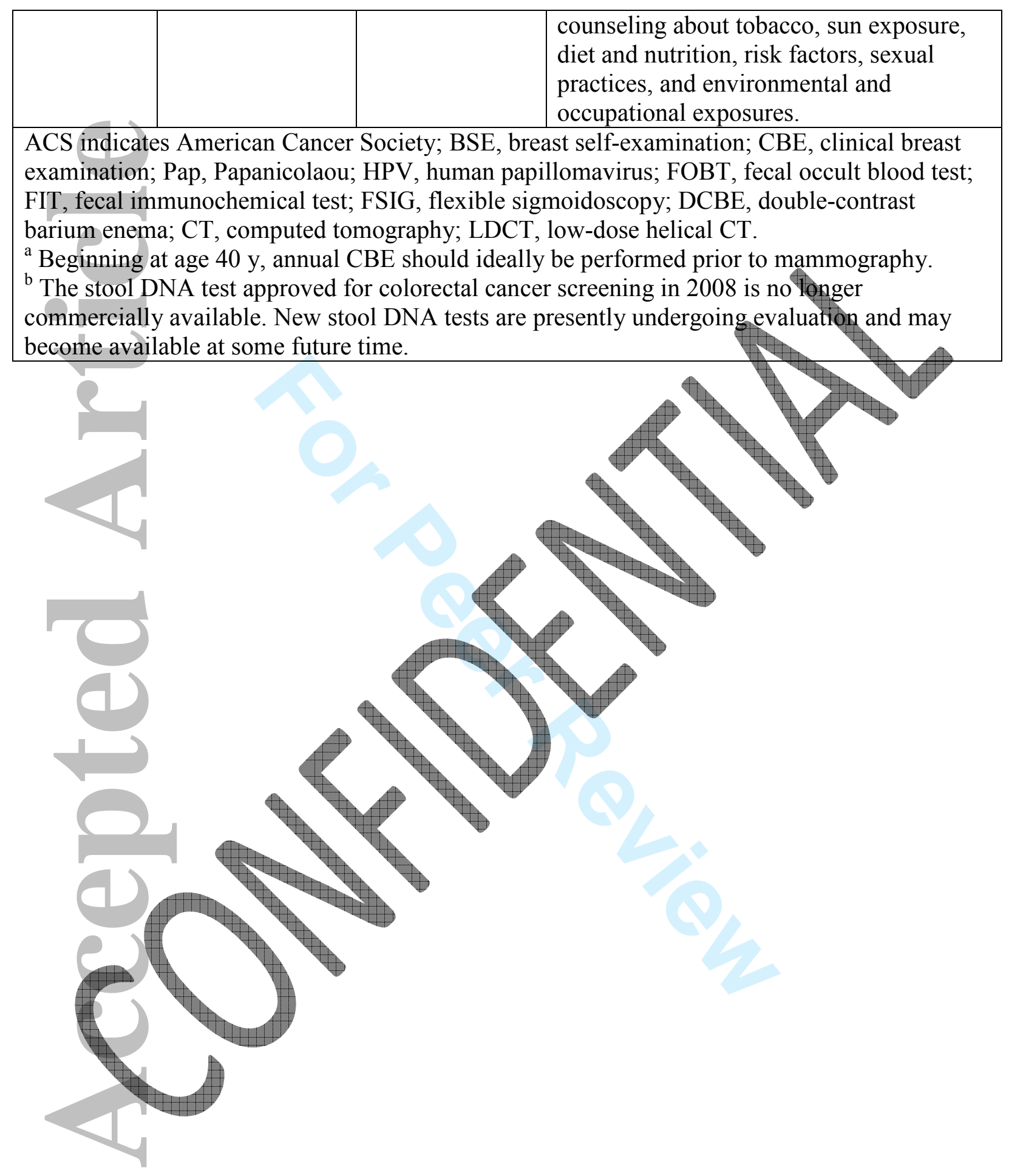


Table 3: Summary of Long-term and Late Effects by Treatment Type

\begin{tabular}{|c|c|c|}
\hline Treatment Type & Long-Term Effects & Late Effects \\
\hline Surgery & $\begin{array}{ll}\text { - } & \text { Lack of skin sensitivity } \\
\text { - } & \text { Body image issues } \\
\text { - } & \text { Sexual dysfunction } \\
\text { - } & \text { Pain } \\
\text { - } & \text { Limited range of motion } \\
\text { - } & \text { Weakness } \\
\text { - } & \text { Poor cosmetic outcome }\end{array}$ & $\begin{array}{ll} & \text { Lymphedema } \\
\text { - } & \text { Neuropathy }\end{array}$ \\
\hline $\begin{array}{l}\text { Radiation therapy }(\mathrm{RT}) \text { to the } \\
\text { breast/chest-wall/regional } \\
\text { nodes }\end{array}$ & $\begin{array}{l}\text { - } \quad \text { Fatigue *^ } \\
\text { - } \quad \text { Skin sensitivity/pain } \\
\text { - } \quad \text { Pain } \\
\text { - } \text { Pneumonitis*^ } \\
\text { - } \quad \text { Poor cosmetic outcome } \\
\text { - } \quad \text { Breast atrophy } \\
\text { asymmetrical breast } \\
\text { volume } \\
\text { - Lymphedema* } \\
\text { - } \quad \text { Numbness or weakness } \\
\text { the upper extremify* } \\
\text { * Risks are increased in } \\
\text { patients whohad RT also to } \\
\text { the supraclavicular nodes } \\
\text { A Risks are increased in } \\
\text { patients who had RT also to } \\
\text { the internal mammary nodes }\end{array}$ & $\begin{array}{l}\text { Skindiscoloration } \\
\text { Breast maybe slightly } \\
\text { smallerand firmer than } \\
\text { the non-irradiated side } \\
\text { (breast asymmetry). } \\
\text { Skin sensitivity/pain } \\
\text { Telangiectasia } \\
\text { - Sexual dysfunction } \\
\text { Lymphedema* } \\
\text { Shortness of breath (lung } \\
\text { pneumonitis or fibrosis)* } \\
\text { - Cardiovascular disease } \\
\text { (e.g. pericardial effusion, } \\
\text { pericarditis) } \\
\text { - Numbness or weakness of } \\
\text { the upper extremity*\# } \\
\text { - Second primary cancers } \\
\text { (e.g., soft-tissue sarcomas } \\
\text { of thorax, shoulder and } \\
\text { pelvis; lung cancer)*^ } \\
\text { * Risks are increased in } \\
\text { patients who had RT also to } \\
\text { the supraclavicular nodes } \\
\text { ^ Risks are increased in } \\
\text { patients who had RT also to } \\
\text { the internal mammary nodes } \\
\text { \# Need to be careful as these } \\
\text { can also be signs of recurrent } \\
\text { cancer, typically with pain. } \\
\text { Appropriate consultation with }\end{array}$ \\
\hline
\end{tabular}




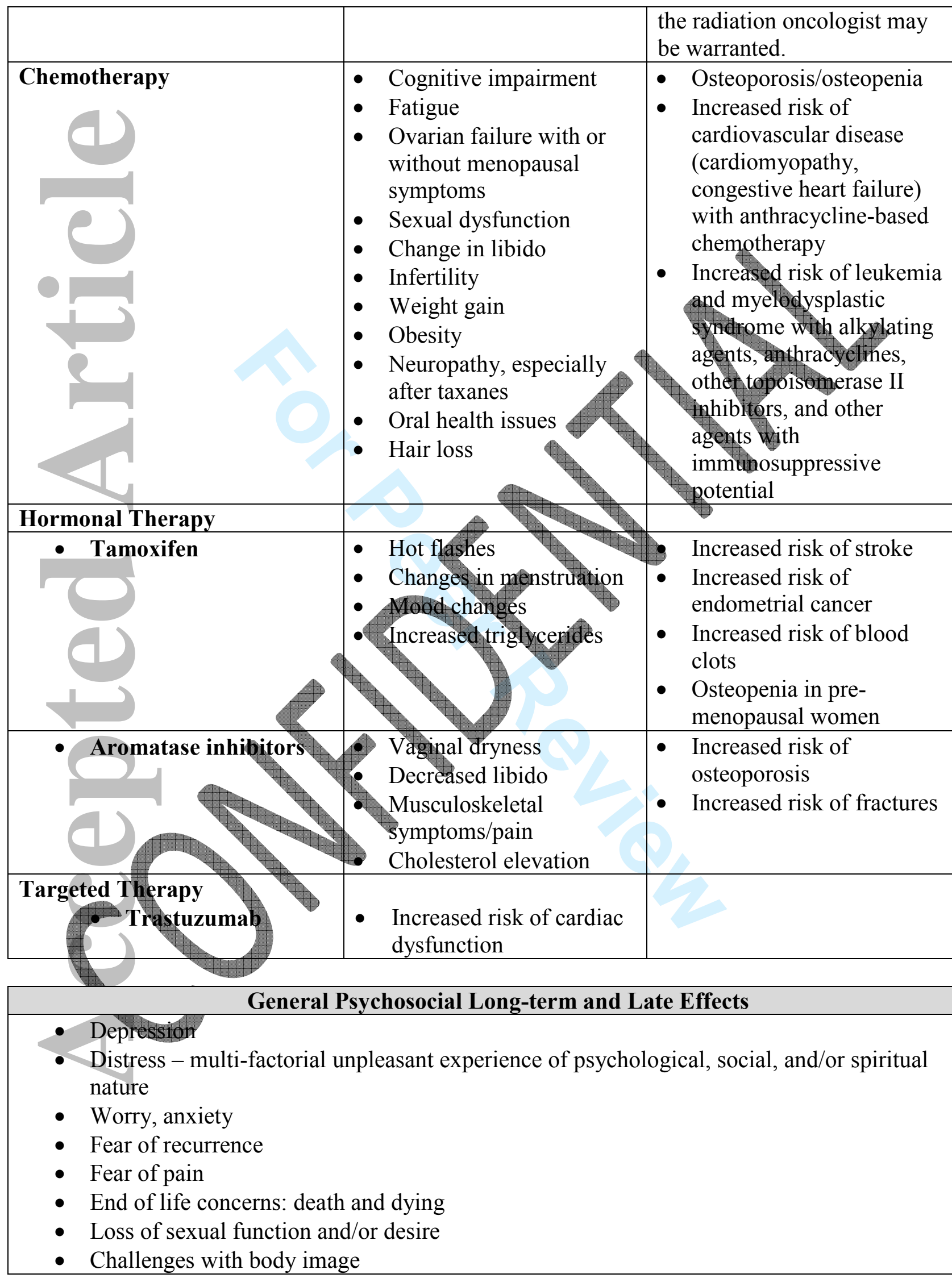


Table 4: Guideline for Assessment and Management of Physical and Psychosocial Long-term / Late Effects

\begin{tabular}{|l|c|}
\hline It is recommended that primary care clinicians: & Level of Evidence $^{\mathbf{a}}$ \\
\hline $\begin{array}{l}\text { 4.1 Body Image Concerns } \\
\text { (a) Should assess for patient body image/appearance concerns. }\end{array}$ & 0 (assessment) \\
(b) Should offer the option of adaptive devices (e.g., breast prostheses, & 0 (adaptive devices) \\
$\begin{array}{l}\text { wigs) and/or surgery when appropriate. } \\
\text { (c) Should refer for psychosocial care as indicated. }\end{array}$ & $\begin{array}{c}\text { IA (couple-based } \\
\text { intervention) }\end{array}$ \\
\hline
\end{tabular}

4.2 Lymphedema

(a) Should counsel survivors on how to prevent / reduce risk of lymphedema, including weight loss for those who are overweight of obese.

(b) Should refer patients with clinical symptoms or swelling suggestive of lymphedema to a therapist knowledgeable about the diagnosis and treatment of lymphedema, such as a physical therapist, occupational therapist, or lymphedema specialist.

4.3: Cardiotoxicity

(a): Should monitor lipid levels and provide cardiovaseular monitoring, as indicated.

(b) Should educate breast cancer survivors on healthy hifestyle modifications, potential cardiac risk factors, and when to teport relevant symptoms (shortness of breath or fatigue) to their health care provider.

4.4 Cognitive Impairment

(a) Should ask patients if they are experiencing cognitive difficulties.

(b) Should assess for reversible contributing factors of cognitive impairment and optimally treat when possible.

(c) Should referpatient with signs of cognitive impairment for neurocognitive assessment and rehabilitation, including group cognitive training if available

4.5 Distress, Depression, and Anxiety

(a) Should assess patients for distress, depression, and/or anxiety.

(b) Should conduct a more probing assessment for patients at a higher

I (assessment)

risk of depression (e.g, young patients, those with a history of prior psychiatric disease, and patients with low socioeconomic status).

III (at-risk groups)

(c) Should offer in-office counseling and/or pharmacotherapy and/or refer to appropriate psycho-oncology and mental health resources as clinically indicated if signs of distress, depression, or anxiety are

I (interventions) present.

4.6 Fatigue

(a) Should assess for fatigue and treat any causative factors for fatigue, including anemia, thyroid dysfunction, and cardiac dysfunction.

(b) Should offer treatment or referral for factors that may impact

0 (monitoring)

I (lifestyle modifications)

0 (assessment)

IA (contributing factors)

IA (group cognitive rehabilitation)

fatigue (e.g., mood disorders, sleep disturbance, pain, etc.) for those who do not have an otherwise identifiable cause of fatigue. 
(c) Should counsel patients to engage in regular physical activity and refer for cognitive behavioral therapy (CBT) as appropriate.

4.7 Bone Health

(a) Should refer post-menopausal breast cancer survivors for a baseline DEXA scan.

(b) Should refer for repeat DEXA scans every 2 years for women taking an aromatase inhibitor, premenopausal women taking tamoxifen and/or a GnRH agonist, and women who have chemoinduced premature menopause.

4.8 Musculoskeletal Health

(a) Should assess for musculoskeletal symptoms, including pain, by asking patients about their symptoms at each clinical encounter. (b) Should offer one or more of the following interventions based on clinical indication: acupuncture, physical activity, referral for physical therapy or rehabilitation.

4.9 Pain and Neuropathy

(a) Should assess for pain and contributing factors forpain with the use of a simple pain scale and comprehensive history of the patient's complaint

(b) Should offer interventions, such as acetaminophen, nonsteroidal anti-inflammatory drugs, physical activity and/or acupuncture, for pain.

(c) Should refer to an appropriate specialist depending on the etiology of the pain once the underlying etiology has been determined (e.g., lymphedema specialist, occupational therapist, etc.).

(d) Should assess for peripheral neuropathy and contributing factors for peripheral neuropathy by asking the patient about their symptoms, specifically numbness and tingling in their hands and/or feet, and the characteristics of that symptom.

(e) Should offer physical activity for neuropathy.

(f) Should offer duloxetine for patients with neuropathic pain, numbness and tingling.

\subsection{Infertility}

Should refer survivors of childbearing age who experience infertility to a specialist in reproductive endocrinology and infertility as soon as possible. 4.11 Sexual Health

(a) Should assess for signs and symptoms of sexual dysfunction or problems with sexual intimacy.

(b) Should assess for reversible contributing factors to sexual dysfunction and treat, when appropriate.

(c) Should offer nonhormonal, water-based lubricants and moisturizers for vaginal dryness.

(d) Should refer for psychoeducational support, group therapy, sexual counseling, marital counseling or intensive psychotherapy, when appropriate.

0 (assessment)

0 (contributing factors)

IA (nonhormonal lubricants and moisturizers) IA (counseling) IA (SNRI and SSRI 


\begin{tabular}{|l|l|}
\hline Should offer selective serotonin-norepinephrine reuptake inhibitors & use) \\
(SNRIs), selective serotonin reuptake inhibitors (SSRIs), gabapentin, & \\
lifestyle modifications and/or environmental modifications to help \\
mitigate vasomotor symptoms of premature menopausal symptoms.
\end{tabular}

${ }^{a}$ Level of evidence: I, meta-analyses of randomized controlled trials (RCTs); IA, RCT of breast cancer survivors; IB, RCT based on cancer survivors across multiple sites; IC, RCT not based on cancer survivors but on general population experiencing a specific long-term or late effect (eg, managing fatigue, lymphedema, etc); IIA, non-RCT based on breast cancer survivors; IIB, nonRCT based on cancer survivors across multiple sites; IIC, non-RCT not based on cancer survivors but on general population experiencing a specific long-term or late effect (eg, managing urinary incontinence, erectile dysfunction, etc); III, case-control or prospective cohort study; 0 , expert opinion, observation, clinical practice, literature review, or pilot study.

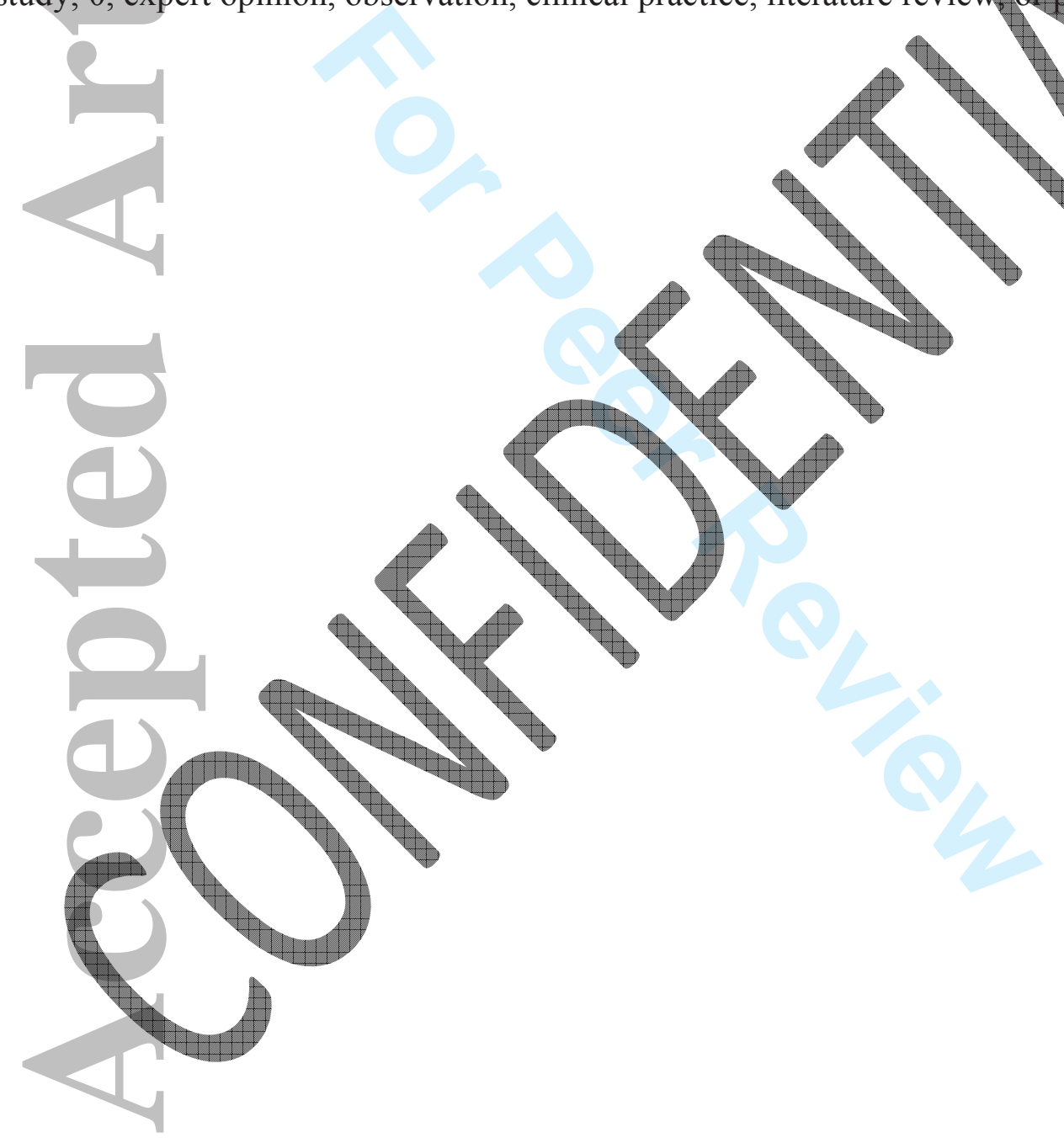




\section{Table 5: Health Promotion Guideline}

\begin{tabular}{|c|c|}
\hline \multirow{2}{*}{\multicolumn{2}{|c|}{$\begin{array}{l}\text { It is recommended that primary care clinicians: } \\
5.1 \text { Information }\end{array}$}} \\
\hline & \\
\hline $\begin{array}{l}\text { (a) Should assess the information needs of the patient related to breast } \\
\text { cancer and its treatment, side effects, other health concerns, and }\end{array}$ & 0 (assessment) \\
\hline $\begin{array}{l}\text { available support services. } \\
\text { (b) Should provide or refer survivors to appropriate resources to meet } \\
\text { these needs. }\end{array}$ & 0 (referral) \\
\hline 5.2 Obesity & \\
\hline (a) Should counsel survivors to acl & e) \\
\hline & \\
\hline 5.3 Physical Activity & \\
\hline $\begin{array}{l}\text { Should counsel survivors to en } \\
\text { with the ACS guideline and sp }\end{array}$ & \\
\hline (a) Should avoid inactivity & \\
\hline $\begin{array}{l}\text { soon as possible following } \\
\text { (b) Should aim for at least } \\
\text { vigorous aerobic exercise }\end{array}$ & $\begin{array}{l}\text { I, IA (aerobic } \\
\text { exercise) }\end{array}$ \\
\hline $\begin{array}{l}\text { (c) Should include strength training exercises at le } \\
\text { Emphasize strength training for women treated wi } \\
\text { chemotherapy or hormone therapy. }\end{array}$ & $\begin{array}{l}\text { IA (strength } \\
\text { training) }\end{array}$ \\
\hline $\begin{array}{l}5.4 \text { Nutrition } \\
\text { Should counsel survivors to a } \\
\text { vegetables, fruits, whole grain }\end{array}$ & IA, III (nutrition) \\
\hline limited in alcohol consumption. & 0 (alcohol) \\
\hline $\begin{array}{l}\text { 5.5 Smoking Cessation } \\
\text { Should counsel survivors to avoid smoking and refer survivors who } \\
\text { smoke to cessation cotunseting and resources. }\end{array}$ & I \\
\hline
\end{tabular}

${ }^{a}$ Level of evidence: I, meta-analyses of randomized controlled trials (RCTs); IA, RCT of breast cancer survivors; IB, RCT based on cancer survivors across multiple sites; IC, RCT not based on cancer survivars but on general population experiencing a specific long-term or late effect (eg, managing fatigue, lymphedema, etc); IIA, non-RCT based on breast cancer survivors; IIB, nonRCT based on cancer sufvivors across multiple sites; IIC, non-RCT not based on cancer survivers but on general population experiencing a specific long-term or late effect (eg, managing urinary incontinence, erectile dysfunction, etc); III, case-control or prospective cohort study; 0, expert opinion, observation, clinical practice, literature review, or pilot study 
Table 6: Care Coordination Guideline

\begin{tabular}{|l|c|}
\hline It is recommended that primary care clinicians: & Level of Evidence $^{\text {a }}$ \\
\hline $\begin{array}{l}\text { 6.1 Survivorship Care Plan } \\
\text { Should consult with the cancer treatment team and obtain a treatment } \\
\text { summary and Survivorship Care Plan. }\end{array}$ & 0 , III \\
\hline $\begin{array}{l}\text { 6.2 Communication with Oncology Team } \\
\text { Should maintain communication with the oncology team throughout your } \\
\text { patient's diagnosis, treatment and post-treatment care to ensure care is } \\
\text { evidence-based and well-coordinated. }\end{array}$ & \\
\hline $\begin{array}{l}\text { 6.3 Inclusion of Family } \\
\text { Should encourage the inclusion of caregivers, spouses, or partners in usual } \\
\text { breast cancer survivorship care and support. }\end{array}$ & 0 \\
\hline
\end{tabular}

${ }^{a}$ Level of evidence: I, meta-analyses of randomized controlled trials (RCTs); HA, RCT of breast cancer survivors; IB, RCT based on cancer survivors across multiple sites; IC, RCT not based on cancer survivors but on general population experiencing a specific long-term or late effect (eg, managing fatigue, lymphedema, etc); IIA, non-RCT based on breast cancer survivors; IIB, nonRCT based on cancer survivors across multiple sites; IIC, non-RCT not based on cancer survivors but on general population experiencing a specific long-term or late effect (eg, managing urinary incontinence, erectile dysfunction, etc); WI, ease-control or prospective cohort study; 0, expert opinion, observation, clinical practice, literature review, or pilot study.

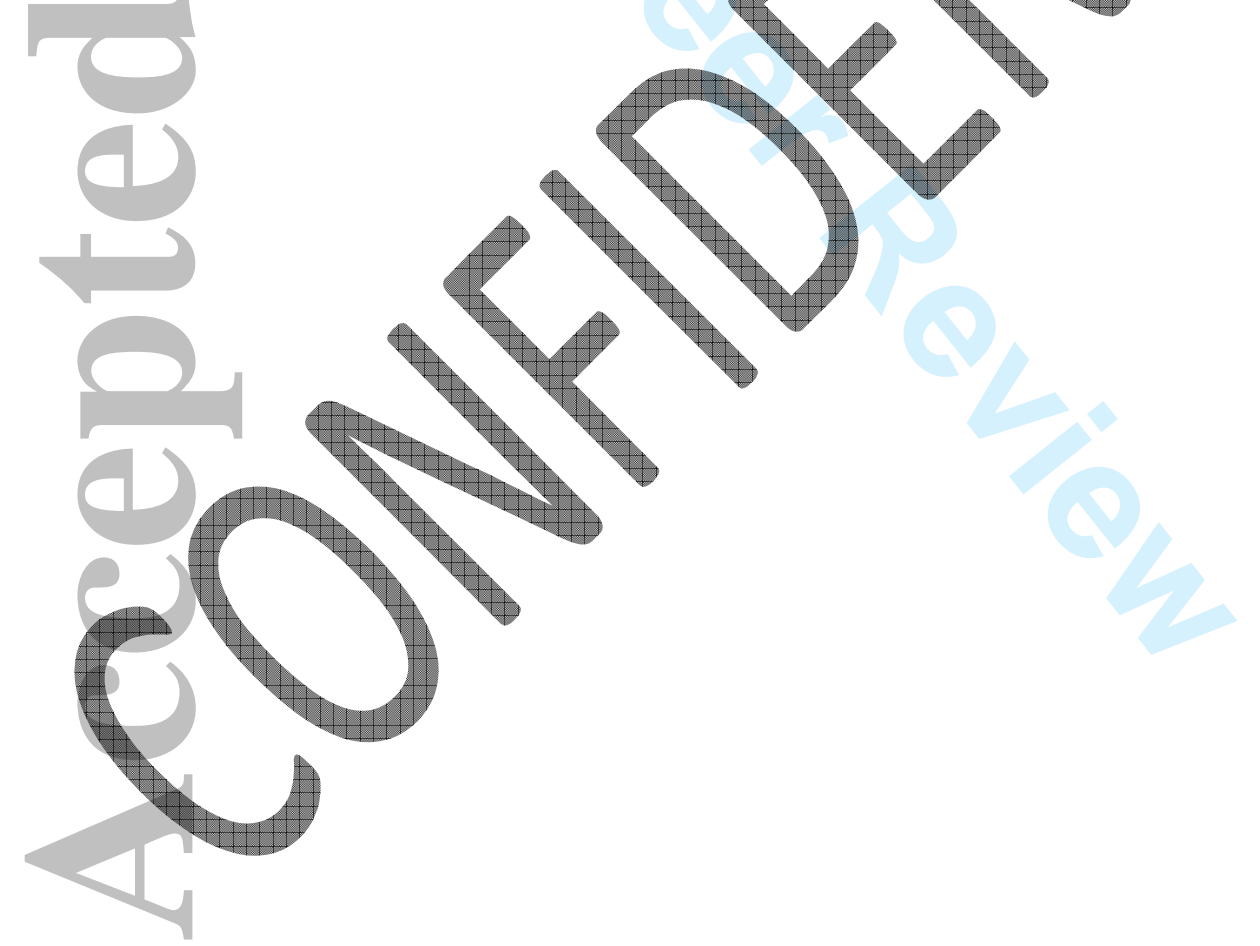




\section{Data Supplement}

\section{American Cancer Society/American Society of Clinical Oncology Breast Cancer Survivorship Care Guideline}

\section{Table of Contents}

Data Supplement 1: Additional Evidence

Figure 1: Depression Algorithm

Figure 2: Anxiety Algorithm

Figure 3: Fatigue Algorithm

Table 1: Chemotherapy-induced peripheral neuropathy Summary of Recommendations Table

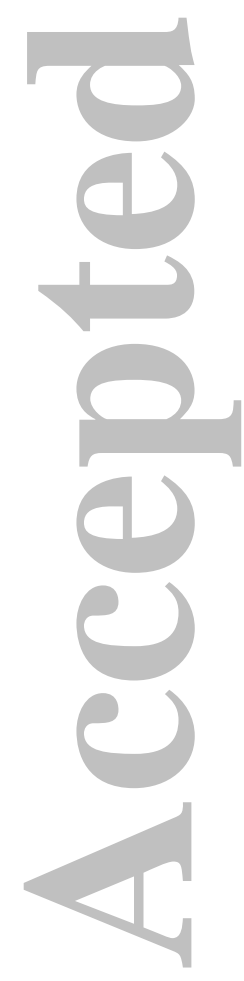


If YES > Referral for emergency evaluation; Facilitate safe environment; One-to-one observation; Initiate interventions to reduce risk of harm to self and/or others. (The presence of other symptoms, e.g., psychosis, severe agitation and confusion (delirium), may also warrant emergency evaluation). If NO > Continue with algorithm

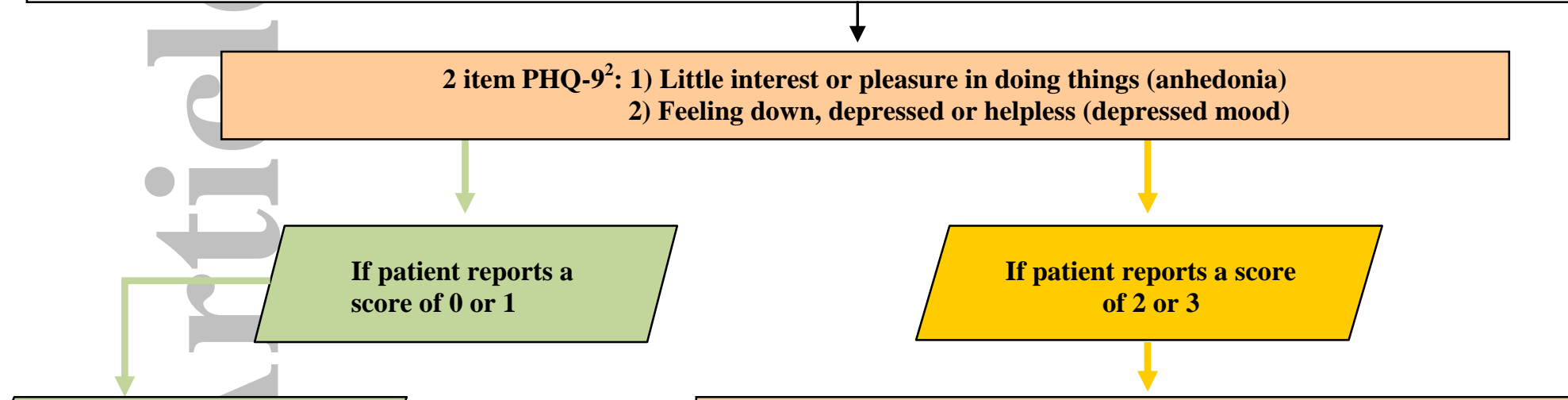

\section{No Further Screening}
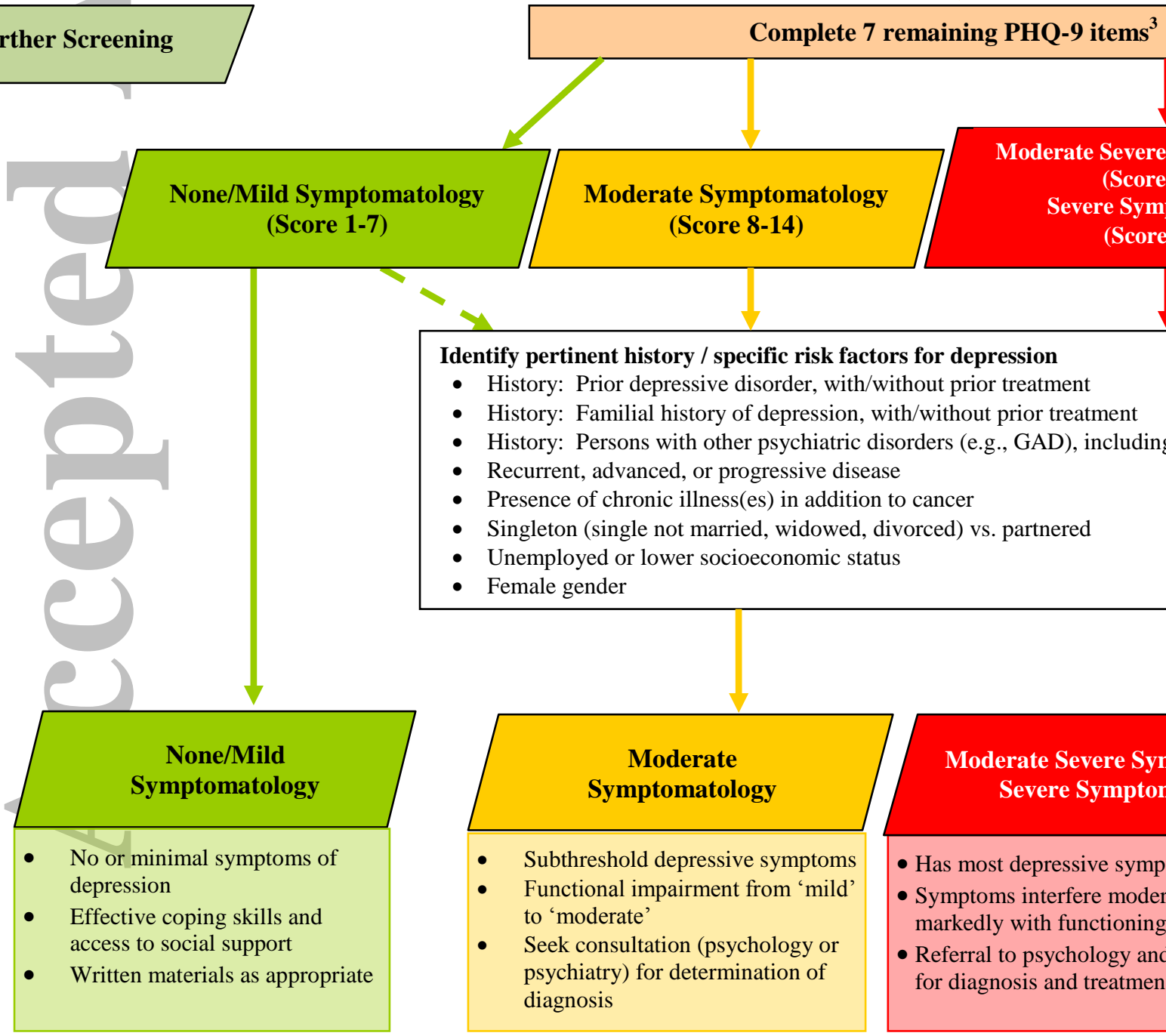

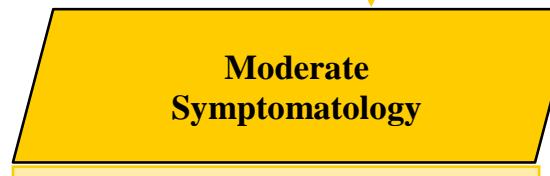

- Subthreshold depressive symptoms

- Functional impairment from 'mild' to 'moderate'

- Seek consultation (psychology or psychiatry) for determination of diagnosis

\section{Moderate Severe Symotomatology} Severe Symptomatology

- Has most depressive symptoms

- Symptoms interfere moderately to markedly with functioning

- Referral to psychology and/or psychiatry for diagnosis and treatment

this algorithm the use of the word depression refers to the PHQ-9screening scale and not to a clinical diagnosis

1. Initial diagnosis/start of treatment, regular intervals during treatment, 3,6, and 12 months post treatment, diagnosis of at recurrence or progression, when approaching death and during times of personal transition or re-appraisal such as family crisis (CAPO guideline: "Assessment of Psychosocial Health Care Needs of the Adult Cancer Patient" by Howell et al, 2009; Cancer Care Nova Scotia Distress Management Pathways, draft 2010).

2. Presence of symptom in the last two weeks, rated as follows: $0=$ not at all, $1=$ several days, $2=$ more than half the days, and $3=$ nearly every day.

3. Content of remaining 7 Items: sleep problems, low energy, appetite, low self view, concentration difficulties, motor retardation or agitation, and thoughts of self harm. 


\section{Care Map - Depression in Adults with Cancer}

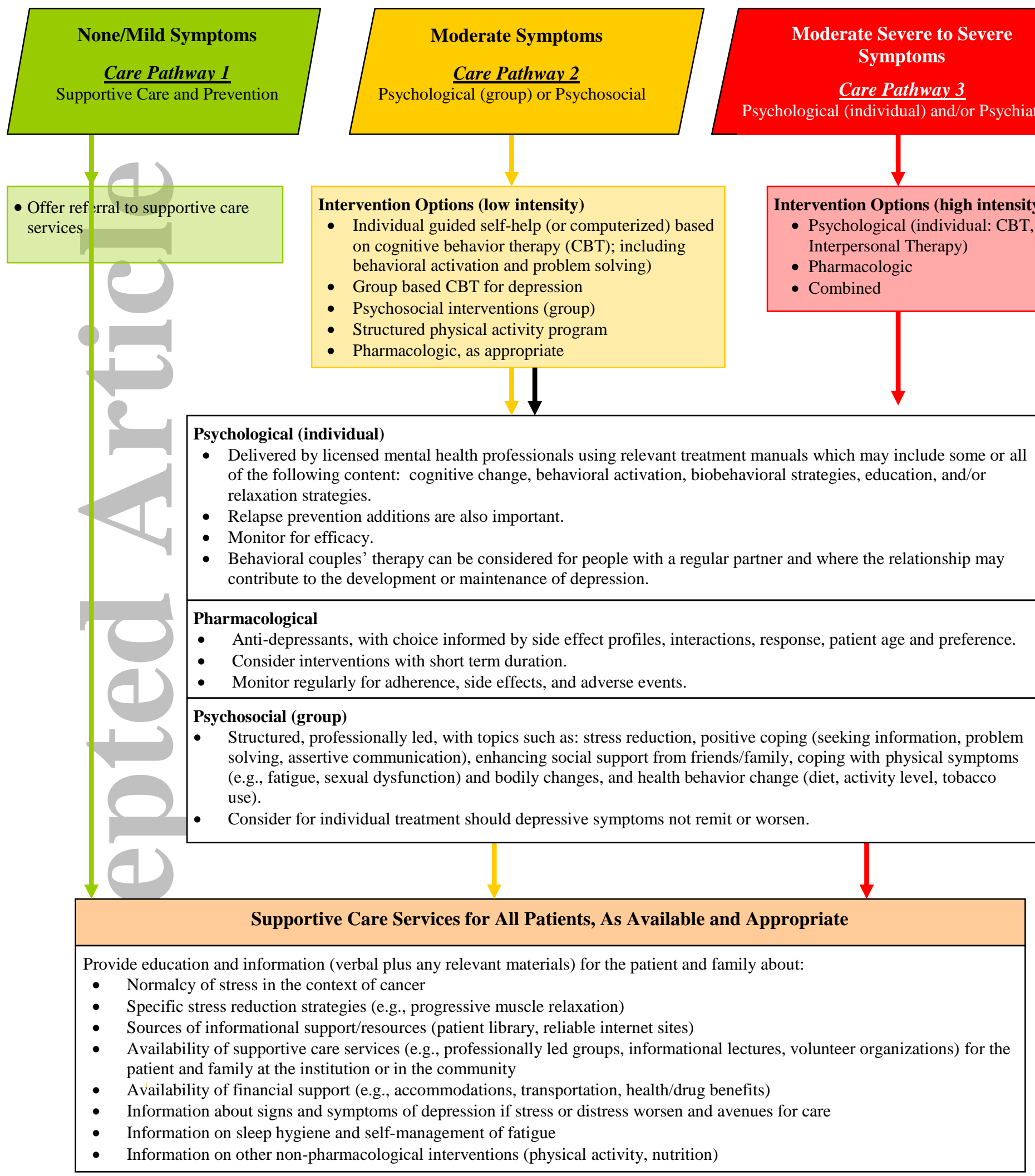

\section{Follow-up and ongoing re-assessment}

It is common for persons with depressive symptoms to lack the motivation necessary to follow through on referrals and/or to comply with treatment recommendations. With this in mind, on a bi-weekly or monthly basis, until symptoms have remitted:

- Assess follow-through and compliance with individual or group psychological/psychosocial referrals, as well as satisfaction with these services.

- Assess compliance with pharmacologic treatment, patient's concerns about side effects, and satisfaction with the symptom relief..

- If compliance is poor, assess and construct a plan to circumvent obstacles to compliance, or discuss alternative interventions that present fewer obstacles.

- After 8 weeks of treatment, if symptom reduction and satisfaction with treatment are poor, despite good compliance, alter the treatment course (e.g., add a psychological or pharmacological intervention; change the specific medication; refer to individyal psychotherapy if group therapy has not proved helpful). 


\section{Screening and Assessment -Anxiety in Adults with Cancer}

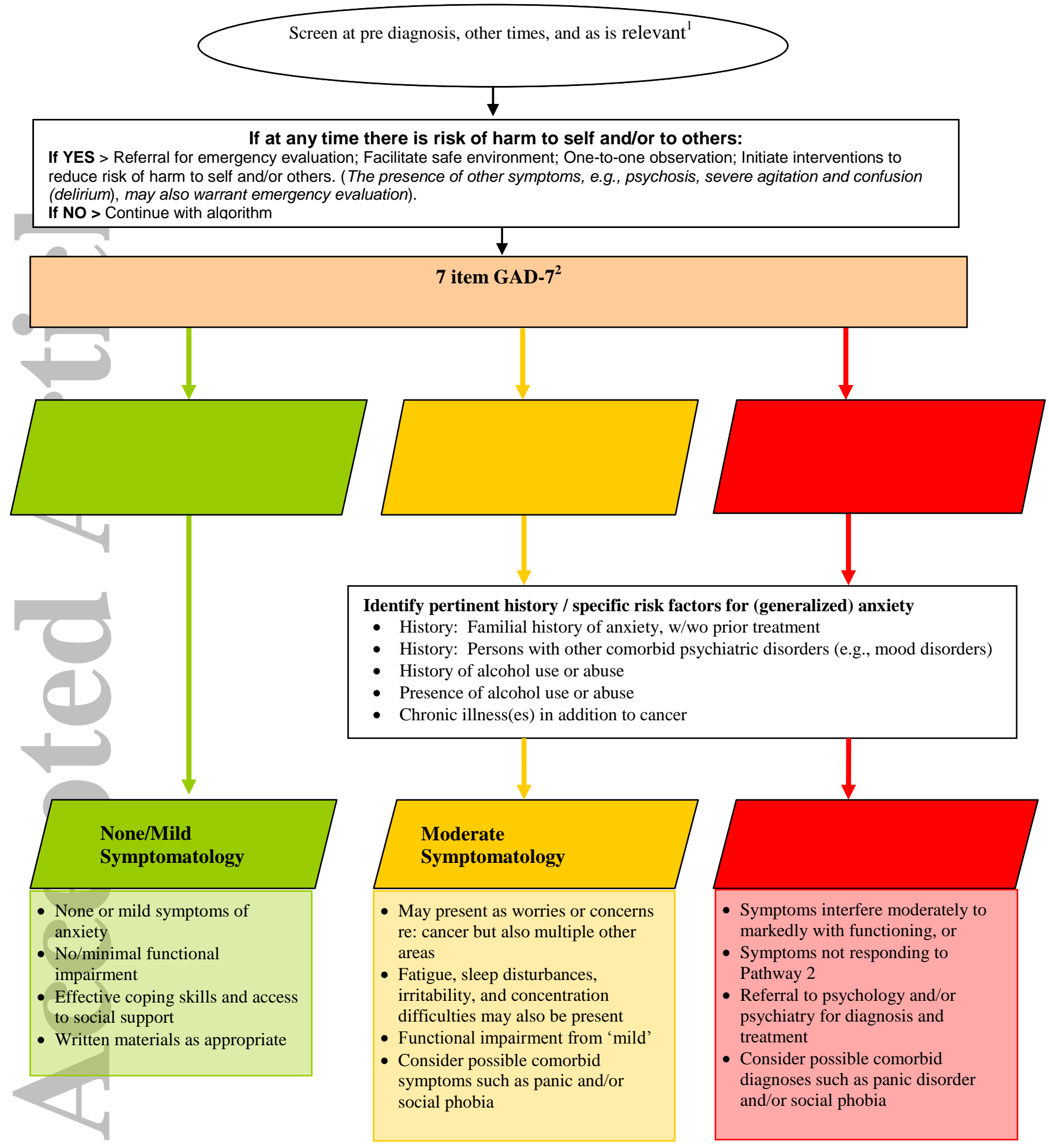

*In this algorithm the use of the word anxiety refers to the GAD-7 scale and not to a clinical diagnosis of anxiety disorder(s).

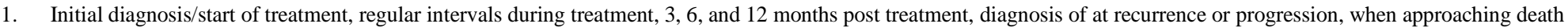

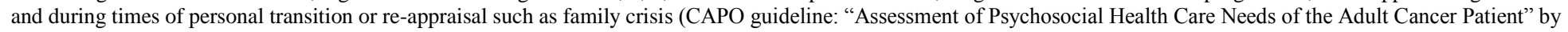
Howell et al, 2009; Cancer Care Nova Scotia Distress Management Pathways, draft 2010).

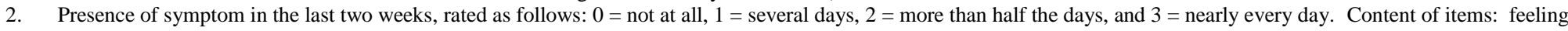

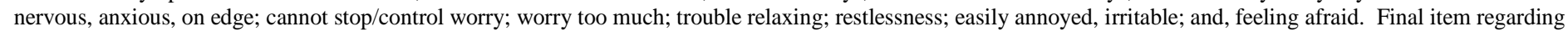
difficulty of the problems

Note: Reference for GAD-7 cutoffs is Spitzer, R.L. et al. (2006). A brief measure for assessing generalized anxiety disorder. Arch Intern. Med. 


\section{Care Map - Generalized Anxiety in Adults with Cancer}

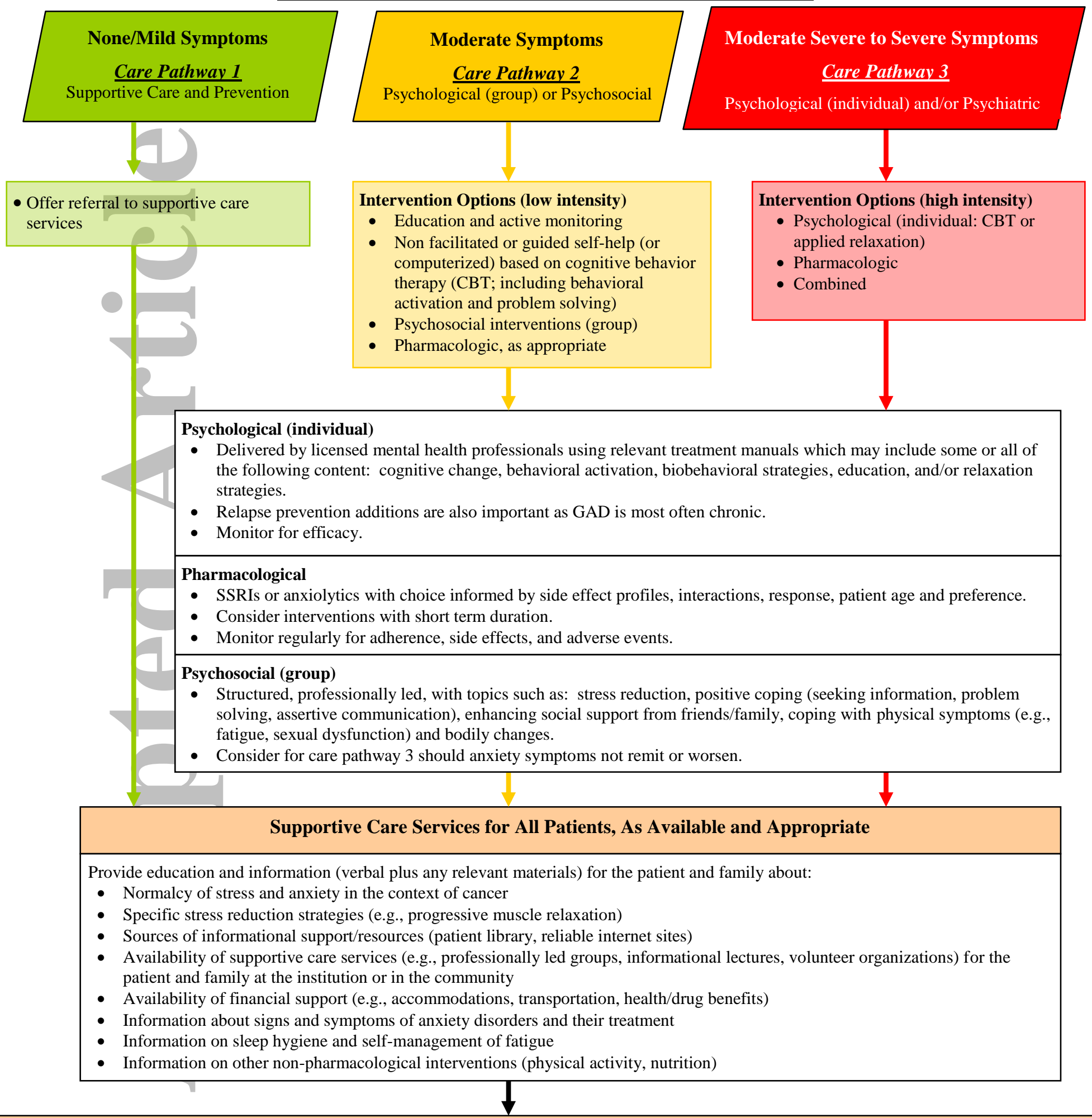

Follow-up and ongoing re-assessment

As cautiousness and a tendency to avoid threatening stimuli are cardinal features of anxiety pathology, it is common for persons with symptoms of anxiety to not to follow through on potentially helpful referrals or treatment recommendations. With this in mind, on a monthly basis or until symptoms have subsided:

- Assess follow-through and compliance with individual or group psychological/ psychosocial referrals, as well as satisfaction with these services.

- Assess compliance with pharmacologic treatment, patient's concerns about side effects, and satisfaction with symptom relief.

- Consider tapering the patient from any antidepressant medications if anxiety symptoms are under control and if the primary environmental sources of anxiety are no longer present.

- If compliance is poor, assess and construct a plan to circumvent obstacles to compliance, or discuss alternative interventions that present fewer obstacles.

$\circ$ After 8 weeks of treatment, if symptom reduction and satisfaction with treatment are poor, despite good compliance, alter the treatment course (e.g., add a psychological or pharmacological intervention; change the specific medication; refer to individual psychotherapy if group therapy has not proved helpful). 
Screening and Assessment - Fatigue in Cancer Survivors

\section{Routinely screen for fatigue}

Use a numeric rating scale as clinically indicated and at least annually.

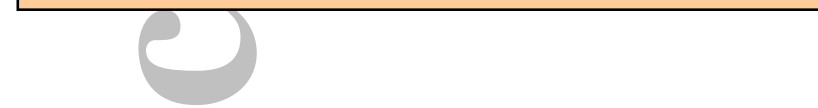

\section{Education and Counseling}

- All patients should be offered specific education about fatigue following treatment (e.g. information about the difference between normal and cancer related fatigue, persistence of fatigue post treatment, and causes and contributing factors).All patients should be offered advice on general strategies that help manage fatigue (e.g., maintaining physical activity) and guidance on self-monitoring of fatigue levels.

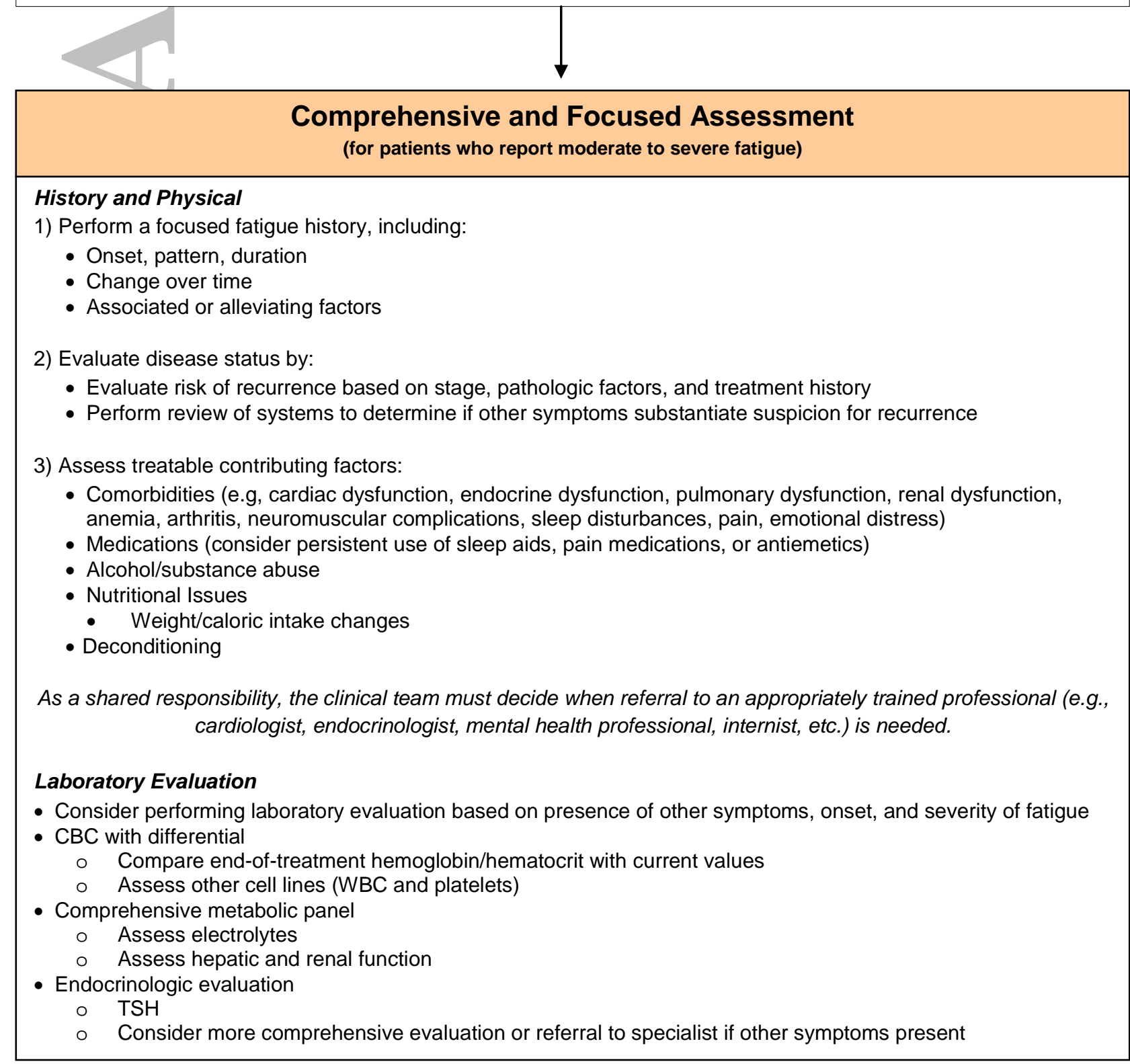




\section{Treat Contributing Factors}

Address all medical and substance-induced treatable contributing factors first (e.g., pain, depression, anxiety, emotional distress, sleep disturbance, nutrition deficit, activity level, anemia, medication side-effects, and comorbidities). See Table 2 for more details.

\section{Interventions for Cancer-Related Fatigue}

Some patients may also benefit from interventions described below to treat fatigue. Currently, there are no clear standards to select among these for an individual patient. Further research is needed to establish a strategy for prioritizing, sequencing, and linking the available options. If treated for fatigue, patients should be followed and re-evaluated on a regular basis to determine whether treatment is effective or needs to be reassessed.

\section{Physical Activity}

- Initiating/maintaining adequate levels of physical activity can reduce cancer-related fatigue in post-treatment survivors.

- Actively encourage all patients to engage in a moderate level of physical activity after cancer treatment (e.g., 150 minutes of moderate aerobic exercise (such as fast walking, cycling, or swimming) per week with an additional 2 to 3 strength training (such as weight lifting) sessions per week, unless contraindicated.

- Walking programs are generally safe for most cancer survivors; the American College of Sports Medicine recommends that cancer survivors can begin this type of program after consulting with their doctors, but without any formal exercise testing (such as a stress test).

- Survivors at higher risk of injury (e.g., those living with neuropathy, cardiomyopathy, or other long-term effects of therapy other than comorbidities) should be referred to a physical therapist of exercise specialist. Breast cancer survivors with lymphedema should also consider meeting with an exercise specialist before initiating upper body strength-training exercise.

\section{Psychosocial Interventions}

- Cognitive behavioral therapy/behavioral therapy can reduce fatigue in cancer survivors.

- Psycho-educational therapies/educational therapies can reduce fatigue in cancer survivors.

- Survivors should be referred to psychosocial service providers who specialize in cancer and are trained to deliver empiricallybased interventions. Psychosocial resources that address fatigue may also be available through the National Cancer Institute (e.g., Moving Beyond Breast Cancer videos).

\section{Mind-Body Interventions}

- There is some evidence that the following interventions can reduce fatigue in cancer survivors:

o Mindfulness-based approaches

o Yoga

o Acupuncture

- The following interventions may offer some benefit, however additional research, particularly in the post-treatment population, is needed:

o Biofield therapies (touch therapy), massage, music therapy, relaxation, reiki, qigong

\section{Pharmacologic Interventions}

- Evidence suggests that psychostimulants (e.g., methylphenidate) and other wakefulness agents, eg., modafinil can be effectively used to manage fatigue in patients with advanced disease or those on active treatment. However, there is very limited evidence of their effectiveness in reducing fatigue in patients who are disease free following active treatment, outside of the treatment of obstructive sleep apnea.

- Small pilot studies have evaluated the impact of supplements, such as ginseng and vitamin D, for cancer-related fatigue. However, there is no consistent evidence of their effectiveness.

\section{Ongoing Monitoring and Follow-up}

Promote ongoing self-monitoring of fatigue levels as a late or long-term cancer or treatment problem in post-treatment survivors.

Adapted from "A pan-Canadian practice guideline and algorithm: screening, assessment and supportive care of adults with cancerrelated fatigue by D. Howell et al., Current Oncology, 20(3), p. e242-e243. Copyright 2003 by Current Oncology. Adapted with permission. 


\section{ASCO GUIDELINES}

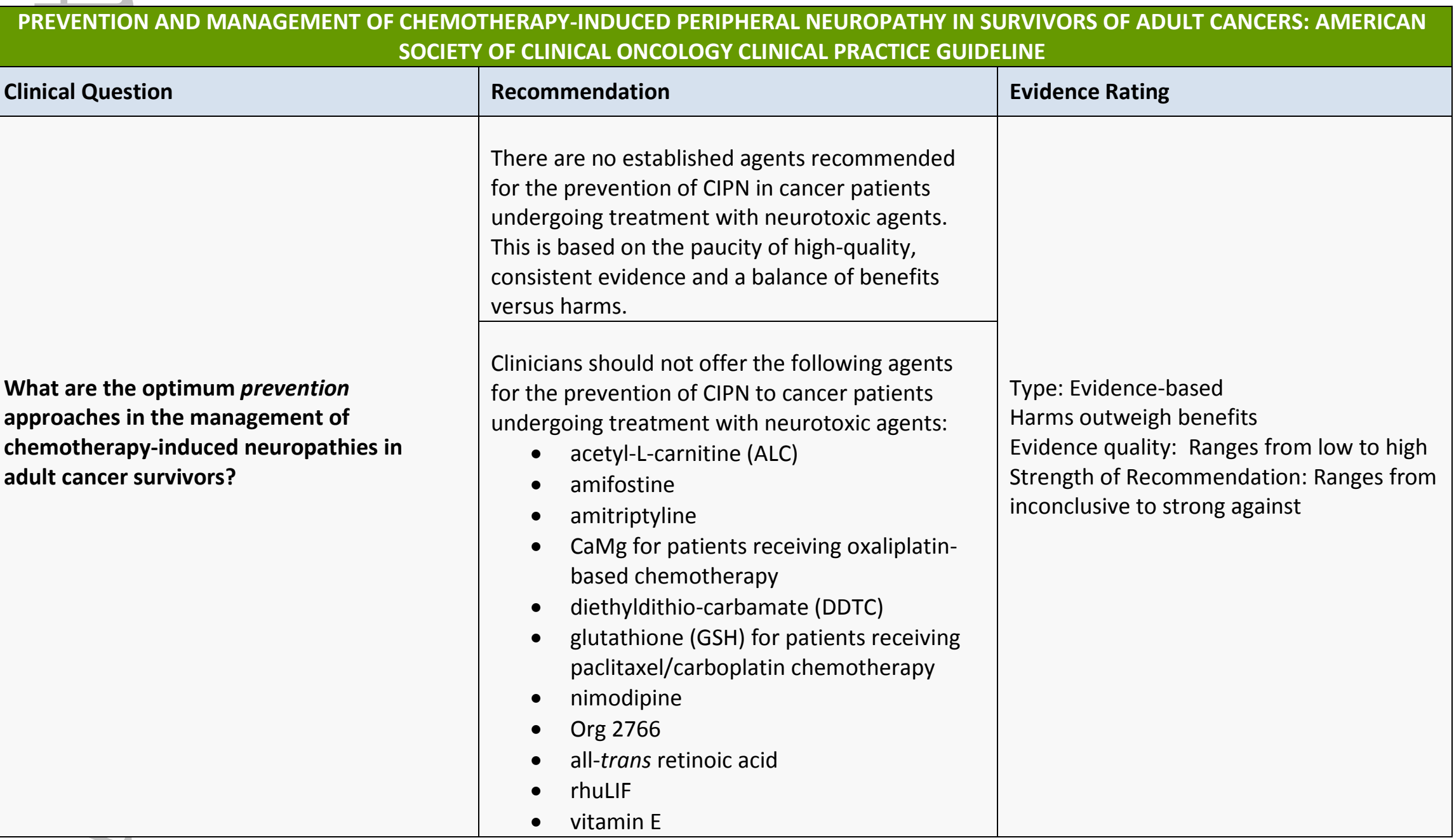



SOCIETY OF CLINICAL ONCOLOGY CLINICAL PRACTICE GUIDELINE

\begin{tabular}{|c|c|c|}
\hline Clinical Question & Recommendation & Evidence Rating \\
\hline \multirow{2}{*}{$\begin{array}{l}\text { Continued, } \\
\text { What are the optimum prevention } \\
\text { approaches in the management of } \\
\text { chemotherapy-induced neuropathies in } \\
\text { adult cancer survivors? }\end{array}$} & $\begin{array}{l}\text { Venlafaxine is not recommended for routine use } \\
\text { in clinical practice. While the venlafaxine data } \\
\text { supports its potential utility, the data were not } \\
\text { strong enough to recommend its use in clinical } \\
\text { practice, until additional supporting data become } \\
\text { available. }\end{array}$ & $\begin{array}{l}\text { Type: Evidence-based } \\
\text { Balance of benefits and harms } \\
\text { Evidence quality: Intermediate } \\
\text { Strength of Recommendation: Inconclusive }\end{array}$ \\
\hline & $\begin{array}{l}\text { No recommendations can be made on the use of } \\
\mathrm{N} \text {-acetylcysteine, carbamazepine, glutamate, } \\
\text { glutathione for patients receiving cisplatin or } \\
\text { oxaliplatin-based chemotherapy, goshajinkigan } \\
\text { (GJG), omega-3 fatty acids, or oxycarbazepine for } \\
\text { the prevention of CIPN at this time. }\end{array}$ & $\begin{array}{l}\text { Type: Evidence-based } \\
\text { Balance of benefits and harms } \\
\text { Evidence quality: Low } \\
\text { Strength of recommendation: Inconclusive }\end{array}$ \\
\hline \multirow{2}{*}{$\begin{array}{l}\text { What are the optimum treatment approaches } \\
\text { in the management of chemotherapy- } \\
\text { induced neuropathies in adult cancer } \\
\text { survivors? }\end{array}$} & $\begin{array}{l}\text { For cancer patients experiencing CIPN, clinicians } \\
\text { may offer duloxetine. }\end{array}$ & $\begin{array}{l}\text { Type: Evidence-based } \\
\text { Benefits outweigh harms } \\
\text { Evidence quality: Intermediate } \\
\text { Strength of Recommendation: Moderate }\end{array}$ \\
\hline & $\begin{array}{l}\text { No recommendations can be made on the use of } \\
\text { acetyl-L-carnitine, noting that a positive phase III } \\
\text { abstract supported its value, but this work has not } \\
\text { yet been published in a peer-reviewed journal } \\
\text { and a prevention trial suggested that this agent } \\
\text { was associated with worse outcomes. }\end{array}$ & $\begin{array}{l}\text { Type: Evidence-based } \\
\text { Harms outweigh benefits } \\
\text { Evidence quality: Low } \\
\text { Strength of Recommendation: Inconclusive }\end{array}$ \\
\hline
\end{tabular}

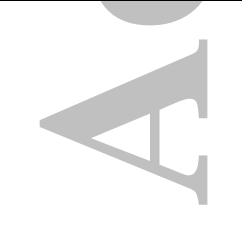
and a prevention trial suggested that
was associated with worse outcomes. 


\begin{tabular}{|c|c|c|}
\hline Clinical Question & Recommendation & Evidence Rating \\
\hline \multirow{2}{*}{$\begin{array}{l}\text { Continued, } \\
\text { What are the optimum treatment approaches } \\
\text { in the management of chemotherapy- } \\
\text { induced neuropathies in adult cancer } \\
\text { survivors? }\end{array}$} & $\begin{array}{l}\text { No recommendations can be made on the use of } \\
\text { tricyclic antidepressants. However, based on the } \\
\text { limited options that are available for this } \\
\text { prominent clinical problem and the demonstrated } \\
\text { efficacy of these drugs for other neuropathic pain } \\
\text { conditions, it is reasonable to try a tricyclic } \\
\text { antidepressant (e.g., nortriptyline or desipramine) } \\
\text { in patients suffering from CIPN following a } \\
\text { discussion with the patients about the limited } \\
\text { scientific evidence for CIPN, potential harms, } \\
\text { benefits, cost, and patient preferences. }\end{array}$ & $\begin{array}{l}\text { Type: Evidence-based } \\
\text { Balance of benefits and harms } \\
\text { Evidence quality: Intermediate } \\
\text { Strength of Recommendation: Inconclusive }\end{array}$ \\
\hline & $\begin{array}{l}\text { No recommendations can be made on the use of } \\
\text { gabapentin, noting that the available data were } \\
\text { limited regarding its efficacy for treating CIPN. } \\
\text { However, the panel felt that this agent is } \\
\text { reasonable to try for selected patients with CIPN } \\
\text { pain given that only a single negative randomized } \\
\text { trial for this agent was completed, given the } \\
\text { established efficacy of gabapentin and pregabalin } \\
\text { for other forms of neuropathic pain, and given } \\
\text { the limited CIPN treatment options. Patients } \\
\text { should be informed about the limited scientific } \\
\text { evidence for CIPN, potential harms, benefits, and } \\
\text { costs. }\end{array}$ & $\begin{array}{l}\text { Type: Evidence-based } \\
\text { Balance of benefits and harms } \\
\text { Evidence quality: Intermediate } \\
\text { Strength of Recommendation: Inconclusive }\end{array}$ \\
\hline
\end{tabular}

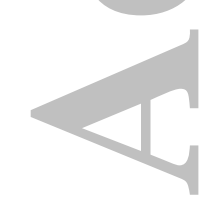

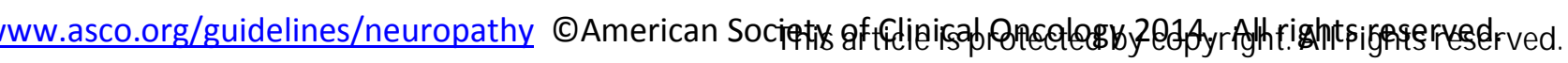


PREVENTION AND MANAGEMENT OF CHEMOTHERAPY-INDUCED PERIPHERAL NEUROPATHY IN SURVIVORS OF ADULT CANCERS: AMERICAN SOCIETY OF CLINICAL ONCOLOGY CLINICAL PRACTICE GUIDELINE

\begin{tabular}{|l|l|l|}
\hline Clinical Question & Recommendation & Evidence Rating \\
\hline & $\begin{array}{l}\text { No recommendations can be made on the use of } \\
\text { a topical gel treatment containing baclofen (10 } \\
\mathrm{mg}) \text {, amitriptyline } \mathrm{HCL}(40 \mathrm{mg}) \text {, and ketamine (20 } \\
\mathrm{mg}) \text {, noting that a single trial supported that this } \\
\text { product did decrease CIPN symptoms. Given the } \\
\text { available data, the panel felt that this agent is } \\
\text { reasonable to try for selected patients with CIPN } \\
\text { pain. Patients should be informed about the } \\
\text { limited scientific evidence for the treatment of } \\
\text { CIPN, potential harms, benefits, and costs. }\end{array}$ & $\begin{array}{l}\text { Evidence quality: Intermediate } \\
\text { Strength of Recommendation: Inconclusive }\end{array}$ \\
\hline
\end{tabular}

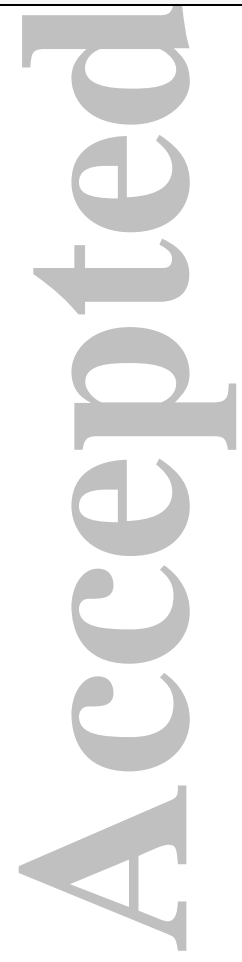

me treatment of

potential harms, benefits, and costs. 